\title{
Thermostability of Biological Systems: Fundamentals, Challenges, and Quantification
}

\author{
Xiaoming $\mathrm{He}^{*}$ \\ Multiscale Biothermostability Engineering Laboratory, Department of Mechanical Engineering and Biomedical \\ Engineering Program, University of South Carolina, 300 Main Street, Columbia, SC 29208, USA
}

\begin{abstract}
This review examines the fundamentals and challenges in engineering/understanding the thermostability of biological systems over a wide temperature range (from the cryogenic to hyperthermic regimen). Applications of the biothermostability engineering to either destroy unwanted or stabilize useful biologicals for the treatment of diseases in modern medicine are first introduced. Studies on the biological responses to cryogenic and hyperthermic temperatures for the various applications are reviewed to understand the mechanism of thermal (both cryo and hyperthermic) injury and its quantification at the molecular, cellular and tissue/organ levels. Methods for quantifying the thermophysical processes of the various applications are then summarized accounting for the effect of blood perfusion, metabolism, water transport across cell plasma membrane, and phase transition (both equilibrium and non-equilibrium such as ice formation and glass transition) of water. The review concludes with a summary of the status quo and future perspectives in engineering the thermostability of biological systems.
\end{abstract}

Key Words: Thermotherapy, thermoablation, cryotherapy, cryoablation, cryosurgery, hyperthermia, cryopreservation, vitrification, desiccation, lyopreservation, freeze-drying, membrane, vascular injury, stasis, cell injury, protein denaturation, phase transition, intracellular ice formation (IIF), water transport, glass transition, blood perfusion, kinetics, nanotechnology.

\section{INTRODUCTION}

Efforts on engineering the thermostability of biological systems could be traced back to thousands of years ago according to the records of early civilizations. For example, high temperatures have been used to treat a variety of diseases including back pain in the traditional Chinese medicine [1-3]; the ancient Hindus heated metal bars to stop bleeding [4]; in 500 B.C., the Greek physician Parmenides believed that if he could create fever, he could cure all illness [5]; dried mummies have been found in Egypt and other places to be well-preserved at ambient temperatures for thousands of years [6]; and the use of cold was recommended by Hippocrates to reduce bleeding and swelling [7]. Nothing speaks for the unlimited potential of temperature in medicine better than an aphorism of Hippocrates [8,9]: "Those diseases which medicines do not cure, iron (author's note: iron means scalpel here) cures; those which iron cannot cure, fire (author's note: fire means temperature here) cures; and those which fire cannot cure, are to be reckoned wholly incurable."

Indeed, temperature (either heat or cold) is still one of the most important tools for the treatment of diseases in modern medicine. Recent research on engineering the (thermo) stability of biologicals at various temperatures for biomedical applications has been focused on either destroying unwanted/diseased cells/tissues or stabilizing cells/tissues for

*Address correspondence to this author at the Multiscale Biothermostability Engineering Laboratory, Department of Mechanical Engineering and Biomedical Engineering Program, University of South Carolina, 300 Main Street, Columbia, SC 29208, USA; Tel: 803-777-0070; Fax: 803-777-0106; E-mail: xmheusc@gmail.com future use in the treatment of diseases as summarized in Fig. (1). The use of abnormally low and high temperatures to locally destroy unwanted tissues is called cryosurgery/cryoablation/cryotherapy and thermal surgery/thermal ablation/thermal therapy/thermotherapy (including hyperthermia for which the temperature is usually between 39 and $45^{\circ} \mathrm{C}$ ), respectively. For thermal stabilization (or biopreservation) applications, different terminologies including cryopreservation, hypothermic preservation and dry or lyopreservation are used for temperatures below $-80{ }^{\circ} \mathrm{C}$, at $\sim 4{ }^{\circ} \mathrm{C}$, and at ambient temperatures, respectively. There is a significant overlap in terms of temperature range between hypothermic and lyopreservation. However, they are quite different since hypothermic preservation is designed for preservation of fully hydrated tissues/organs in a short period usually from days to weeks while lyopreservation is aimed at stabilizing biologicals in the long term (i.e., up to years) in a dehydrated state. More detailed discussions of the different applications are given below.

\subsection{Thermal Destruction}

On the thermal destruction side, whole body hyperthermia (usually with brain cooling to avoid thermal damage to the extremely heat susceptible cerebral tissue $[10,11]$ ) with temperatures usually between $39-45{ }^{\circ} \mathrm{C}$ has been used for many years as an adjuvant treatment to enhance the effect of chemo and radio therapy of malignant diseases (i.e., cancer) [12-16]. More recently, thermal therapy and cryosurgery have been developed as single treatment modalities for various benign and malignant diseases [17-22]. With the advancement of modern surgical techniques such as laparoscopy, both thermal therapy and cryosurgery can be per- 


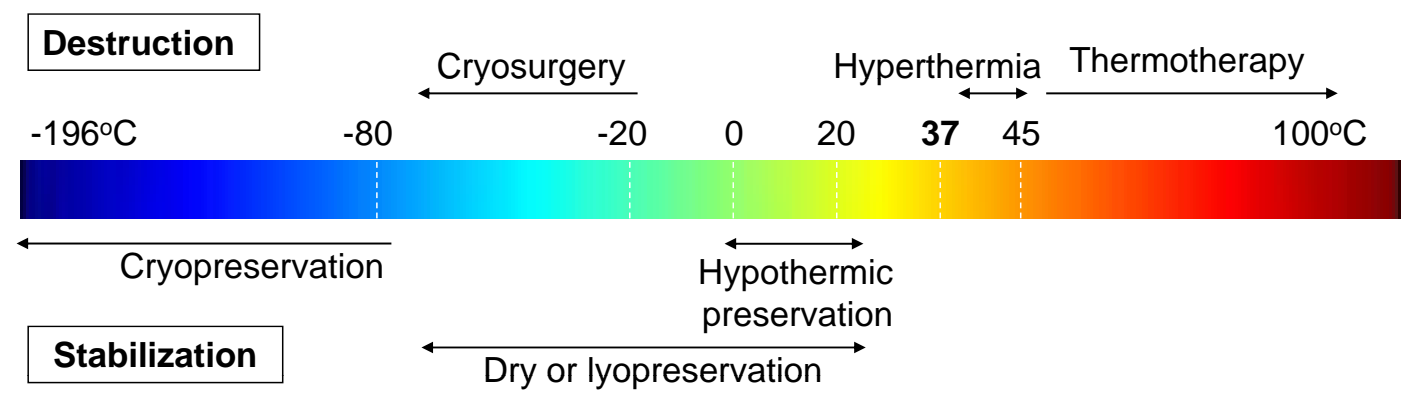

Fig. (1). A summary of typical biomedical applications for which the goal is to engineer the thermostability (for either destruction or stabilization) of biological systems from cryogenic to hyperthermic temperatures.

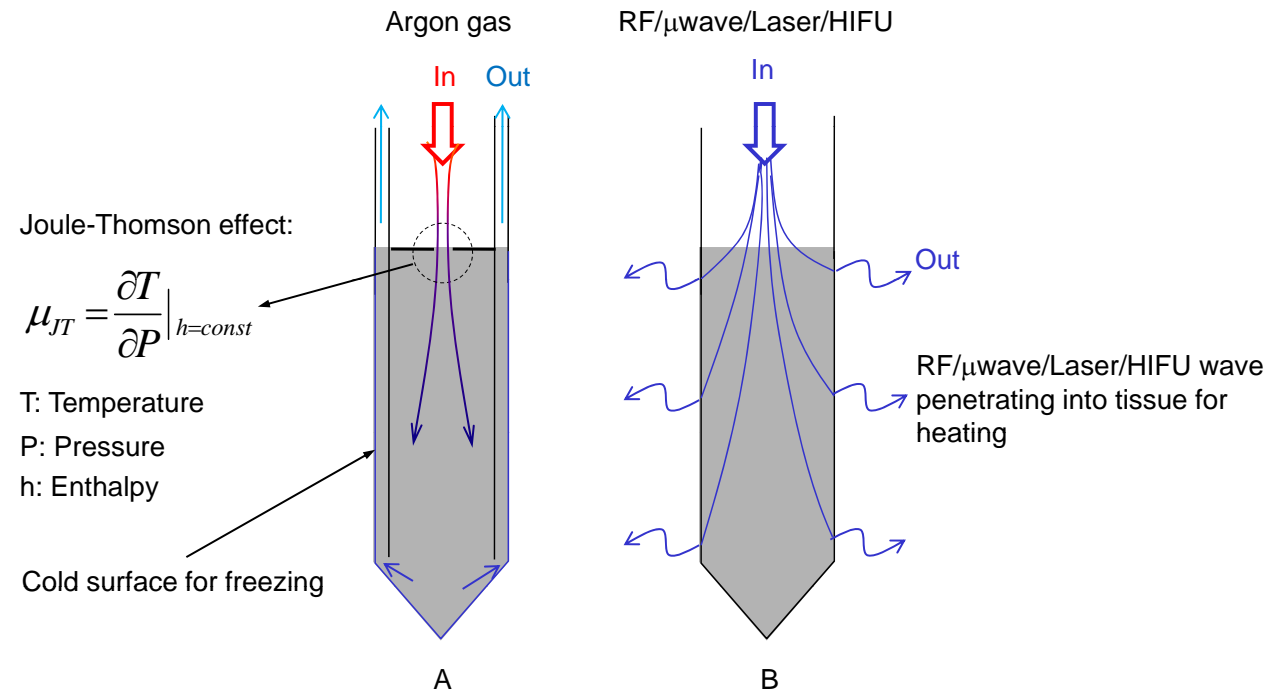

Fig. (2). Sketches of a typical cryoprobe (A) designed based on the Joule-Thomson effect for destroying tissue by freezing and a typical thermal probe (B) using energy carried either in an electromagnetic (e.g., radio frequency, microwave, or laser) or acoustic wave field (HIFU, high intensity focused ultrasound) to destroy tissue by heating.

formed in a minimally invasive manner to reduce the patient suffering and hospital stay during and post surgical operation [23-25]. Consequently, they are becoming increasingly popular and have been studied in essentially all surgical subspecialties as a minimally invasive alternative to the conventional radical surgical intervention [26-28].

\subsubsection{Thermal Destruction at Cryogenic Temperatures (Cryotherapy): Cooling Approaches}

In cryosurgery, unwanted or diseased tissue is destroyed by freezing it to subzero temperatures (usually below $-20{ }^{\circ} \mathrm{C}$ ) typically using one or multiple cryoprobes (up to a few millimeters in diameter, Fig. 2A). The tissue is frozen through direct contact with the cryoprobe which is cooled to a cryogenic temperature by circulating cryogenic media at a temperature usually below $-100{ }^{\circ} \mathrm{C}$ inside the cryoprobe lumen $[29,30]$. Liquid nitrogen $\left(-196{ }^{\circ} \mathrm{C}\right)$ is one of the commonly used cryogenic media, particularly in cryoprobes designed before the 1990s. Gases such as argon, carbon oxide, and nitrous oxide at cryogenic temperatures obtained by throttling (i.e., from high to low pressure) as a result of the JouleThomson effect [31] are becoming increasingly popular. Liquid nitrogen has been replaced with these gases in more recent designs of cryoprobes for better control of the probe temperature. An additional advantage of cryoprobes designed based on the Joule-Thomson effect is that the circulating gas for freezing in the cryoprobe can be switched to a different gas such as helium, whose temperature actually increases after throttling, due to a negative Joule-Thomson coefficient (i.e., $\mu_{\mathrm{JT}}$ defined in Fig. $\mathbf{2 A}$ ) of the gas at around room temperature. This coefficient is positive for argon at room temperature or below. This feature is utilized to achieve fast, active (instead of slow, passive) thawing of the diseased tissue after freezing, which is important for accurate control of the frozen tissue volume. Other gas mixtures (mainly Freon) at cryogenic temperatures (usually higher than $-130{ }^{\circ} \mathrm{C}$ ) obtained utilizing a refrigeration cycle system essentially like that of a household refrigerator/freezer, are also used in some cryoprobe designs.

\subsubsection{Thermal Destruction at Hyperthermic Temperatures (Thermotherapy): Heating Approaches}

In thermal therapy, unwanted or diseased tissue is thermally ablated or destroyed by locally heating the tissue to above $50{ }^{\circ} \mathrm{C}$ for minutes or even seconds typically using one (for removing a small unwanted tissue volume) or an array (for removing a large unwanted tissue volume) of thermal probes (also up to a few millimeters in diameter, Fig. 2B). Unlike the cryoprobes for cryosurgery that must have a cold surface to freeze tissue, a thermal probe for thermal therapy is not necessary to be hot and even not necessary to be in direct contact with the tissue, particularly when laser or high intensity focused ultrasound (HIFU) is used as the energy source [32-37]. This is because it is the electromagnetic or 
acoustic wave field applied on the tissue through the thermal probe that heats up and thus destroys the tissue. Moreover, a cooling mechanism might be employed to protect the thermal probe from being overheated when the probe does have direct contact with the tissue to be thermally destroyed $[38,39]$. This is because the efficacy of the probe for emitting electromagnetic or acoustic wave might be significantly compromised at the high temperature necessary for destroying unwanted tissue.

The electromagnetic wave over a wide range of frequency (or wavelength) including radiofrequency (RF), microwave, and laser, has been used for heating. The terms of radiofrequency (RF) and microwave have often been used interchangeably in the hyperthermic literature for electromagnetic waves with frequency over a broad range from several hundred kilohertz $(\mathrm{kHz})$ to several hundred gigahertz $(\mathrm{GHz})$. Traditionally, RF is referred as electromagnetic wave with frequency from $300 \mathrm{kHz}$ to $1 \mathrm{GHz}$ and microwave is from $300 \mathrm{MHz}$ to $300 \mathrm{GHz}$. The corresponding wavelength of RF and microwave in air is $\sim 1000-0.3 \mathrm{~m}$ and $\sim 1000-1$ $\mathrm{mm}$, respectively. Considering the speed of light in water (the major building component of most soft tissue) is approximately half of that in air $\left(3 \times 10^{8} \mathrm{~m} / \mathrm{s}\right)$, the wavelength of $\mathrm{RF} /$ microwave in most soft tissue should decrease by half as well. Typical RF/microwave frequencies used for heating biological tissue in the hyperthermic literature are around $2.45 \mathrm{GHz}, 915 \mathrm{MHz}, 40.68 \mathrm{MHz}, 27.12 \mathrm{MHz}$, and 13.56 $\mathrm{MHz}$, which are the frequencies allocated by the Federal Communications Commission (FCC) for medical use in USA. The two highest frequencies $(2.45 \mathrm{GHz}$ and $915 \mathrm{MHz})$ are usually (although not always) referred as microwave while the rest are called RF in the thermal therapy literature.

Both conductive (more important at low frequencies) and dielectric (more important at high frequencies) heating mechanisms contribute to the absorption of electromagnetic energy by biological tissue [40-42]. The former is due to the electrical resistance of biological tissue and is the major heat generation mechanism at low frequencies (e.g., $<1 \mathrm{MHz}$ ). The latter is due to friction between molecules in tissue as a result of the alternating movement of polar molecules (particularly the water dipoles in a biological tissue) trying to align themselves with the alternating $\mathrm{RF} / \mathrm{microwave}$ electric field. Therefore, dielectric heating is frequency dependent and is the major heating mechanism at high frequencies (e.g., $>100 \mathrm{MHz}$ ), particularly in the nonconductive biological tissue. A more comprehensive review of the biological effect of $\mathrm{RF} /$ microwave can be found elsewhere [40].

Lasers (acronym for light amplification by stimulated emission of radiation) of infrared, visible light, and ultraviolet with a wave length much less than $1 \mathrm{~mm}$ (typically $\sim 150$ $\mathrm{nm}-100 \mu \mathrm{m}$ in the infrared domain) have also been used for thermal destruction. Correspondingly, the wave frequency is much higher than $300 \mathrm{GHz}$ but usually less than $10^{16} \mathrm{~Hz}$. In this case, the tissue is heated by absorbing photons carried in the laser wave field [32]. Due to the small wave length, laser wave could be scattered significantly along its propagation path in biological tissue which is generally inhomogeneous. Light scattering can significantly enhance tissue absorption of the laser energy on one hand and limit the penetration depth of the laser wave in tissue on the other. Generally, the heating depth of a single interstitial laser probe is only ap- proximately one tenth of that of an interstitial $\mathrm{RF} / \mathrm{microwave}$ probe under comparable working conditions. Therefore, multiple probes or multiple laser shots at different locations in the targeted tissue are necessary to destroy a large tissue volume. It is interesting and important to note that lasers with wavelength from 800 to $1,200 \mathrm{~nm}$ can be absorbed much more strongly by metals than water [33]. Therefore, lasers in this wavelength range can be utilized to specifically destroy unwanted tissue by heating metallic (e.g. gold) nanoparticles delivered into the tissue $[43,44]$.

The acoustic (or mechanical) wave used for heating and destroying unwanted tissue is generally referred as high intensity focused ultrasound (HIFU). The frequency of medical acoustic waves (a mechanical wave) is typically from 1 to 3 $\mathrm{MHz}$. As a result, the wavelength of the HIFU mechanical wave is typically less than $\sim 1.5 \mathrm{~mm}$ since the speed of sound in water is $\sim 1500 \mathrm{~m} / \mathrm{s}$ between $0-100{ }^{\circ} \mathrm{C}$. Therefore, tissue scattering of the mechanical wave is significant, which can enhance its absorption by tissue and at the same time limit its penetration depth in tissue. The latter is due to undesired heating of the surface tissue such as the dermis. Consequently, multiple HIFU shots at different locations in the targeted tissue are necessary to destroy a large diseased tissue volume. At a low intensity, tissue absorption of acoustic energy can be attributed to interstitial mechanical friction as a result of the alternating movement in tissue driven by the alternating acoustic (mechanical) wave while at a very high intensity, cavitation will occur as a result of microbubble formation/collapse and its interaction with the acoustic wave [35]. A significant enhancement of heat generation has been observed when cavitation occurs [36,37]. In addition, the generation of shock wave associated with microbubble collapse during cavitation can destroy tissue mechanically [35].

\subsection{Thermal Stabilization}

The goal of thermal stabilization (or biopreservation) is to preserve important biologicals such as biomolecules, cells, tissues, and organs for future use (e.g., transplantation) in modern medicine. For short term stabilization, biologicals are usually cooled to around ice temperature (hypothermic preservation) without ice formation or freezing. The purpose is to slow down metabolism and degradation of the biologicals to extend their shelf life to days and up to weeks after explantation [45-47]. Studies on short term hypothermic preservation are mainly focused on organs, for which longterm stabilization has not been practically successful. For long-term stabilization, however, biologicals (e.g., proteins, cells and small tissue slices) are usually processed and stabilized in an amorphous or glassy phase, which can be best demonstrated in an extended phase diagram shown in Fig. (3). The glassy phase is a thermodynamically metastable state with an extremely high viscosity and low molecular mobility and activity. Therefore, any processes that require the diffusion of participating molecules including both degradative and life supporting processes in a biological system are essentially arrested/suspended in a desired glassy phase. Practically, five different approaches including the conventional slow-freezing, conventional vitrification using a high concentration of cryoprotectant (or cryoprotective agent, or CPA for short), low-CPA vitrification, freezedrying, and evaporative/convective drying (or desiccation) have been studied to bring biologicals from an aqueous liq- 


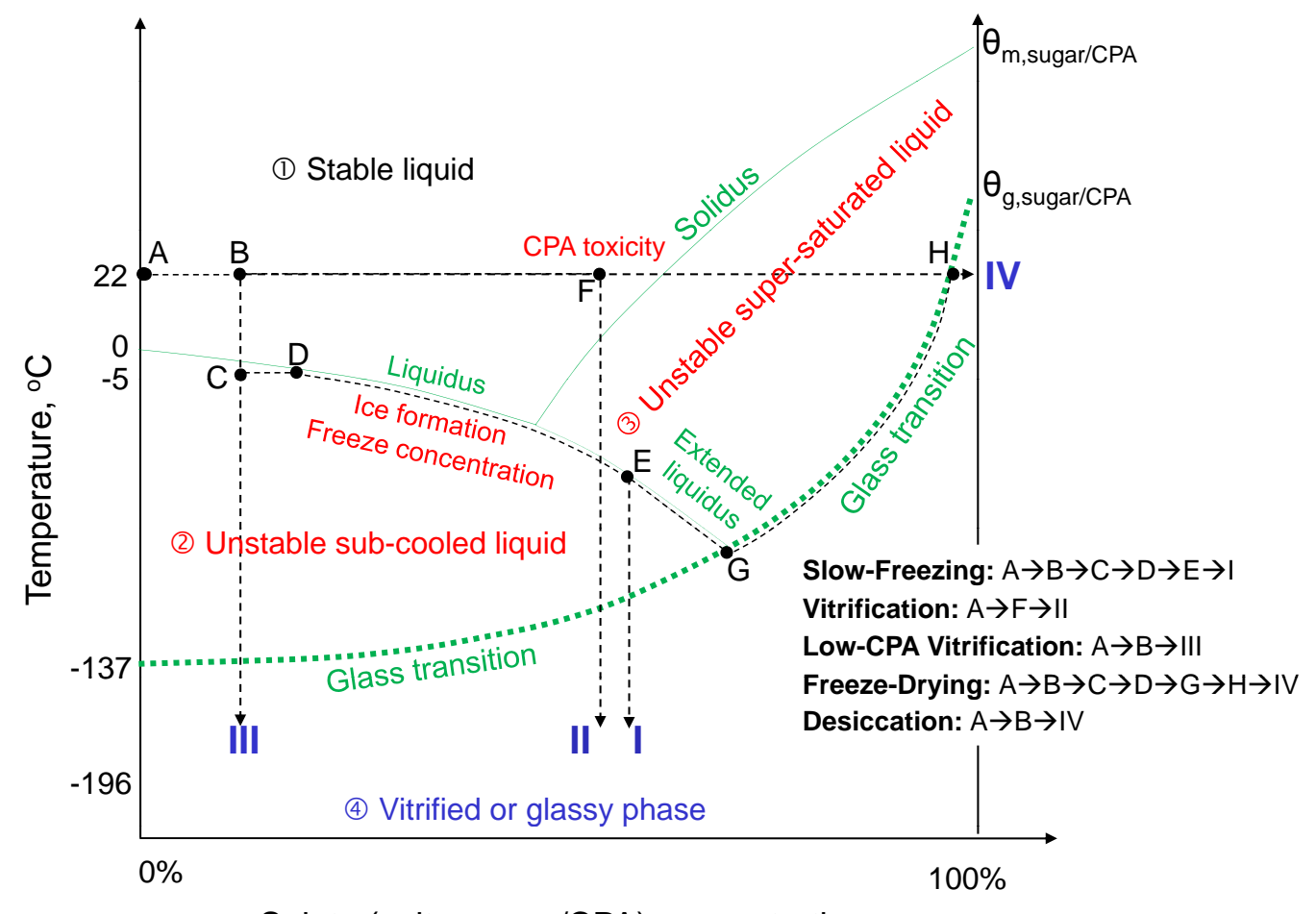

Solute (salts+sugar/CPA) concentration

Fig. (3). An illustration on the extended phase diagram of the various approaches to achieve thermal stabilization on biologicals at either cryogenic or ambient temperature from an initial liquid state (A) to a final glassy phase (e.g., I, II, III, or IV): The phase diagram is divided into four thermodynamic regimens by the liquidus, extended liquidus, solidus, and the glass transition curve; the four regimens are the liquid, subcooled liquid, supersaturated liquid, and the glassy phase; cells (in a liquid solution initially) must enter the glassy phase for long-term preservation; CPA represents cryoprotectant, and $\theta_{\mathrm{g}}$ and $\theta_{\mathrm{m}}$ represent the glass transition and melting temperature, respectively. Of note, the diagram is not to scale (for example, the melting temperature of pure CPAs is usually below $20{ }^{\circ} \mathrm{C}$ ). Figure reprinted from reference [53] with permission from Xiaoming $\mathrm{He}$ (the author).

uid state at room temperature to a glassy phase at either a cryogenic or ambient temperature as shown in Fig. (3). The former is usually called cryopreservation while the latter is usually called dry or lyopreservation. A more detailed discussion of each of the approaches for long-term cell/tissue preservation is given in the following sub-sections.

\subsubsection{Thermal Stabilization at Cryogenic Temperature (Cryopreservation)}

Thermal stabilization of biologicals at a cryogenic temperature can be achieved with two major approaches: the conventional slow-freezing with inevitable ice formation and the ice-free vitrification [48-53]. For the conventional slowfreezing approach, the following steps are typically adopted $(\mathrm{A} \rightarrow \mathrm{B} \rightarrow \mathrm{C} \rightarrow \mathrm{D} \rightarrow \mathrm{E} \rightarrow \mathrm{I}$ in Fig. 3): (1), biologicals such as cells in an aqueous solution (state A) are first loaded with CPA(s) such as DMSO (dimethylsulfoxide), glycerol, propylene glycol (or 1,2-propanediol), and ethylene glycol at a concentration usually up to $15 \mathrm{wt} \%$ (or up to $2 \mathrm{M}$, state $\mathrm{B}$ ); (2), the samples are sub-cooled usually to between -2 and -7 ${ }^{\circ} \mathrm{C}$ (phase $\mathrm{C}$ : note, phase rather than state is used to indicate that it is not in equilibrium) to seed ice in the extracellular space by touching the sample contained usually in a cryovial with a deeply cooled (e.g., in liquid nitrogen) object $(C \rightarrow D)$; (3), the samples are further cooled slowly (typically, $<10$ ${ }^{\circ} \mathrm{C} / \mathrm{min}$ ) along the liquidus to between -40 and $-100{ }^{\circ} \mathrm{C}$, a process called freeze concentration $(\mathrm{D} \rightarrow \mathrm{E})$; and $(4)$, the samples are transferred into liquid nitrogen for long-term storage $(\mathrm{E} \rightarrow \mathrm{I})$. In this approach, the formation of extracellular ice leads to freeze concentration of the unfrozen solutions by ejecting solutes and cells from the frozen to unfrozen phases. As a result, dehydration of cells in the unfrozen phase ensues, which minimizes intracellular water available for ice formation inside the cells so that the cells can enter the glassy phase (I) easily when transferring into liquid nitrogen. This approach typically requires a specialized machine usually called controlled rate freezer (CRF) to achieve freezing in a controllable manner. The time required for the slow-freezing process is typically hours.

Vitrification by definition is ice free. In other words, no (or negligible) ice formation or freezing will occur in the sample during cooling $[48,51,54]$. Conventional vitrification $(\mathrm{A} \rightarrow \mathrm{F} \rightarrow \mathrm{II}$ in Fig. 3) has also been studied for both cells and tissue. In this approach, biological samples (state A) are first loaded with a very high concentration of CPA(s) (up to $\sim 7$ M, state F) [48,51,54]. The samples are then cooled directly from ambient temperature to a cryogenic temperature usually in liquid nitrogen (state II) and stored there for future use. Although the conventional vitrification approach can be used to eliminate the detrimental effect of ice formation altogether, the unusually high concentration of CPA required by the approach is toxic to most mammalian cells even in a short period of exposure (ranging from seconds to minutes dependent on the specific cells and tissues) [55-60]. Therefore, the samples should be cooled as soon as possible after loading with CPAs. A mixture of multiple CPAs is often used to reduce the cytotoxicity of the high CPA concentration required [61]. In addition, large, membrane impermeable molecules such as sugars (typically sucrose and treha- 
lose) have been used to minimize ice formation and protect cell membrane from injury during cooling [62-64]. Vitrification can be done without a specialized machine and the time required is generally much shorter than that for slowfreezing.

Low-CPA vitrification ( $\mathrm{A} \rightarrow \mathrm{B} \rightarrow \mathrm{III}$ in Fig. 3) is a further advancement of the conventional vitrification with the goal to reduce the CPA concentration (e.g., at state F vs. B) required for vitrification to a low, nontoxic level (similar to that used for slow-freezing). This can be done by creating an ultrafast cooling rate to cool the cells for cryopreservation. This is because the higher the cooling rate, the less the amount of cryoprotectants is required for achieving vitrification [64-69]. For example, even pure water can be vitrified without any ice formation when the cooling rate is about one million degree Celsius per second [69-71].

Various devices have been utilized to achieve fast cooling rates $\left(\sim 20,000{ }^{\circ} \mathrm{C} / \mathrm{min}\right)$ such as the traditional French type straw, open pulled straw, electron grid, and cryoloops [56,72-74]. As a result of the fast cooling rate, the amount of cryoprotectants required for vitrification can be reduced to around $4 \mathrm{M}$. To achieve an ultrafast cooling rate, two recent studies reported the use of a micro-fabricated oscillating heat pipe (OHP) device [75,76]. Although their theoretical analysis shows that an ultrafast cooling rate of $\sim 10^{6}{ }^{\circ} \mathrm{C} / \mathrm{min}$ could be achieved, testing of the device for low-CPA vitrification using living cells has not been reported to date. Another recent study reported that a cooling rate as high as 200,000 ${ }^{\circ} \mathrm{C} / \mathrm{min}$ can be achieved by plunging an ultra-thin walled (10 $\mu \mathrm{m})$ quartz microcapillary (QMC, $180 \mu \mathrm{m}$ inner diameter, slightly bigger than the diameter of a human oocyte) into liquid nitrogen [64]. As a result, the CPA concentration required for vitrification of mouse embryonic stem cells and mouse oocytes was found to be as low as $2.5 \mathrm{M}$ altogether $[64,77]$, which is close to the upper boundary of CPA concentrations used for slow-freezing. More recently, it was found that the required CPA concentration could be further reduced to $\sim 1.5 \mathrm{M}$ when mouse mesenchymal stem cells were encapsulated in $\sim 100 \mu \mathrm{m}$ alginate microcapsules for vitrifying using the thin-walled (380 $\mu \mathrm{m}$ inner diameter) QMC [78]. Therefore, the QMC-based low-CPA vitrification technique is promising to provide a solution to the major challenge facing the conventional vitrification approach associated with cytotoxicity of high CPA concentration. Because low-CPA vitrification avoids the shortcomings of both the conventional slow-freezing and vitrification approaches while combining their advantages, it is becoming increasingly popular, particularly for the cryopreservation of important and osmotically sensitive mammalian cells such as oocytes, sperm, stem cells, and many primary cells important for tissue engineering, cell-based therapy, and assisted reproduction.

\subsubsection{Thermal Stabilization at Ambient Temperatures (Ly- opreservation)}

With the development of modern cell-based medicine, the demand on wide distribution of biopreserved products to end users in medical units at both urban and remote locations is increasingly high. The difficulty to widely distribute cryopreserved biologicals in liquid nitrogen has motivated cryobiologist and engineers to develop approaches for long-term stabilization of biologicals at ambient temperature. The idea
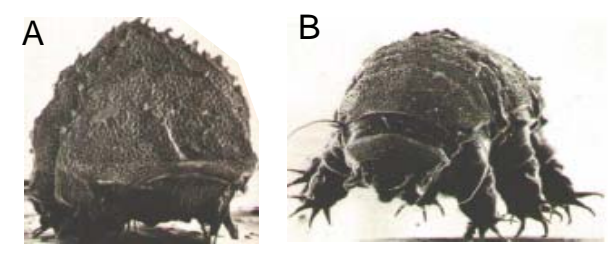

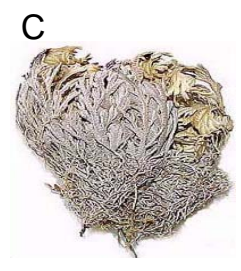

Dehydrated

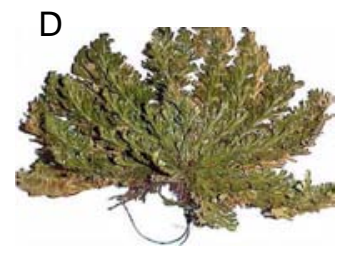

Rehydrated
Fig. (4). Tardigrade (A and B) and resurrection plant (C and D) can survive extreme drought in nature upon rehydration - a phenomenon called anhydrobiosis or life without water. Figure reprinted and redrawn from references $[85,86]$ with permission from John $\mathrm{H}$. Crowe at $\mathrm{U}$ of California-Davis (for panels A and B) and Wayne P. Armstrong at Palomar College (for panels C and D).

of dry or lyopreservation at ambient temperature is actually not new since many lower organisms (e.g., tardigrade shown in Fig. 4A and B), resurrection plants (e.g., Selaginella Lepidophylla shown in Fig. 4C and D), and seeds can survive extreme drought in nature upon rehydration, a phenomenon called anhydrobiosis or life without water [79-86]. A high concentration of sugars (typically sucrose for plants and trehalose for lower organisms) has been found in these organisms and plants when they are in the anhydrobiotic state. Learning from nature, both sucrose and trehalose have been used as the protective agent (also termed lyoprotectant) in protocols for lyopreservation [87-91]. In practice, two approaches have been studied to bring biologicals in aqueous samples to a dry state: freeze-drying (or lyophilization) and evaporative or convective drying (or desiccation) as shown in Fig. (3), as well.

A typical freeze-drying protocol is as follows $(\mathrm{A} \rightarrow \mathrm{B} \rightarrow \mathrm{C} \rightarrow \mathrm{D} \rightarrow \mathrm{G} \rightarrow \mathrm{H} \rightarrow \mathrm{IV}$ in Fig. 3): (1), a biological sample such as proteins and cells in an aqueous solution (state A) is first supplemented with lyoprotectants (e.g. sucrose and trehalose) at a concentration of up to $\sim 15 \mathrm{wt} \%$ (state B); (2), the sample is sub-cooled to usually between -3 and $-7{ }^{\circ} \mathrm{C}$ (phase $\mathrm{C}$ ) to seed ice in the solution by touching the samples with a deeply cooled object $(\mathrm{C} \rightarrow \mathrm{D}) ;(3)$, the sample is further cooled to between -30 and $-50{ }^{\circ} \mathrm{C}$ slowly at a cooling rate usually less than $10^{\circ} \mathrm{C} / \mathrm{min}(\mathrm{D} \rightarrow \mathrm{G}) ;(4)$, the ice formed in the sample during freezing is then sublimated by exposing the sample to a vacuum usually less than $10 \mathrm{~Pa}$ at phase $\mathrm{G}$ (primary drying); and (5) a secondary drying process is then done by heating the sample in vacuum slowly to ambient temperature to further dehydrate the sample for additional hours to days $(\mathrm{G} \rightarrow \mathrm{H} \rightarrow \mathrm{IV})$. The samples are then sealed and preserved in the dry phase (IV) at ambient temperature for future use. Freeze-drying has been used successfully in achieving lyopreservation of many biomacromolecules such as proteins and lipids and many pharmaceutical drugs. It has also been used for achieving lyopreservation of prokaryotic cells such as bacterium, red blood cells, and platelets, but not eukaryotic cells at this time. For freezedrying, it is crucial to keep the temperature low enough (be- 
low the so-called collapse temperature [92-106]) during primary drying (at phase G). Otherwise, the sample may collapse (can't maintain the morphology of the frozen sample) resulting in incomplete drying and heterogeneity in the freeze-dried product, which could significantly decrease the biostability of the freeze-dried biologicals [107-109]. More importantly, a recent study reported that the collapse temperature of cell culture medium-based trehalose solutions important for freeze-drying mammalian cells can be much lower than that of a simple binary trehalose-water solution and trehalose solutions used for freeze-drying pharmaceuticals and prokaryotes [110].

Unlike freeze-drying, during desiccation by evaporative/convective drying $(\mathrm{A} \rightarrow \mathrm{B} \rightarrow \mathrm{IV}$ in Fig. 3) water in an aqueous sample is removed by exposing the sample to a dry environment (e.g., dry air, inert gas such as nitrogen, and vacuum) without freezing (or ice formation) after loading with up to $15 \mathrm{wt} \%$ lyoprotectants. Desiccation by evaporative/convective drying has been used to achieve lyopreservation of both biomacromolecules such as proteins and lipids, pharmaceutical drugs, and prokaryotic cells (such as bacterium, red blood cells, and platelets), but not eukaryotic mammalian cells. A major engineering difficulty to dry the glass-forming trehalose based solution for cell lyopreservation by convective drying is that a thin glassy skin can easily form on the interface between the solution and the dry environment, resulting in incomplete drying and heterogeneity in the dried product. This problem might be minimized by breaking down the solution into micron-sized droplets or thin-films [108].

Beside the engineering challenge to effectively dry the trehalose solutions, effective delivery of the small hydrophilic lyoprotectants (e.g., trehalose and sucrose) into mammalian cells has been challenging as the first step toward cell preservation at ambient temperature. This is because lyoprotectant such as trehalose must be present both intra and extracellularly to provide the maximum protection during drying, but mammalian cells lack a mechanism to synthesize trehalose endogenously and their plasma membrane is impermeable to the sugars [111-113]. Over the past decades, a number of approaches have been explored to introduce trehalose into living cells for preservation purpose. The most straightforward approach is to deliver exogenous trehalose into the cytosol of living cells by direct microinjection. This approach has been successfully used for intracellular delivery of trehalose to cryopreserve mammalian oocytes that have a large size $(\sim 100 \mu \mathrm{m}$ in diameter $)$ and are generally in a small quantity (less than a few hundred) [113-116].

However, the microinjection approach is difficult (if not impossible) to apply for most living cells that are generally much smaller $(<\sim 20 \mu \mathrm{m})$ than mammalian oocytes and usually present in a large quantity (millions). Small living cells have been genetically engineered to synthesize trehalose endogenously. This approach requires the constant production of adenoviral vectors that exhibit significant cytotoxicity, particularly at high multiplicities of infection [117-119]. Trehalose has also been introduced into mammalian cells or their organelles through engineered or native transmembrane pores [91,112,120-122], electroporation [123,124], fluid- phase endocytosis [125-127], and lipid phase transition $[127,128]$.

In spite of the various approaches being explored, a consistent report of cell preservation using trehalose for small eukaryotic living cells is still absent $[88,111,129,130]$. This could be due to the inability to deliver a sufficient amount of intracellular trehalose $(\geq \sim 0.1 \mathrm{M})$ for cell preservation using some of the approaches (e.g., fluid phase endocytosis). In addition, cells could be too severely compromised during the delivery step to withstand further freezing/dehydration stresses during preservation, considering the highly invasive nature of some of the approaches (e.g., electroporation). Recently, research has been sought to use liposomal and polymeric nanoparticles as the intracellular delivery vehicles of small hydrophilic molecules including the lyoprotectants with promising outcomes [131-135].

Besides the non-reducing disaccharide (trehalose and sucrose), small stress proteins particularly, the late embryogenesis abundant (LEA) proteins have been suggested to be an important part of the molecular repertoire that renders desiccation tolerance in anhydrobiotic organisms and are attracting more and more research attention [79-84,136-141].

\section{BIOLOGICAL EFFECT OF ABNORMAL TEM- PERATURES}

The biological responses to either abnormally low or high temperatures have been reported at the molecular, cellular and tissue (both in vitro and in vivo) levels [142-149]. Some important structures/conformations of important bi-
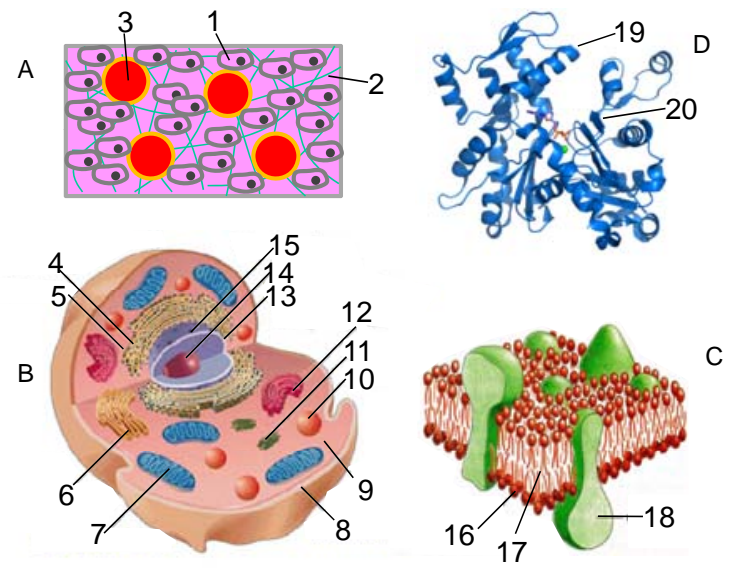

Fig. (5). An illustration (not to scale) of some important structures/confirmations of a typical biological tissue (A), mammalian cell (B), cell plasma membrane (C), and protein (D): A biological tissue typically consists of cells (1), extracellular matrix (2) and blood vessels (3) through which oxygen and nutrients are transported to the cells; a mammalian cell consists of many important sub-cellular organelles such as the rough endoplasmic reticulum (4), ribosome (5), smooth endoplasmic reticulum (6), mitochondria (7), plasma membrane (8), cytosol (9), lysosome (10), centriole (11), Golgi apparatus (12), and nucleus that are demonstrated as nuclear membrane (13), nucleolus (14), and nuclear membrane pore (15); the cell plasma membrane contains a phospholipid bilayer with hydrophilic heads (16) and hydrophobic tails (17), and membrane proteins (18) that works as transport channels, receptors, and structural connections between intracellular skeleton and extracellular matrix; and the most important secondary structures of a protein are $\alpha$ helix (19) and $\beta$ sheet (20). 

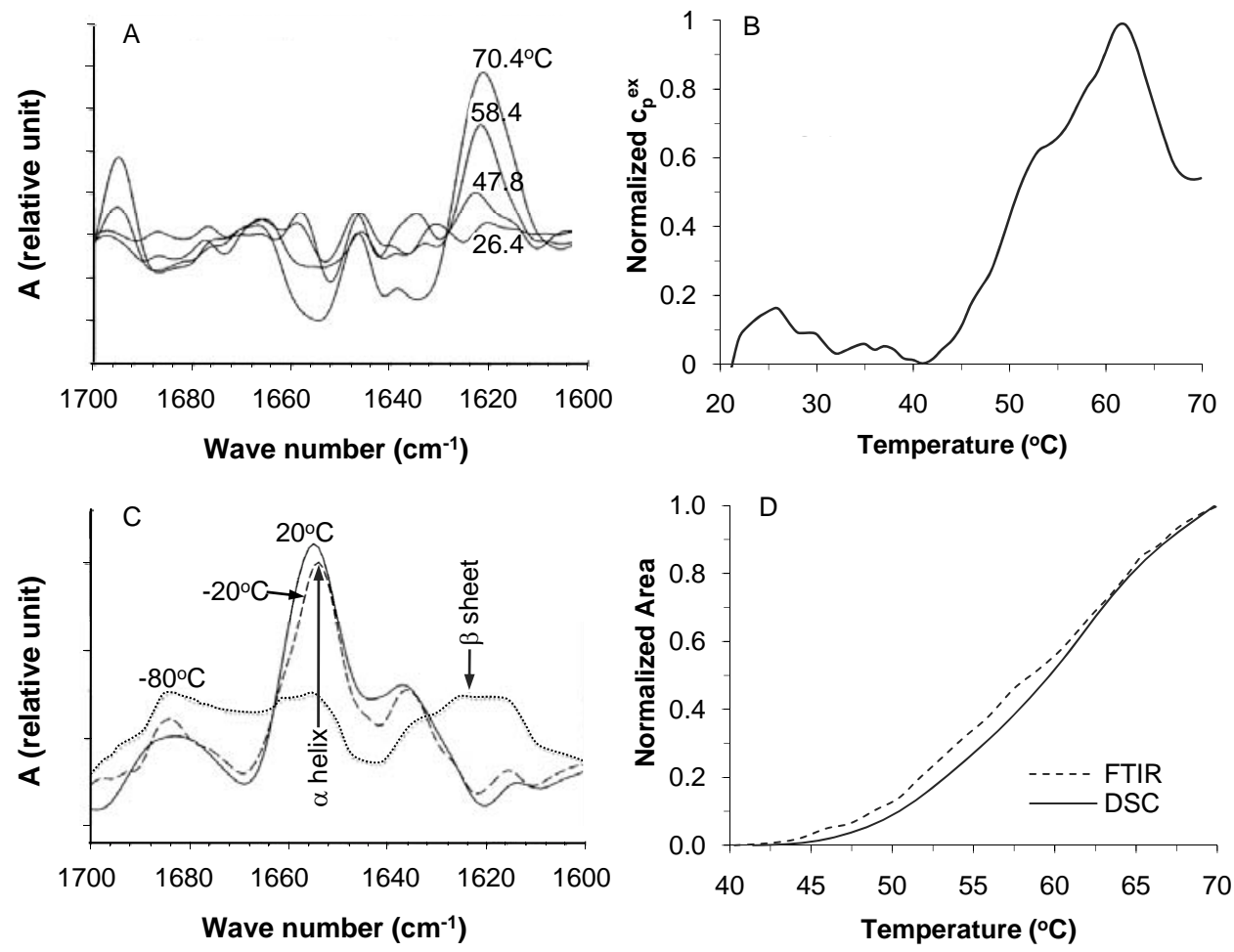

Fig. (6). Fourier transform infrared (FTIR) and differential scanning calorimetry (DSC) signatures of thermally induced changes in cellular proteins in situ: (A), FTIR spectra at different temperatures showing the increase of extended $\beta$ sheet structure and a simultaneous decrease of the $\alpha$ helix structure in cellular protein during heating mammalian cells slowly $\left(2{ }^{\circ} \mathrm{C} / \mathrm{min}\right)$; (B), DSC endotherm demonstrating heat absorption as a result of protein denaturation during heating mammalian cells slowly also at $2{ }^{\circ} \mathrm{C} / \mathrm{min}$; (C), FTIR spectra showing extensive change of protein secondary structure from $\alpha$ helix to extended $\beta$ sheet in thawed cells after freezing slowly to $-80{ }^{\circ} \mathrm{C}$, but not $-20{ }^{\circ} \mathrm{C}$; and (D), the DSC and FTIR measurements match well, suggesting protein denaturation is one of the major events that result in cell injury during heating between $40-70{ }^{\circ} \mathrm{C}$. Figure reprinted and redrawn from references [158,195] with permission from Elsevier (for panels A and C) and Springer (for panels B and D).

ologicals (e.g., tissue, cell, cell membrane, and protein) that have been reported to be the target of both cryo and hyperthermic injury are shown in Fig. (5). The driving forces leading to the biological responses at abnormally high temperature are different from those at abnormally low temperatures due to the different biophysical events involved. The biological responses at hyperthermic temperature appear to be dominantly thermotropic. At abnormally low temperatures, however, additional biophysical events such as ice formation and freeze concentration (see $\mathrm{D} \rightarrow \mathrm{E} \rightarrow \mathrm{G}$ in Fig. 3) as a result of ice formation at subzero temperatures can lead to additional biological alterations at the molecular, cell, and tissue levels.

\subsection{Hyperthermic Injury}

A bevy of studies have been performed to investigate the alterations in biologicals exposing to hyperthermic temperatures. At the molecular level, lipid, protein, DNA, and RNA are the major structural and functional macromolecules of living cells and tissues. DNA and some structured RNAs do not undergo conformational change until above $\sim 85-90{ }^{\circ} \mathrm{C}$ [150-153]. Therefore, they are unlikely to play an important role in cell killing at temperatures ranging from 37 to $85^{\circ} \mathrm{C}$ for most thermal therapy protocols. Other RNAs that can perform enzymatic functions and form protein/RNA complexes such as ribosomes [151,154] could be potential targets in thermal therapy applications [153]. Both protein denaturation and lipid alteration (phase transition) have been commonly observed after thermal treatment [143]. Although many studies on protein denaturation were done using purified proteins, the attention of recent studies have gradually shifted to study such changes in situ in living cells using various analytical techniques including differential scanning calorimetry (DSC), Fourier transform infrared (FTIR) spectroscopy, and circular dichroism (CD) spectroscopy [155159]. These studies have shown that alterations to lipid mainly occur below $\sim 45{ }^{\circ} \mathrm{C}$ while major protein denaturation starts from 40 to $45^{\circ} \mathrm{C}$ (Fig. 6A and B) dependent on the heating rate and continue to occur at more than $100{ }^{\circ} \mathrm{C}$. In view of the fact that major cell injury occurs at temperatures above $45{ }^{\circ} \mathrm{C}$, protein denaturation has been proposed to play a more important role in defining cell injury than the change in lipids. This argument may be further strengthened by identifying the denaturation of specific proteins or protein groups that is the rate limiting step for thermal injury to cells [159]. However, lipid alterations are still considered to be important in defining the rate of hyperthermic injury because many cellular proteins (especially membrane proteins) are embedded in lipids and their stability is strongly affected by the lipids surrounding them [160-165].

Of note, with much attention being focused on studying the effect of hyperthermic temperatures on macromolecules, recent studies have found that a variety of molecules can be used to augment the performance of high temperatures for thermal destruction [166]. For example, the small peptide of 

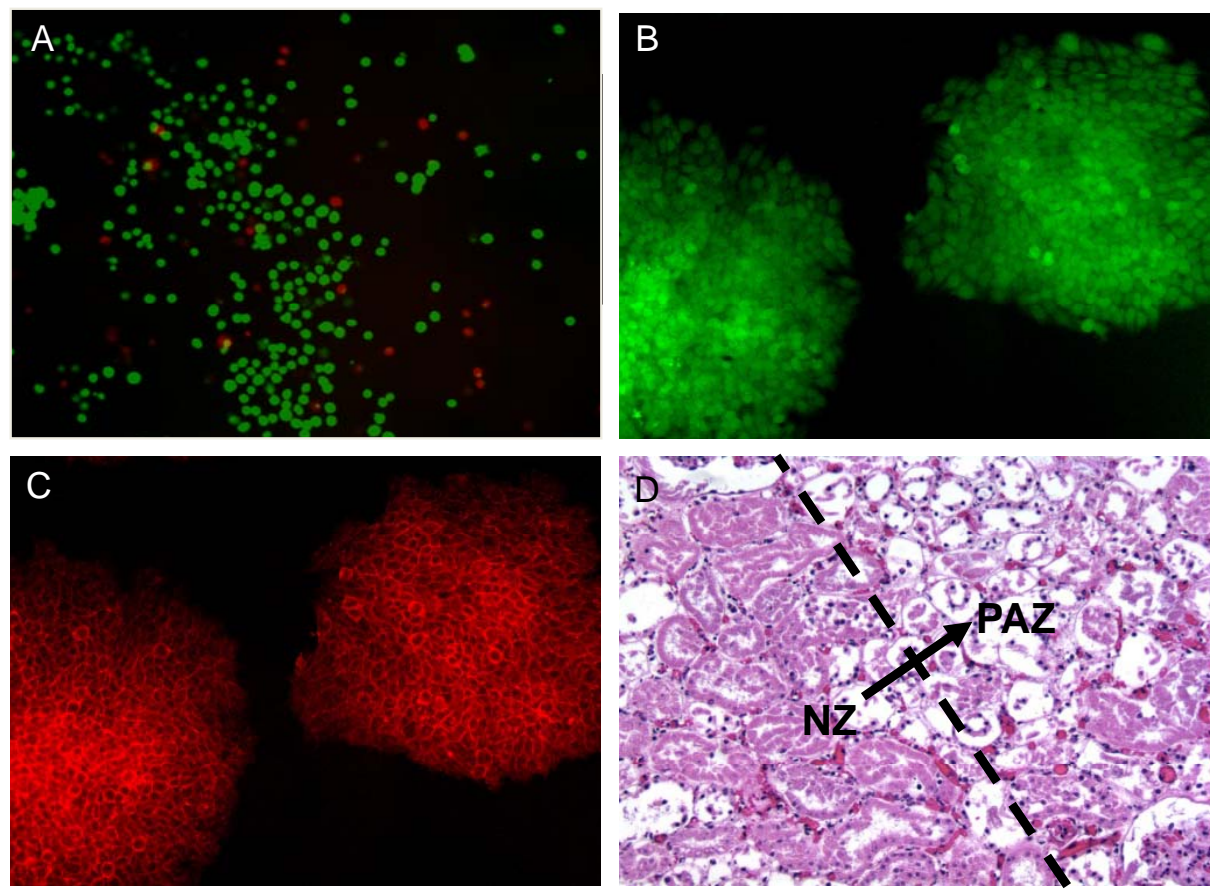

Fig. (7). Viability and function of mammalian cells post thermal treatment evaluated by exemplary assays: (A), immediate viability of cells assayed using calcein AM (green fluorescence indicating cellular metabolic activity and intact membrane of viable cells) and ethidium homodimer (red fluorescence indicating compromised cell membrane of injured and potentially dead cells); (B) and (C), expression of green fluorescent protein (GFP) under the control of Oct-4 gene (B) and a membrane surface glycoprotein (SSEA-1, C) indicating the undifferentiated properties of R1 murine embryonic stem cells post thermal treatment; and (D) histological difference between viable and damaged renal cells in normal porcine kidney tissue after 2 day's culture in media post thermal treatment showing the transition (arrow) from the lower left zone of significant necrotic tissue to the upper right zone with mainly intact tissue: Damaged cells lack nuclei. Figure reprinted and redrawn from references [38,64] with permission from Elsevier (for panels B and C) and Informa (for panel D).

tissue necrosis factor-alpha (TNF- $\alpha, 12.6 \mathrm{kD})$ has been shown to sensitize tumor for thermal therapy when delivered to the tumor site using functionalized gold nanoparticles [167]. Anticancer drugs encapsulated in liposomes have been shown to significantly increase the effect of hyperthermia in inhibiting tumor growth in vivo [168-170]. Using therapeutic adjuvants such as TNF- $\alpha$ and anticancer drugs to augment thermal therapy and the targeted delivery of these adjuvants specifically into tumor using various nanoparticles (gold, magnetic, liposomal, and polymeric nanoparticles and carbon nanotubes for heating, as well) are attracting more and more attention in the field of thermal therapy [43,170-176].

At the cellular level, thermal damage to essentially all the subcellular organelles (e.g., the plasma membrane, mitochondria, Golgi apparatus, and endoplasmic reticulum in Fig. 5B) have been reported in the hyperthermic literature, presumably due to the damage to their two important building blocks, the cellular proteins and lipids as discussed above [142]. The plasma membrane that provides cells with the first protection from its extracellular environment has been the major focus of many studies on hyperthermic injury. Hyperthermic injury to the plasma membrane usually is manifested as bleb formation and hyper-permeability to large molecules that are impermeable to the plasma membrane of intact cells (Fig. 7A). Damage to the plasma membrane and other sub-cellular organelles can further cause cells to lose their capability of attaching to a substrate and the subsequent proliferation and therefore, cell death ensues. Of note, when cells are exposed to a hyperthermic temperature below 43 ${ }^{\circ} \mathrm{C}$, they can adapt themselves to the sub-lethal temperature and become more thermally resistant to subsequent heat treatments, a phenomenon called thermotolerance [14,177]. Cells obtain this capability by increasing the concentration of a group of constitutive stress proteins called the heat shock proteins inside the cells [178-184]. Heat shock proteins are known to protect critical cellular proteins for normal cellular function under stress conditions including that as a result of abnormal hyperthermic temperatures [180,181].

At the in vitro tissue level, living cells are embedded in their native extracellular matrix (mainly collagen, Fig. 5A), which is different from the substrate or culture medium for attached and suspended cells, respectively. The effect of different extracellular matrices on the thermal sensitivity of mammalian cells has been reported in a few studies [185188]. The results however, are still inconsistent. Some studies show that cells are more thermally sensitive in their native matrix while others show no significant difference or even the opposite [185-188]. Further studies in a more controlled fashion are required to clarify the discrepancy in the existing literature in this regard.

At the in vivo tissue level, blood perfusion (Fig. 5A) and inflammatory wounding healing responses have been shown to play an important role in determining the extent of thermal injury: The thermal threshold required to destroy cells embedded in in vivo tissue is lower than that in vitro $[38,167,189,190]$. This observation has been attributed to vascular stasis as a result of thermal damage to tissue vasculature during and post thermal therapy, which leads to the deprivation of nutrition and oxygen, a secondary mechanism that kills the cells in addition to direct cell injury. Inflamma- 


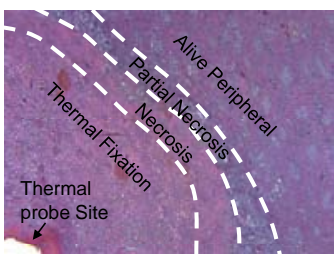

A

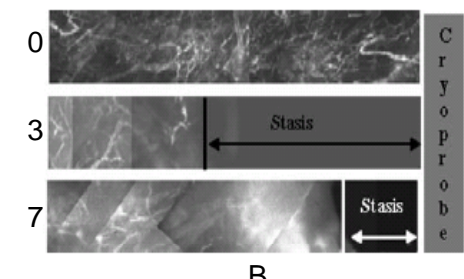

B
Fig. (8). Both histology and blood perfusion defects have been used to evaluate tissue injury in vivo: (A), a micrograph showing the patterns of in vivo hyperthermic injury in porcine renal tissue 7 days after thermal treatment and (B) in vivo blood perfusion defects due to cryothermic injury in prostate tissue at different times (i.e. 0 , 3 and 7 days) measured in situ by fluorescence contrast. Although wound healing was observed in the necrotic and partially ablated zone, a central lesion named thermal fixation knowing for its resistance to wound healing response were observed in kidney tissue exposed to hyperthermic temperatures (A). Wound healing was observed throughout the cryogenic lesion leading to its shrinkage from day 3 to day 7 (B). Figure reprinted and redrawn from references [38,247] with permission from Informa (for panel A) and ASME (for panel B).

tory wound healing response has been reported to be limited to the peripheral (i.e., the partial ablation and necrotic zone in Fig. 8A) of the thermal lesion in vivo even after more than one week $[38,191]$. The lack of wound healing response in the central zone (i.e., the thermal fixation zone in Fig. 8A) of a hyperthermic lesion in vivo is presumably due to the lack of blood perfusion as a result of vascular stasis post thermal therapy in the observed time period. Sufficient blood perfusion is necessary for recruiting inflammatory cells such as neutrophils and macrophages for the wound healing response to occur [192]. As a result of the lack of wound healing response in the central lesion, it is reported that the host actually takes the central lesion as a foreign body and tries to wall out the central lesion from its surrounding tissue by dystrophic calcification in the peripheral zone [38,191,193]. More studies are necessary to clarify the long-term (i.e., in months and years) fate of the central zone in a hyperthermic lesion in vivo.

\subsection{Cryothermic Injury}

The response of biologicals to cryogenic temperature may not be simply thermotropic in that two additional biophysical events including ice formation and freeze concentration/dehydration may occur and can result in significant damage to cells $[50,68,194]$. As with hyperthermic injury, cryothermic injury has been investigated at the molecular, cellular and tissue (both in vitro and in vivo) levels [142144]. At the molecular level, alterations in both lipid and proteins in response to cryogenic temperatures have been observed [195-197]. Dehydration and excursion in temperature are the thermodynamic driving forces for lipid phase separation and phase change among various states including liquid crystal lamellar (hydrated), gel (less hydrated), and even inverted micellar (Hex II) in bulk lipid membranes (composed of many types of lipids) [144]. Both phase separation and the Hex II phase change in lipids have been reported to be highly correlated with cell membrane damage which ultimately destroys cells upon thawing in various plant systems [198,199]. Presumably, lipid phase change and separation are also important in defining cryothermic injury to the plasma membranes of mammalian cells, although it has not been as clearly demonstrated as that in plant systems.

Protein denaturation during freezing is also inevitable because a freezing process is generally associated with change in $\mathrm{pH}$ and solute/electrolyte concentration, both of which can result in conformational alterations of proteins [143]. It has been reported that denaturation of cellular protein was minimal in thawed cells after freezing them to $-20{ }^{\circ} \mathrm{C}$ (Fig. 6C) [195]. However, significant denaturation of cellular proteins was observed when the cells were frozen to $-80{ }^{\circ} \mathrm{C}$ and thawed (Fig. 6C) [195]. In the latter case, an apparent shift of the secondary structure of cellular protein from $\alpha$-helix to extended $\beta$-sheet (Fig. 6C) is observable in the FTIR spectra, indicating denaturation and aggregation of cellular proteins. Interestingly, cell viability also correlates well with the denaturation of cellular proteins at $-80{ }^{\circ} \mathrm{C}$ according to the study [195]. Finally, as with hyperthermic injury, various molecules including TNF- $\alpha$ [200-205], antifreeze proteins [206,207], excessive electrolytes [208,209], immunopotentiator [210-213], and various anticancer drugs [214-218] have been shown to augment the efficacy of low temperatures for thermal destruction. For example, TNF- $\alpha$ has been found to increase the thermal threshold of cryoinjury to prostate cancer cells from $\sim-20$ to $0{ }^{\circ} \mathrm{C}$ [200], which is significant because it indicates that all cancer cells could be killed in a frozen tumor iceball and it is much more convenient to monitor the size of the frozen tumor iceball (e.g., using ultrasonography) than the subzero temperature inside the iceball. Therefore, using therapeutic adjuvants such as TNF- $\alpha$ to augment cryoinjury and the controlled/targeted delivery of the adjuvants into tumor and tumor cells using nanotechnology have attracted more and more attention in the field of thermal destruction at cryogenic temperatures [201,219,220].

At the cellular level, cryothermic injury can be attributed to ice formation induced mechanical damage and freeze concentration induced physiochemical deviation from the physiological state. The latter can be connected to the alteration to cellular proteins and lipids at the molecular level as discussed previously. Ice formation can occur both intracellularly and extracellularly. Although significant intracellular ice formation (IIF) is generally considered to be a lethal event, extracellular ice is not as damaging [50,194]. Significant IIF could destroy the cellular plasma membrane and other sub-cellular organelles mechanically as a result of volumetric expansion associated with the phase change or solidification of cellular water to ice, and the stochastic event of crack formation in the frozen cellular interior during freezing and thawing. The growing dendritic front of ice during IIF could also dismantle the native structure of cellular proteins, lipids, and subcellular organelles. In addition, significant IIF could lead to freeze concentration of the cellular interior which is detrimental to cellular proteins and lipids. Therefore, multiple mechanisms contribute to the lethality of significant IIF to cells.

For applications with a low concentration of CPA (e.g., cryopreservation by the conventional slow-freezing) or without CPA (e.g., thermal destruction or cryosurgery), significant IIF and freeze concentration induced excessive dehydration are well-established to be the two primary biophysical events that cause cryoinjury. Since freeze concentration requires sufficient time for dehydration of cellular water across 


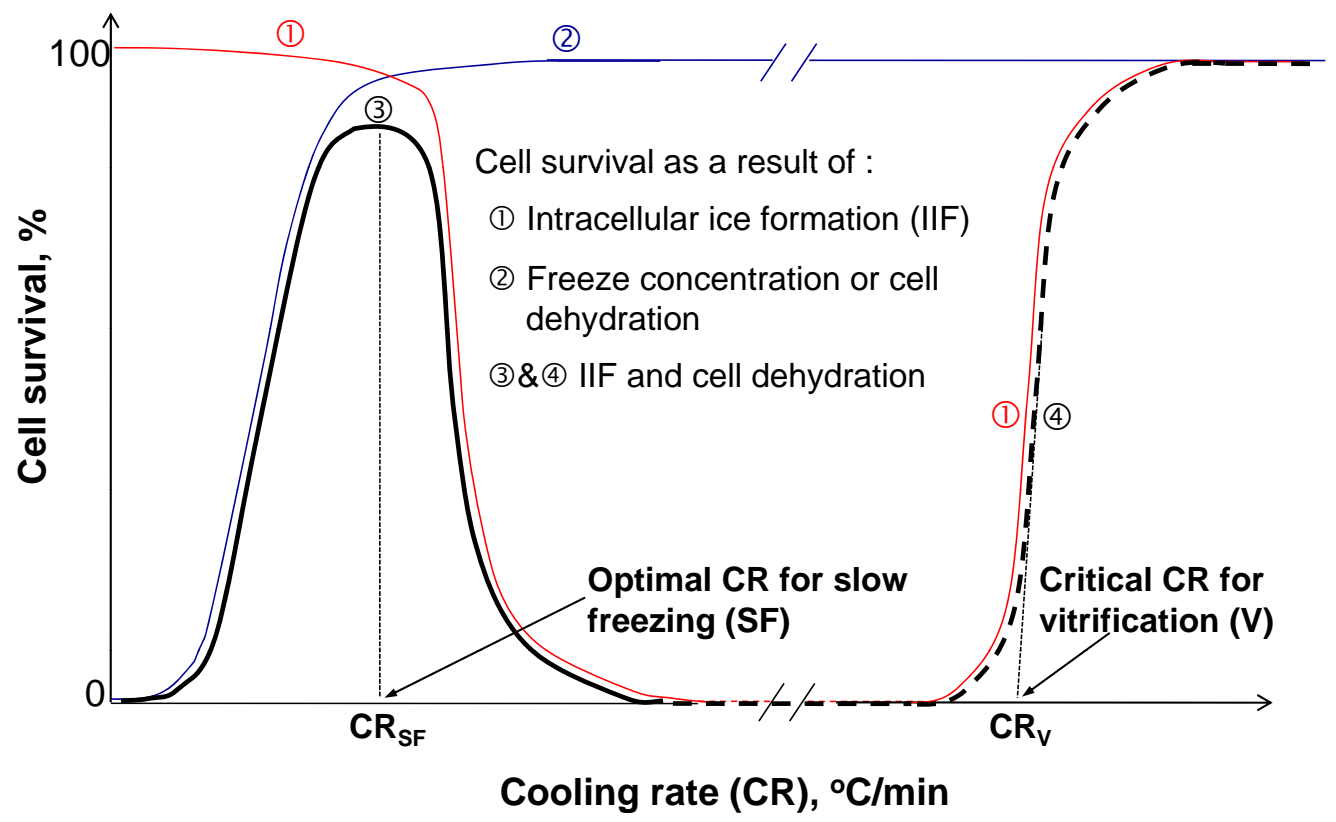

Fig. (9). Cell survival as a function of cooling rate due to intracellular ice formation (IIF) only (1), freeze concentration induced cell dehydration (solute effect) only (2), and the combination of the two factors (3) and (4)): During slow-freezing, the solute effect and IIF determines cell survival at low and high cooling rates, respectively; the combined effect of IIF and freeze concentration (i.e., solute effect) results in the classical inverted $U$ curve of cell survival vs. cooling rate and an optimal cooling rate $\left(\mathrm{CR}_{\mathrm{SF}}\right)$ is observable for slow-freezing; the optimal cooling rate is cell type and also cryoprotectant concentration dependent; and when the cooling rate is higher than a critical cooling rate $\left(\mathrm{CR}_{\mathrm{V}}\right)$, cells are vitrified without freezing (or ice formation) and high cell survival ensues. Figure reprinted from reference [53] with permission from Xiaoming He (the author).

the cell plasma membrane, its cell damaging effect is apparent only when cooling cells at slow cooling rates. For IIF, however, a higher cooling rate (tens to hundreds of degree Celsius per minute) is required so that intracellular water has no time to diffuse out of the cell and is available for IIF. This differential dependence on cooling rate of the damaging effect of IIF and freeze concentration results in the classical inverted U curve (dark solid line (3) in Fig. 9) of cell viability vs. cooling rate for the conventional slow-freezing (for cryopreservation) and cryosurgery applications [50]. Of note, this inverted $U$ curve does not apply to thermal stabilization by vitrification. For conventional vitrification, the cell injury mechanism is related to the high concentration of CPA used, which leads to cell damage by applying a significant osmotic stress and disturbing the normal metabolic pathways at super-zero temperatures before cooling and after warming the cells [55-60,221]. For low-CPA vitrification, cells loaded with a low concentration of CPA are brought to the vitrified phase without any ice formation or freeze concentration. Therefore, the traditional inverted $U$ curve for cell survival vs. cooling rate can be modified and extended into the ultrafast cooling rate domain where cell viability increases with increasing cooling rate (dark dashed line (4) in Fig. 9), which typically occurs when the cooling rate is as high as thousands to millions of degree Celsius per second when the CPA concentration is lower than 2-4 M.

At the in vitro tissue level, the cell injury mechanism discussed at the molecular and cellular level should still apply. In general, cells isolated from a tissue tend to transport water more quickly than cells within the intact tissue [144]. Therefore, cells form intracellular ice more readily in tissues due to enhanced water trapping as well as cell-ECM (extracellular matrix) and cell-cell contact issues. For example, IIF in primary hepatocytes, fibroblast, smooth muscle cells were observed to be enhanced after placing them in a matrix (of either collagen or fibrin) over suspension [222-224]. IIF has been suggested to propagate through the gap junction between adjacent cells [225-227]. Mechanically, abnormal thermal stress higher than the yield stress has been shown to accumulate in tissue and micro and macro crack formation in the tissue is commonly observed, which can lead to damage to the cells and the integrity of the extracellular matrix in both cryosurgery and cryopreservation applications [228237]. Freezing has been shown to result in extensive damage to the vasculature in renal tissue, which presumably is responsible for the side effect of significant bleeding post cryosurgical operation of the kidney [238-243]. Blood vessel is the target of freezing induced mechanical damage, presumably because it resembles the defect in an otherwise more homogeneous tissue [229]. Freezing has also been shown to dramatically affect the biomechanical properties such as the porosity of the extracellular matrix of soft tissues [244] and the Young's modulus and ultimate tensile strength (UTS) of blood vessels [236]. Considering the tight connection between cells and extracellular matrix through focal adhesion, mechanical damage to the extracellular matrix may further disrupt the integrity of cellular membrane. Of note, the presence of CPA can greatly reduce the mechanical damage, particularly when the CPA concentration is high enough to result in vitrification [245,246].

At the in vivo tissue level, several studies have shown that the subzero temperature required for causing tissue necrosis is higher than that in vitro [200,239,247]. Again, this observation has been attributed to the vascular stasis as a result of freezing induced damage to tissue vasculature during freezing and thawing, which results in the deprivation of nutrition and oxygen to cells, a secondary mechanism that kills cells in addition to direct cell injury. The wound healing 
response in an in vivo cryolesion however, is quite different from that in an in vivo hyperthermic lesion in that wound healing has been observed throughout the whole cryolesion [191]. For example, the cryolesion shrinks from day 3 to day 7 (Fig. 8B) indicating wound healing response that assimilates the necrotic tissue and allow the regeneration of normal tissue in the cryolesion [144,247]. This is probably because the frozen tissue has generally been observed to be reperfused immediately after thawing and vascular stasis does not occur usually until a few hours after thawing in cryosurgical applications [239,247]. Presumably, the short period of temporary reperfusion of the frozen tissue after thawing allows the recruitment of inflammatory cells for the subsequent wound healing response in the whole damaged tissue domain.

\subsection{Measurement of Thermal (Cryo and Hyperthermic) Injury}

Various methods have been utilized to measure thermal injury to biologicals. At the molecular level, x-ray crystallography, nuclear magnetic resonance (NMR) spectroscopy, Fourier transform infrared (FTIR) spectroscopy, circular dichroism (CD), electron microscopy, and differential scanning calorimetry (DSC), have been used to investigate thermally induced alterations to many proteins and lipids and sometimes DNA/RNAs [143,187]. Both x-ray crystallography and NMR spectroscopy can determine definitively the 3D structure of pure proteins. However, x-ray crystallography requires the protein sample to be in the crystal state and NMR spectroscopy can only be used to study small proteins or protein domains $(\leq 20 \mathrm{kD})$ [151]. Both FTIR (Fig. 6A and C) and CD have been widely used to study the structural change of proteins (secondary structures such as $\alpha$-helix and $\beta$-sheet in Fig. 5D) and lipids in response to a thermal challenge $[143,187]$. DSC is the only technique that can be used to investigate the calorimetric effect associated with the structural change in proteins (denaturation and agglomeration, Fig. 6B), lipids (phase transition and separation), and DNA/RNAs (denaturation, breaking up the intra-molecular hydrogen bond). Although isolated proteins and lipids have been used in many studies of thermal injury, there is a shift of research interests to investigate the in situ protein denaturation and lipid change in living cells recently. This is important because protein and lipid stability is strongly affected by the biochemical microenvironment in which they reside [143]. This is particularly important for determining the correlation between cell injury and thermally induced alterations in proteins and lipids. A number of studies using FTIR and DSC in this regard have reported strong correlations between cell injury and in situ thermal denaturation of protein in a number of cell types including prostate cancer cells (Fig. 6D), primary liver cells, and red blood cells $[156,158,159,195]$.

Immediate cell viability (or injury) post thermal treatment is usually judged by the integrity of cell plasma membrane. The ability of an intact plasma membrane to exclude some membrane impermeable dye (e.g., ethidium homodimer showing red fluorescence in Fig. (7A), propidium iodide, and trypan blue) has been the most convenient way to visualize thermally induced damage to mammalian cells using microscopy (fluorescence capability is required for using ethidium homodimer and propidium iodide) $[187,248]$. The hydrolysis of calcein-AM (a non-fluorescent hydrophobic compound that easily permeates intact cells) by intracellular esterases (important enzymes for intracellular hydrolytic reactions) to produce calcein (a hydrophilic compound with strong green fluorescence that is impermeable to the plasma membrane of intact cells) has also been widely used to judge immediate cell viability using fluorescence microscopy (Fig. 7A). However, it has been shown that many cells with compromised membrane (judged by impermeable dyes) also show strong green fluorescence of calcein. Therefore, caution should be taken when calcein AM is used solely to judge immediate cell viability [187].

Since thermal damage to the other subcellular organelles can also determine the eventual fate of cells exposed to abnormally high and low temperatures, a better assay to evaluate the true (or long-term) cell viability can be done by checking the capability of the cells to attach to a substrate and subsequently proliferate [187]. The former is usually termed attachment efficiency and is evaluated by calculating the percentage of attached cells with regard to total cells seeded 3-12 hrs after thermal treatment and seeding. Proliferation is obtained by monitoring the change in cell number in a sample in several consecutive days after treatment. Clonogenics, another assay for determining the long-term cell survival, is calculated as the ratio (or percentage) of the number of cell colonies formed for thermally treated cells to that of control (i.e., no thermal treatment) samples usually after 7-10 days of culture after seeding [249]. This assay avoids counting cells in multiple days for the proliferation assay. For thermal stabilization applications, it is also important to verify that the cells retain important cell specific functions. For example, it is important to make sure hepatocytes (or liver cells) retain the normal function of urea production and albumin synthesis after biopreservation [222]. For stem cells, it is important to make sure that they retain pluripotency (e.g., the undifferentiated properties indicated by the expression of some stem cells specific markers shown in Fig. 7B and C for murine embryonic stem cells), multipotency, and/or the capability to differentiate into more specialized adult cells post biopreservation [250].

Histology (hemotoxylin\&eosin or H\&E stain) is commonly used to judge cell (Fig. 7D) and vascular injury in tissue [192]. Although being qualitative initially, histology has been used to quantify thermal injury to cells in tissue in several recent studies (Fig. 8A) [38,186,251]. Membrane impermeable fluorescence dyes have also been used to quantify cell injury in tissue after thermal treatment [186,251]. For some tissues abundant of collagen such as rat tail tendon, joint capsule, and myocardium, thermal injury is reflected by collagen denaturation which can be measured by a variety of techniques such as DSC, loss of birefringence observable using polarized light microscopy, loss of transparency, and shrinkage as reviewed elsewhere [143,148,252]. For injury assessment in situ in the host, perfusion defect (or absence of blood perfusion) in the damaged tissue is commonly used, which can be measured by MR contrast agent (e.g., gadolinium) exclusion or by fluorescence contrast in situ (Fig. 8B) [200,253-255]. Recent studies have shown that tissue injury assessed by perfusion defect corresponds quantitatively with tissue necrosis determined by histology using biopsy [256,257]. 


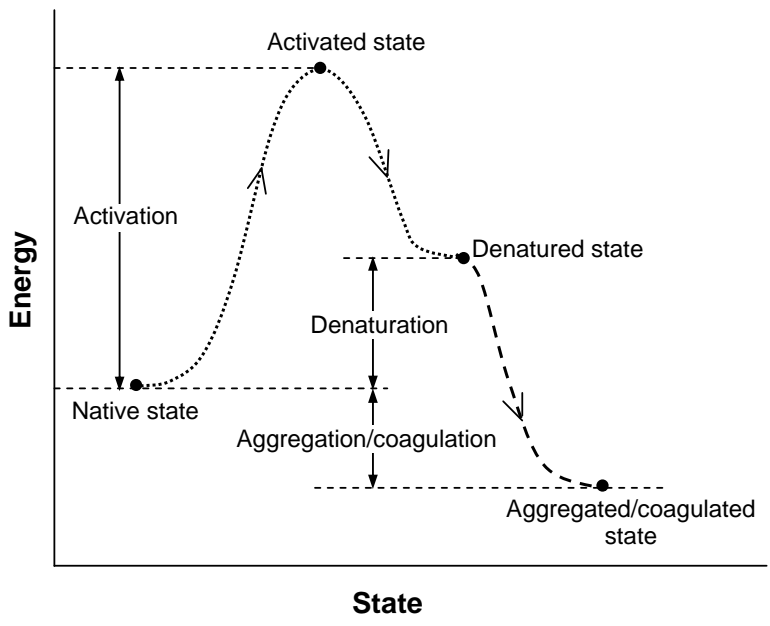

Fig. (10). An illustration of energy-state relationship of the $1^{\text {st }}$ order kinetic process of thermally induced protein denaturation: The native protein is activated after absorbing energy followed by denaturation and potentially aggregation and agglomeration: Aggregation and agglomeration make the process irreversible. Figure reprinted and redrawn from reference [143] with permission from John Wiley \& Sons.

Among the various methods, clonogenics (or proliferation) and histology are the gold standard for judging cell and tissue viability, respectively. Besides the methods used to determine it, the cell viability $(0-100 \%)$ is also dependent on many other factors including the specific thermal history applied, the attachment state (i.e., suspended, attached on dish, attached in 3D matrices) of the cells, and the cell culture microenvironment (e.g., pH) [187].

\section{BIOPHYSICAL MODELING OF THERMAL IN- JURY}

Besides injury measurement, there is a need of injury models to predict the outcome of thermal treatment for better understanding of the injury mechanism in research and pretreatment planning in the clinic. Injury models need to be verified or parameters in the model need to be extracted using experimental data a priori. With the verified model, injury to biologicals under any thermal history can be predicted. Furthermore, models may help us understand the injury mechanism by comparing the model parameters with those of known biological processes such as protein denaturation, lipid alteration, and DNA breakage [142,146,252]. Modeling hyperthermic injury at the molecular, cellular and tissue level has been reported in the literature for a wealth of biologicals [142,146,252]. However, modeling of cryothermic injury is not as well-developed due to the complication of two additional biophysical events: freeze concentration (leading to cell dehydration) and IIF in addition to the thermotropic effect of cryogenic temperature per se.

\subsection{Modeling of Hyperthermic Injury}

Several models have been developed to predict hyperthermic injury to biologicals including the statistical model, enzyme denaturation model, thermal isoeffective dose (TID) model, and various kinetic models [142,146,258-261]. Among the various models, the TID and kinetic models are the most widely used.

\subsubsection{Kinetic Models}

The first order irreversible kinetic model has been the most commonly used for predicting hyperthermic injury. In this model, biologicals including biomacromolecules, cells, and tissue are considered to be either in a native $(\mathrm{N})$ or injured (I) state with an injury rate (or rate constant in the chemistry literature) $\mathrm{k}$ as follows:

$$
N \stackrel{k}{\longrightarrow} I
$$

An energy-state illustration of the first order kinetic model for describing the denaturation of proteins is given in Fig. (10), where the denatured state of proteins is equivalent to the injured state of cells or tissue in Equation 1. Thermally induced protein denaturation is often irreversible as a result of aggregation/coagulation and agglomeration following denaturation, which eventually results in irreversible cell death.

Assuming all biologicals being in the native state initially, the fraction of biologicals in the native state after being exposed to a thermal history $\mathrm{T}(\mathrm{t})$ can be calculated as follows :

$$
F_{N}=\exp \left(-\int_{0}^{t} k d t\right)
$$

where $F$ represents fraction, $t$ is time, and the subscript ' $N$ ' represents native state. The injury rate (or rate constant) can be calculated using the Arrhenius model as follows [262264]:

$$
k=A \exp \left[-\Delta E /\left(R_{g} T\right)\right]
$$

where $\mathrm{R}_{\mathrm{g}}$ is the universal gas constant $\left(8.314 \mathrm{~J}_{\text {mole }}{ }^{-1} \mathrm{~K}^{-1}\right)$, $\mathrm{T}$ (in $\mathrm{K}$ ) is the thermal history (time dependent), and $\Delta \mathrm{E}$ and $\mathrm{A}$ are the two kinetic model parameters (constants) usually called activation energy and frequency factor, respectively. This equation can be rewritten in the following format by taking the natural logarithm on both sides of the equation:

$$
\ln (k)=\ln (A)-\Delta E /\left(R_{g} T\right)
$$

Equation 4 shows that the injury rate $(\mathrm{k})$ is constant for a given temperature. Therefore, Equation 2 can be rewritten as follows under isothermal heating conditions:

$$
F_{N}=\exp (-k t)
$$

Equation 5 has been frequently used to fit to data of fractional cell survival vs. isothermal heating time under various constant temperatures, through which the cell injury rate at various constant temperatures can be determined. With the known injury rate at various constant temperatures, the two model parameters (i.e., $\Delta \mathrm{E}$ and $\mathrm{A}$ ) can be determined by fitting to the data of $\mathrm{k} \mathrm{vs}$. $\mathrm{T}^{-1}$ at various constant temperatures using the linear relationship between the natural logarithm of $\mathrm{k}$ and $\mathrm{T}^{-1}$ given by Equation 4 . The frequency factor and activation energy can be determined from the intercept and the slope of the linear fit, respectively. The procedures for determining the activation energy and frequency factor are demonstrated in Fig. (11).

In the hyperthermic literature, a terminology called injury and often represented by $\Omega$ is defined as follows [262-264]: 

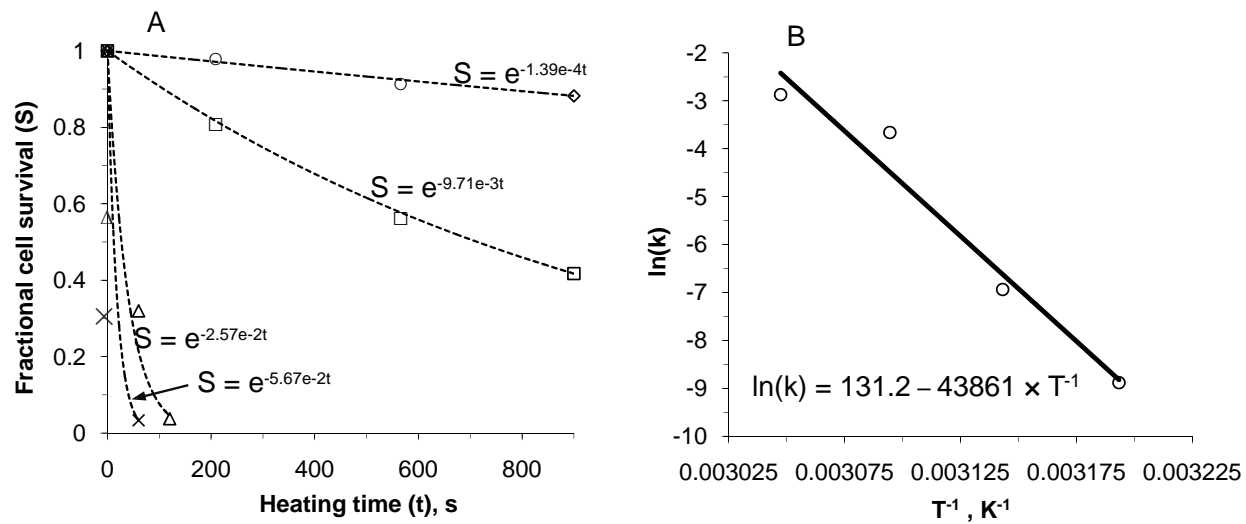

Fig. (11). An illustration of the procedures for determining the activation energy and frequency factor using Equations 4 and 5: (A), determining the injury rate at various temperatures by fitting Equation 5 to experimental data on cell survival vs. exposure time and (B) determining activation energy and frequency factor by fitting Equation 4 to the natural logarithm of injury rate vs. the inverse of temperature obtained from (A). Figure reprinted and redrawn from reference [187] with permission from ASME.

$$
\Omega=\int_{0}^{t} k d t
$$

According to Equation 6, $\mathrm{k}$ is the first derivative of injury $(\Omega)$ with respect to time, which explains why $\mathrm{k}$ is often called injury rate in the hyperthermic literature. The relationship between $\Omega$ and the fraction of biologicals in the native state for a thermal treatment can be determined by combining Equations 6 and 2 as follows:

$$
F_{N}=\exp (-\Omega)
$$

From this equation, it is clear that an accumulated injury of 1 (i.e., $\Omega=1$ ) implies that the fractional survival is $\mathrm{e}^{-1}$ or $36.7 \%$.

The reaction rate $\mathrm{k}$ can also be calculated using the absolute rate theory model as follows [265,266]:

$$
\begin{aligned}
& k=\left(k^{\prime} / h^{\prime}\right) T \exp \left[-\Delta g^{\prime \prime} /\left(R_{g} T\right)\right] \\
& \Delta g^{\prime \prime}=\Delta h^{\prime \prime}-T \Delta s^{\prime \prime}
\end{aligned}
$$

where $\mathrm{k}^{\prime}$ is the Boltzmann constant $\left(1.38 \times 10^{-23} \mathrm{~J} \mathrm{~K}^{-1}\right), \mathrm{h}^{\prime}$ is the Planck's constant $\left(6.625 \times 10^{-34} \mathrm{~J} \mathrm{~s}\right)$, and $\Delta \mathrm{h}^{\prime \prime}, \Delta \mathrm{s}^{\prime \prime}$, and $\Delta \mathrm{g}^{\prime \prime}$ are enthalpy, entropy, and Gibb's free energy of activation for the thermal injury process, respectively. The two kinetic model parameters for the absolute rate theory model are the enthalpy and entropy of activation. The relationship between the parameters of the absolute rate theory model and those of the Arrhenius model for a first order reaction such as that described by Equation 1 is as follows [148]:

$$
\begin{gathered}
\Delta E=\Delta h^{\prime \prime}+R_{g} T \\
A=\left(k^{\prime} / h^{\prime}\right) T \exp \left(\Delta s^{\prime \prime} / R_{g}+1\right)
\end{gathered}
$$

According to Equation 10, the difference (i.e. $\mathrm{R}_{\mathrm{g}} \mathrm{T}$ ) between $\Delta \mathrm{E}$ and $\Delta \mathrm{h}^{\prime \prime}$ is less than $3 \mathrm{~kJ} /$ mole when temperature is below $80^{\circ} \mathrm{C}$. This small difference is negligible for most situations due to the relatively high value of the activation energy for cell/tissue injury and protein denaturation (typically, more than $50 \mathrm{~kJ} / \mathrm{mole}$ ) [142]. The frequency factor is linearly dependent on temperature and exponentially dependent on the entropy of activation. Since the unit for tem- perature is Kelvin, it is usually more than $293.15 \mathrm{~K}$ (assuming room temperature is $20{ }^{\circ} \mathrm{C}$ ) for thermal therapy applications. Therefore, the dependence of the frequency factor on temperature is weak considering that the temperature for cell killing is usually between 50 and $70{ }^{\circ} \mathrm{C}$ in most thermal therapy applications.

Many studies have been performed to determine the parameters in the first order kinetic model for many different types of biologicals at the molecular (mainly proteins), cell, and tissue levels. These kinetic parameters for a wealth of biologicals have been summarized/tabulated and the following conclusion can be drawn by a careful examination of the kinetic data (Fig. 12) [142]:

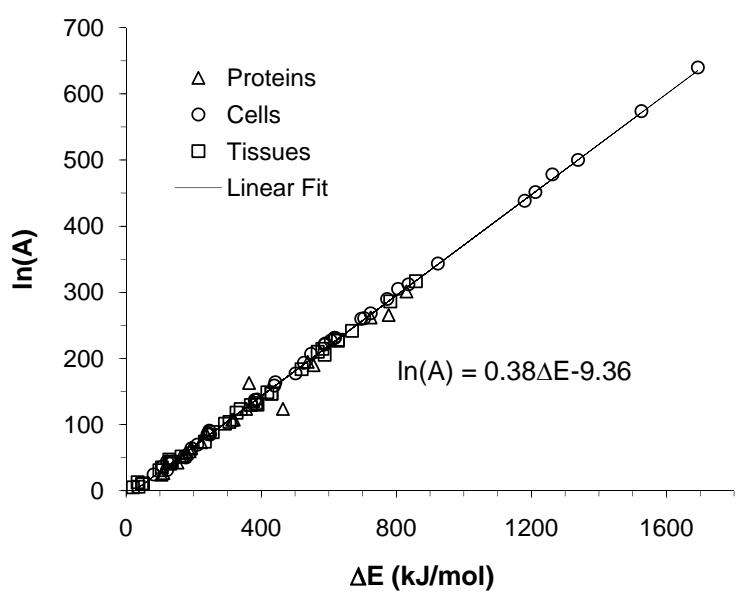

Fig. (12). A summary of the kinetic parameters in the first order kinetic model for various proteins, cells, and tissues: A simple, phenomenological, linear relationship exists between activation energy and the natural logarithm of frequency factor in the first order kinetic model for hyperthermic injury. Figure reprinted and redrawn from reference [142] with permission from Begell House.

- The literature values of activation energy varies over a broad range from 50 to $1600 \mathrm{~kJ} / \mathrm{mole}$ dependent on the type of biologicals (i.e., lipids, proteins, cells and/or tissues), temperature range, $\mathrm{pH}$, and assay used. The activation energy for lipid change is typically lower than that for protein denaturation and cell/tissue injury. The activation energy for 
protein denaturation and cell/tissue injury however, is on the same order of magnitude, suggesting protein denaturation should be an important mechanism of thermally induced cell/tissue injury.

- Clonogenic assay for single cells usually results in very high activation energy $(\sim 350-1600 \mathrm{~kJ} / \mathrm{mole})$ whereas it is generally much lower for histology and fluorescence viability dye assays $(\sim 100-800 \mathrm{~kJ} / \mathrm{mole})$.

- An approximate, phenomenological, linear relationship between the natural logarithm of frequency factor and activation energy exists (see Fig. 12). This approximate linear relationship is attributed to the small variation of Gibbs free energy of activation given by Equation 9 for a thermal injury process despite the large variation of activation enthalpy (related to activation energy by Equation 10) and entropy (related to the frequency factor by Equation 11). The Gibb's free energy of activation $\left(\Delta g^{\prime \prime}\right)$ typically varies between 100 and $115 \mathrm{~kJ} / \mathrm{mole}$.

- Temperature break points below and above which the activation energy changes significantly are mainly located at $\sim 43^{\circ} \mathrm{C}$ and $\sim 50^{\circ} \mathrm{C}$ if they do exist $[142,187]$. The break point at $43^{\circ} \mathrm{C}$ has been suggested to be a result of thermotolerance. The reason for a break point at $50^{\circ} \mathrm{C}$ is unclear yet.

- With few exceptions, the literature values of frequency factor are greater than $2.0 \times 10^{13} \mathrm{~s}^{-1}$ which is larger than the frequency factor predicted using Equation 11 assuming 0 activation entropy. In other words, the activation entropy for the kinetic process of thermally induced alterations in protein, cells, and tissue are typically positive.

Besides the first order kinetic model, higher order kinetic models have also been developed for modeling thermal injury $[259,260]$. However, higher order kinetic models have not been widely used probably due to the difficulty to definitively determine the multiple (>2) parameters in those models using experimental data.

\subsubsection{Thermal Isoeffective Dose (TID) Model}

The thermal isoeffective dose (TID) model was proposed nearly 30 years ago [267] and has been widely used in both the traditional and many recent hyperthermic literatures [149]. In the TID model, a thermal history (i.e., timetemperature data) is converted to a cumulative equivalent minutes (isoeffect) at $43^{\circ} \mathrm{C}$. As a result, the comparison of thermal doses and treatment planning of thermal therapy become straightforward, which may explain why the TID model has been widely used [268,269]. The time required to achieve the isoeffect of $43{ }^{\circ} \mathrm{C}$ at a constant temperature in terms of thermal injury is calculated as follows [149]:

$$
t(\theta)=C E M 43 C_{S} / R^{43-\theta}
$$

where $\theta$ is temperature in ${ }^{\circ} \mathrm{C}, \mathrm{CEM} 43 \mathrm{C}_{\mathrm{S}}$ is the cumulative equivalent minutes required to decrease cell survival from the initial $(100 \%)$ to a given criterion ( $\mathrm{S}$ can be calculated as $\left.\mathrm{F}_{\mathrm{N}} \times 100 \%\right)$ at $43{ }^{\circ} \mathrm{C}$, and $\mathrm{R}$ is the number of minutes required to compensate for a $1{ }^{\circ} \mathrm{C}$ temperature change to achieve an isoeffect of cell injury. The parameter R (not dimensionless) is a function of temperature and the activation energy of a thermal injury process [267]:

$$
R=\exp \left\{-\Delta E /\left[R_{g} T(T+1)\right]\right\}
$$

If assuming $36.7 \%\left(\mathrm{e}^{-1}\right)$ cell survival as the criterion, the threshold time CEM43C can be calculated from the Arrhenius model as follows:

$$
C E M 43 C_{36.7 \%}=1 / k_{43 C}=A^{-1} \exp \left\{\Delta E /\left[R_{g}(43+273.15)\right]\right\}
$$

Note that CEM43C $36.7 \%$ is the same as the inverse of the injury rate at $43{ }^{\circ} \mathrm{C}\left(\mathrm{k}_{43} \mathrm{C}\right)$. To calculate CEM $43 \mathrm{C}$ assuming a different cell survival $\mathrm{S}\left(\mathrm{CEM} 43 \mathrm{C}_{\mathrm{S}}\right)$, the following equation can be used [187]:

$$
C E M 43 C_{S}=C E M 43 C_{36.7 \%} \ln \left(S^{-1}\right)
$$

where the subscript $\mathrm{S}$ and $36.7 \%$ represent the percentage of survival that is assumed as the criterion for calculating the cumulative equivalent time at $43{ }^{\circ} \mathrm{C}$.

In many traditional literature of hyperthermia, a simplified version of the TID model was used that assumes a universal CEM43C of either 120 or $240 \mathrm{~min}$ for complete injury of all cells at $43{ }^{\circ} \mathrm{C}$. The parameter $\mathrm{R}$ in the simplified TID model is taken as 0.25 and 0.5 for temperatures below and above $43{ }^{\circ} \mathrm{C}$, respectively. According to Equations 13-15, both the CEM43C and $\mathrm{R}$ are dependent on the activation energy and frequency factor ( $\mathrm{R}$ is also temperature dependent), both of which are strongly cell type dependent. Therefore, caution should be taken when using the simplified TID model for predicting thermal injury in different types of cells. The CEM43C for a variety of cells and tissue of urologic origin together with the temperature and cell typedependent $\mathrm{R}$ values for thermal therapy applications have been tabulated elsewhere [187].

\subsection{Modeling of Cryothermic Injury}

Modeling of cryothermic injury is more challenging since it is complicated by two additional but important biophysical events: freeze concentration and ice formation. To the author's knowledge, quantitative and mechanistic modeling of the effect of low temperature, freeze concentration, and ice formation on the stability of biomacromolecules such as lipids and proteins has not been reported. At the cell and tissue levels, formation of extracellular ice leads to freeze concentration along the liquidus in the phase diagram (see Fig. 3) which further results in cell dehydration at a slow cooling rate (e.g., $<10{ }^{\circ} \mathrm{C} / \mathrm{min}$ ). On the other hand, IIF will occur when the cooling rate is fast so that the intracellular water has no time to leave the cells through exosmosis, but not fast enough $\left(<\mathrm{CR}_{\mathrm{V}}\right.$ shown in Fig. 9) to supersede the kinetics of ice formation. As with the molecular level injury, quantitative and mechanistic modeling of cryoinjury at the cellular and tissue levels has not been well studied. So far, much of the effort in modeling cryoinjury has been focused on modeling intracellular ice formation (IIF) and cell dehydration during freezing. IIF has been studied using both phenomenological and mechanistic models [194,270]. The mechanistic model has been widely used and delineates the ice formation as two consecutive events: Nucleation of ice nuclei and the subsequent growth of the nuclei [194,271]. Nucleation of intracellular ice can be catalyzed by either a surface (surface catalyzed nucleation, SCN) such as the cell plasma membrane or a volume of subcooled solution (volume catalyzed nucleation, VCN) such as the cytoplasm 
[194,271]. The rate of ice nucleation (I) due to either VCN or SCN can be modeled as follows $[68,272]$ :

$$
I=\Omega_{0} \frac{N}{N_{0}} \frac{\eta_{0}}{\eta}\left(\frac{T}{T_{f 0}}\right)^{0.5} \exp \left[\frac{-\kappa_{0}\left(T_{f} / T_{f 0}\right)^{4}}{\left(T-T_{f}\right)^{2} T^{3}}\right]
$$

where $T_{f}$ is the equilibrium freezing point of the intracellular solution, $\mathrm{N}$ is the number of water molecules either in the cells (for VCN) or in contact with the cell plasma membrane (for SCN), $\eta$ is viscosity, and $\Omega$ and $\kappa$ are two model parameters that are usually called the kinetic and thermodynamic coefficient, respectively, and the subscript 0 represents the isotonic solution state before freezing (ice formation). The two model parameters under isotonic solution state $\left(\Omega_{0}\right.$ and $\left.\kappa_{0}\right)$ need to be determined by experimental studies and have been reported in the literature for a number of cell types as summarized elsewhere [142,194,273]. The cumulative probability of intracellular ice formation $\left(\mathrm{P}_{\mathrm{IIF}}\right)$ can then be calculated as follows $[68,194]$ :

$$
\begin{aligned}
& P_{I I F}^{V C N}=1-\exp \left(-\int_{0}^{t} V I^{V C N} d t\right) \\
& P_{I I F}^{S C N}=1-\exp \left(-\int_{0}^{t} A I^{S C N} d t\right) \\
& P_{I I F}^{T o t}=P_{I I F}^{S C N}+\left(1-P_{I I F}^{S C N}\right) P_{I I F}^{V C N}
\end{aligned}
$$

where $\mathrm{V}$ and $\mathrm{A}$ are the cell volume and surface area available for catalyzing the nucleation of intracellular ice, respectively. Significant IIF is usually manifested as darkening of the cell cytoplasm when observed under a bright field of light microscopy as demonstrated in Fig. (13), which has been used widely to quantify the kinetics of intracellular ice formation [274,275].

Of note, the above IIF model is valid only when ice nucleation (the first step of IIF) is the rate-limiting step of IIF which is often true when freezing cells/tissues at not very high cooling rates (e.g., less than a few hundred Celsius per minute) and in the absence of a high concentration of CPA (e.g., less than $10 \mathrm{wt} \%$ ) [194]. Under these conditions, ice will immediately propagate (or grow) throughout the entire intracellular space once the ice nuclei form, which results in the darkening event. When cooling cells/tissue with much higher cooling rates and/or a high concentration of intracellular CPA (e.g., during vitrification and after significant cell dehydration during slow-freezing), the rate limiting-step of IIF is the growth of the ice nuclei (the second step of IIF). The IIF under these conditions is said to be diffusion-limited for which more complicated models are needed to predict the amount of ice in cells [67,69,276-278]. To accurately predict the diffusion-limited ice nucleation and growth, an advanced model such as the free volume model that can be used to predict the effect of glass transition on solution viscosity and diffusion coefficient might be necessary. Such free volume model for a couple of cryo and lyoprotectants has been reported in [107].

In order to predict the probability of IIF using the above model during slow-freezing where freeze concentration induced cell dehydration is significant, information on the cell

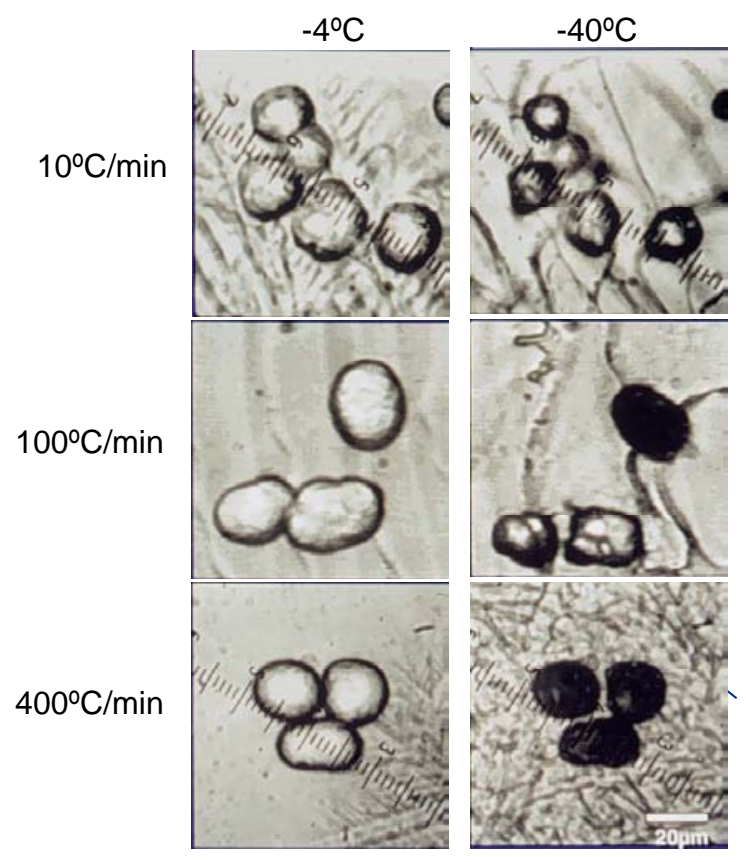

Fig. (13). Dependence on cooling rate of intracellular ice formation (IIF) when freezing hepatocytes from -4 (after seeding extracellular ice) to $-40{ }^{\circ} \mathrm{C}$ showing the darkening of the cellular interior as a result of significant IIF under a bright field of light microscope: When the cooling rate is very low $\left(10{ }^{\circ} \mathrm{C} / \mathrm{min}\right)$, cell dehydration dominates (A); when the cooling rate is high $\left(400{ }^{\circ} \mathrm{C} / \mathrm{min}\right)$, IIF dominates (C); and when the cooling rate is intermediate (100 ${ }^{\circ} \mathrm{C} / \mathrm{min}$ ), both IIF and cell dehydration can occur (B). Figure reprinted and redrawn from reference [272] with permission from John Wiley \& Sons.

volume, $\mathrm{V}$ (or cell surface area, $\mathrm{A}$, related to the diameter of the cells when the cells assume a spherical geometry), during freezing is required. The following model has been commonly used to predict the cell volume change during freezing [67,279]:

$$
\frac{d V}{d t}=-\frac{L_{p} A R_{g} T}{v_{w}}\left[\ln \frac{V-V_{b}-V_{s}}{V-V_{b}-V_{s}+\varphi_{s} n_{s} v_{w}}-\frac{\Delta h_{f}}{R_{g}}\left(\frac{1}{T_{r e f}}-\frac{1}{T}\right)\right]
$$

where $v_{\mathrm{w}}$ is the partial molar volume of water, $\mathrm{n}$ represents amount (in mole), $\varphi_{\mathrm{s}}$ is dissociation constant of solutes (e.g., 2 for $\mathrm{NaCl}$ ), $\mathrm{V}_{\mathrm{s}}$ is volume of solutes, $\mathrm{V}_{\mathrm{b}}$ is osmotically inactive volume in cells, $\Delta \mathrm{h}_{\mathrm{f}}$ is latent heat of fusion of water, $\mathrm{T}_{\mathrm{ref}}$ is a reference temperature usually taken as the equilibrium melting point of the intracellular solution, $\mathrm{T}$ is thermal history, the subscripts $\mathrm{s}$ and $\mathrm{w}$ represent solute (including CPAs) and water, respectively, and $\mathrm{L}_{\mathrm{p}}$ is the cell plasma membrane permeability to water that can be calculated as follows [280]:

$$
L_{p}=L_{p g} \exp \left[-\frac{E_{L p}}{R_{g}}\left(\frac{1}{T}-\frac{1}{T_{r e f}}\right)\right]
$$

where $L_{p g}$ is the permeability of the cell membrane to water at the reference temperature $\left(\mathrm{T}_{\text {ref }}\right)$ and $\mathrm{E}_{\mathrm{Lp}}$ is the activation 
energy for the water transport across the cell plasma membrane. In the equation, $\mathrm{L}_{\mathrm{pg}}$ and $\mathrm{E}_{\mathrm{Lp}}$ are two model parameters that need to be determined a priori using experimental data. Cell dehydration during freezing can be measured using either a specialized cryostage mounted on a light microscope [275] or differential scanning calorimetry [281-284]. Many studies have been performed to determine the two model parameters for various cells, which were reviewed and tabulated elsewhere [142,273,284,285].

Although cell dehydration and intracellular ice formation (IIF) can be predicted using the above models, a quantitative understanding of the mechanistic link between the two biophysical events and cell injury has not been well established despite some early efforts in this respect as reviewed elsewhere [142]. The incidence of significant IIF (defined as darkening of cell cytoplasm) correlates strongly with cell death in many cell types (i.e., $50 \%$ of IIF in many cell populations yields 50\% of dead cells) [194]. However, the exact amount or percentage of intracellular ice that is significant enough to result in irreversible cell death is still unclear. Some studies even suggest that a small amount of intracellular ice might be beneficial to cell survival [286,287]. Therefore, further studies to establish mechanistic models capable of accounting for the effect of all the freezing induced biophysical events including intracellular ice formation and freeze concentration (i.e., the so-called solute effect), and low temperatures per se is important to further our understanding of low temperature biology and its biomedical application such as cryosurgery and cryopreservation.

\section{THERMOPHYSICAL QUANTIFICATION}

Heat transfer in living systems is unique because of the effect on heat transfer of blood perfusion (and sometimes metabolism) (Fig. 5A) [21]. Generally, the thermal response in a bioheat transfer process (either heating or cooling) can be modeled using the following energy balance equation together with appropriate initial and boundary conditions:

$$
\rho \frac{\partial(c T+\Lambda L)}{\partial t}=\nabla \cdot\left(k_{T} \nabla T\right)+Q_{E E}+Q_{B P}+Q_{M}
$$

where $\rho$ is density, $c$ is specific heat, $L$ is latent heat (per unit mass), $\wedge$ is the latent heat release pattern that could be temperature and/or time dependent [142], $\mathrm{k}_{\mathrm{T}}$ is thermal conductivity, Q represents heat source/sink term, and the subscripts $\mathrm{EE}, \mathrm{BP}$, and $\mathrm{M}$ represent the source/sink term due to the applied external energy, blood perfusion, and metabolism, respectively. A detailed discussion about the different terms is given below. Note that the effect on heat transfer due to convection is omitted in the above energy equation since convection in the bulk (excluding the blood vessel that is accounted for by the heat source/sink term due to blood perfusion $\left(\mathrm{Q}_{\mathrm{BP}}\right)$ ) soft tissue is generally considered to be negligible.

\subsection{Metabolic Heat Generation}

In many studies of thermal therapy and cryosurgery, metabolic heat generation is taken as zero because it is generally much smaller than that due to blood perfusion and the externally applied energy source. In some studies particularly for the modeling of heating or cooling without freezing (no ice formation), the metabolic source term is taken to be temperature dependent as follows [288,289]:

$$
Q_{M}=Q_{M, 37 C} \phi^{(\theta-37) / 10}
$$

where $\mathrm{Q}_{\mathrm{M}, 37 \mathrm{C}}$ is the baseline metabolic heat generation at 37 ${ }^{\circ} \mathrm{C}$ that is tissue type dependent and is summarized in [146] for a number of tissues/organs, $\phi$ is a model parameter that should be tissue type dependent as well although it is usually taken as 3 in the literature [288,289].

\subsection{External Energy Source Term}

The external energy source term $\left(\mathrm{Q}_{\mathrm{EE}}\right)$ is related to the socalled specific absorption rate (SAR) in the literature, particularly when $\mathrm{RF} / \mathrm{microwave}$ is used as the energy source for thermally destroying unwanted tissue or warming cryopreserved biologicals. The unit of $\mathrm{Q}_{\mathrm{EE}}$ is power per volume while SAR is in power per weight. Therefore, $\mathrm{Q}_{\mathrm{EE}}$ is the product of SAR and density. The direct approach for determining this external source term is to solve either the electromagnetic (for microwave, RF, and laser) or mechanical (for high intensity focused ultrasound or HIFU) wave equation to determine the electrical or pressure field (i.e., $\vec{E}$ and p), respectively [35,290,291]. For RF/microwave applications, $\mathrm{Q}_{\mathrm{EE}}$ can be calculated from the electric field as follows [40]:

$$
Q_{E E}=\left(\sigma+\omega \varepsilon^{\prime \prime}\right)\|\vec{E}\|^{2}
$$

where $\sigma$ is electrical conductivity, $\omega$ is angular frequency, $\varepsilon^{\prime \prime}$ is the imaginary part of electrical permittivity, and $\|\vec{E}\|$ represents the magnitude of electric field. For laser and HIFU heating, the governing equations for wave propagation become very nonlinear as a result of wave scattering and cavitation (for HIFU). Therefore, a simplified model derived based on the well-known Beer-Lambert law of absorption has been utilized to predict the $\mathrm{Q}_{\mathrm{EE}}$ of a plane wave as follows [292]:

$$
Q_{E E}=\alpha I_{0} e^{-\alpha z} f(r)
$$

where $\alpha$ is absorption coefficient that accounts for all the mechanisms of heat generation, $I_{0}$ is the incident wave intensity, $\mathrm{z}$ is the coordinate in the direction of laser or HIFU wave propagation, and $f(r)$ is a function of the intensity distribution in the radial direction which is usually taken in the form of Gaussian distribution as follows [292]:

$$
f(r)=\exp \left[-2\left(r / r_{0}\right)^{2}\right]
$$

where $r$ is the radial coordinate and $r_{0}$ is known as the 'e $e^{-2}$ radius' of the wave beam since at $r=r_{o}, f(r)=e^{-2}$.

Besides theoretical prediction, experimental measurement of SAR (or $\mathrm{Q}_{\mathrm{EE}}$ ) has also been widely adopted for complicated probe designs, particularly when RF/microwave is used as the energy source. Since the experimental method can only determine SAR values at discrete, representative locations, analytical expressions are usually used to fit to the experimental data to predict SAR in a continuous domain [38,39]. For example, Fig. (14) shows the measured SAR pattern together with its fit for a typical axisymmetric dipolar helical microwave probes using the following equations [38]: 


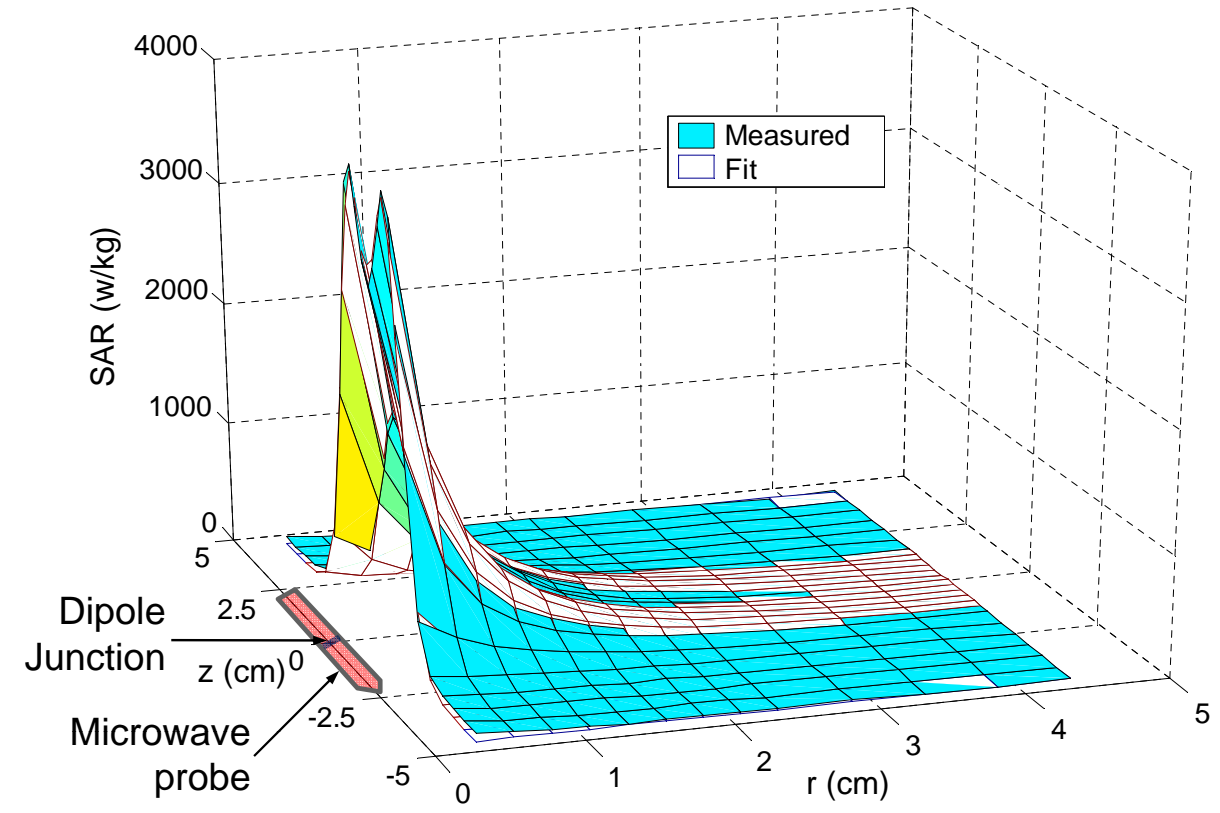

Fig. (14). A typical SAR pattern of a dipole microwave probe showing the penetration of microwave energy into the tissue space (in $r$ direction). The frequency of the microwave used is $921 \mathrm{MHz}$. Figure reprinted and redrawn from reference [38] with permission from Informa.

$$
\begin{aligned}
& S A R=Q_{E} / \rho=A e^{-2 \beta r} r^{-n}\left(1+a|z|+b z^{2}\right. \\
& \left.+c|z|^{3}+d z^{4}\right) e^{\left(z / z_{0}\right)^{2}}
\end{aligned}
$$

where $\mathrm{r}$ is radial coordinate originated from the probe centerline, $\mathrm{z}$ is the axial coordinate originated from the middle of the microwave thermal probe, $\beta\left(=0.413 \mathrm{~cm}^{-1}\right.$ for kidney tissue) is attenuation constant, $|\mathrm{z}|$ represents the absolute of $\mathrm{z}$, and the constant model parameters $\mathrm{A}, \mathrm{n}, \mathrm{a}, \mathrm{b}, \mathrm{c}, \mathrm{d}$, and $\mathrm{z}_{0}$ are $1.24 \times 10^{3}, \quad 0.9523,-0.3065,2.783,-0.941,0.2295$, and 1.0515 , respectively. The two SAR peaks at $r=0$ are the result of the dipole design of the microwave thermal probe. The SAR distribution along the axial direction of the probe (except near the two ends) is more homogeneous than that along the radial direction. SAR generally decreases exponentially in the radial direction due to tissue absorption of the electromagnetic energy.

\subsection{Thermal Effect of Blood Perfusion}

The effect of blood perfusion on thermal modeling in unfrozen tissue particularly during heating has been the focus of many studies in the literature. In frozen tissue however, blood perfusion is stopped and has no thermal effect. The classical and probably the most frequently used model of the blood perfusion term is given as follows (note, Equation 22 with the blood perfusion term given below is often called the classical Pennes bioheat equation) [293]:

$$
Q_{B P}=w \rho_{B} c_{B}\left(T_{a}-T\right)
$$

where $\mathrm{w}$ is blood perfusion rate and the subscripts $\mathrm{B}$ and a represent blood and artery, respectively. This model assumes that blood enters tissue at the arterial temperature and leaves at an equilibrated temperature which is the same as the local tissue temperature, regardless of the tissue vasculature. This assumption has been questioned by many studies in the literature. It has been shown that thermal equilibration between blood and tissue occurs before the blood reaches the capillary bed, and heat exchange between blood and tissue in aorta and large arteries (D $>3 \mathrm{~mm}$ ) is negligible in terms of affecting the blood temperature [294,295]. Further theoretical studies have shown that thermal equilibration between blood and tissue actually occurs in precapillary arteries (or arterioles) that are approximately $50 \mu \mathrm{m}$ in diameter [296]. On the venous side, blood temperature begins to deviate from its surrounding tissue in approximately the terminal vein class (or venules also $\sim 50 \mu \mathrm{m}$ in diameter) [296]. Blood vessels with a diameter between $50 \mu \mathrm{m}$ and $3 \mathrm{~mm}$ are therefore termed thermally significant vessels. These results show that the heat transfer process between blood and tissue is very different from the mass transfer process. The latter occurs dominantly in the capillary bed. Therefore, it is important to account for the effect on heat transfer of different classes (or diameters) of blood vessels differently for accurate thermal modeling. The model for blood perfusion in the classical Pennes bioheat equation seems inadequate for accurate thermal modeling.

Further investigation have shown that arterioles and venules that lead to and from the capillary bed lie in closely matched pairs with a countercurrent flow pattern, and models are therefore developed to take into account of this observation [296-305]. In this case, up to three separate but coupled governing equations are required to model the coupled heat transfer processes in arteries, veins, and the tissue region as reviewed elsewhere [146,306,307]. Although models accounting for the effects of vessel size and countercurrent flow are more theoretically rigorous, their application is very limited [146]. This is probably because the more mechanistic models require knowledge of the complex anatomy of the vasculature in a specific tissue, which unfortunately, is often unknown [306]. On the other hand, many recent studies have verified the applicability of the Pennes bioheat equation in a variety of tissues/organs by experimental data, especially in tissues/organs (e.g., kidney cortex) where small blood vessels $(\mathrm{D}<0.3 \mathrm{~mm}$ ) dominate [308311]. Blood vessels of $0.3-3 \mathrm{~mm}$ in diameter could have a significant local cooling or heating effect to the adjacent 
tissue, which is not considered in the Pennes bioheat equation and should be accounted for in thermal modeling with special attention.

With much attention being focused on modeling the thermal effect of blood perfusion using more realistic vasculature data, the magnitude of the blood perfusion (i.e., w) has been often taken as constant. However, the blood perfusion during heating has been observed to be strongly dependent on both heating time and temperature [312-314], which has been shown to significantly affect the thermal and injury modeling [38,315,316]. For example, the change of blood perfusion has been modeled as follows [317]:

$$
w=w_{37 C} e^{-\Omega}
$$

where $w_{37 C}$ is the baseline blood perfusion rate at $37{ }^{\circ} \mathrm{C}$ that can be found in the literature for many types of tissues [146] and $\Omega$ is injury to the vasculature which can be calculated using Equation 6. Therefore, this model basically takes the blood perfusion change in response to heat as a first order kinetic process. This model may be sufficient to predict the change of blood perfusion in tumor, which has been observed to decrease monotonically with the increase of thermal dose (i.e., the accumulation of heat with time reflected by injury, $\Omega$ ) [312-314]. However, it is inadequate to model blood perfusion response to heating in normal tissue, which has been observed to increase initially followed by a gradual decrease when the thermal dose is accumulated to beyond a threshold level to result in stasis in the tissue vasculature [38]. The initial increase of blood perfusion in response to heating in normal tissue has been attributed to the host mediated physiological response, in which elevated blood perfusion is used to dissipate heat to bring the temperature back to normal. Tumor tissue vasculature is believed to be generally

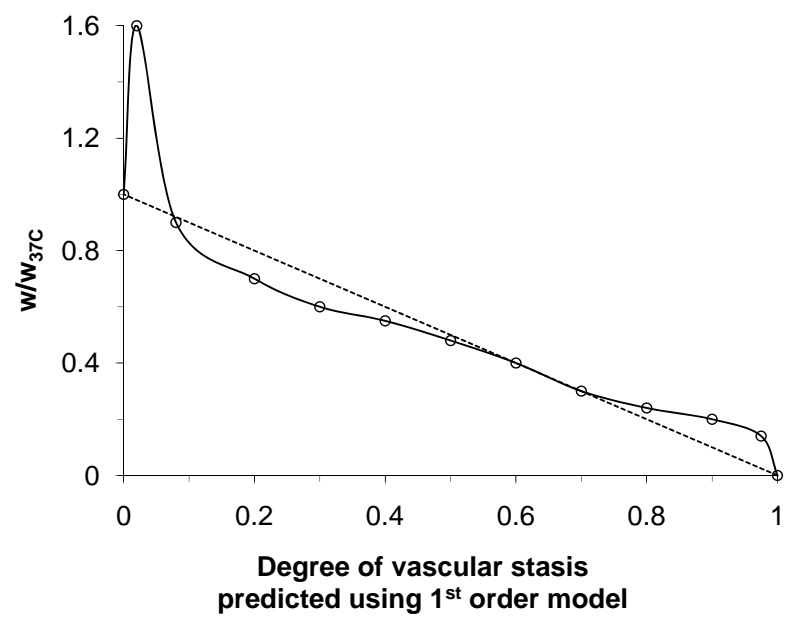

Fig. (15). Change of normalized blood perfusion $\left(w / w_{37 C}\right)$ in normal porcine kidney tissue during heating as a function of vascular stasis predicted using the $1^{\text {st }}$ order kinetic model: Blood perfusion increases initially when the predicted vascular stasis is less than $10 \%$ followed by a gradual decrease and eventually complete stasis, indicating the first order model is insufficient in predicting the change of blood perfusion in response to heating in normal tissue. It is reported that the initial increase in blood perfusion from the baseline value is absent in heating tumor tissue in vivo. Figure reprinted and redrawn from reference [38] with permission from Informa. less well organized and leaky and therefore, lacks such a host mediated physiological response [318-320]. To model the blood perfusion response to heating in normal tissue, Equation 29 can be corrected as follows [38]:

$$
w=w_{37 C} f\left(e^{-\Omega}\right) e^{-\Omega}
$$

where $\mathrm{f}\left(\mathrm{e}^{-\Omega}\right)$ is a correction function. The blood perfusion response in thermal therapy of normal porcine kidney tissue has been reported (see Fig. 15) and can be fit using Equation 30 with the following correction function:

$$
f(x)_{N P K T}=\left\{\begin{array}{l}
\left(33.6 x^{4}+37 x^{3}-51.8 x^{2}+32.2 x-7.5\right) / 10^{4}, x>0.9 \\
276.9 x^{4}-315.3 x^{3}+169.2 x^{2}-42.9 x+5.1, x \leq 0.9
\end{array}\right.
$$

where the subscript NPKT represents normal porcine kidney tissue and $\mathrm{x}$ represents $\exp (-\Omega)$ with $\Omega$ given by Equation 6 . The two kinetic parameters $(\Delta \mathrm{E}$, and $\mathrm{A})$ in Equation 6 for calculating $\mathrm{x}$ are $98.73 \mathrm{~kJ} / \mathrm{mole}$ and $1.81 \times 10^{13} \mathrm{~s}^{-1}$, respectively [38]. Further studies to quantify the two kinetic parameters and determine the correction function (for normal tissues only) for various types of living systems are necessary for the wide application of this time and temperature dependent model for blood perfusion and therefore, accurate modeling of the thermal response in heating tumor and the surrounding normal living tissue.

\subsection{Latent Heat and Its Absorption/Release Pattern}

A major component of biological materials is water, which undergoes phase change from liquid to either vapor when boiling occurs as a result of heating or ice when solidification/freezing occurs as a result of cooling. For an extremely slow cooling/heating process, phase change of pure liquid water to either the vapor or ice phase should occur at its equilibrium freezing $\left(\sim 0{ }^{\circ} \mathrm{C}\right)$ or boiling $\left(\sim 100{ }^{\circ} \mathrm{C}\right)$ point accompanying with a significant amount of release (for freezing) or absorption (for boiling) of latent heat, respectively. Due to the existence of impurities such as salts and cryoprotectants in tissue water, the latent heat release during freezing of biological materials, however, occurs over a temperature range called the mushy zone [321]. For thermal modeling, the upper boundary $\left(\theta_{\mathrm{ub}}\right)$ of the mushy zone are typically taken as the equilibrium freezing point $\left(\theta_{\text {efp }}\right)$ of a solution, which is a colligative quantity and can be estimated based on the osmolality of the solution as follows [322]:

$$
\theta_{e f p}=-1.8580 \mathrm{sm}
$$

where Osm represents osmolality and the subscript efp represents equilibrium freezing point. Osmolality is the ratio of the total amount (in mole) of particles (ions and nondissociated molecules) in a solution to the total amount (in $\mathrm{kg}$ ) of solvent (water) in the solution. For a dilute, aqueous solution at room temperature (when the density of water is $1 \mathrm{~kg} / \mathrm{L}$ ), the value of osmolality is similar to that of osmolarity that is the ratio of the total amount (in mole) of particles in a solution to the total volume (in liter or L) of the solution. For a typical physiological solution with an osmolality of 0.3 , the equilibrium freezing point is around $-0.56{ }^{\circ} \mathrm{C}$ according to the equation. The lower boundary $\left(\theta_{\mathrm{lb}}\right)$ of the mushy zone used for thermal modeling varies significantly from studies to studies (typically between -4 and $-10{ }^{\circ} \mathrm{C}$ and can 
be as low as $\left.-40{ }^{\circ} \mathrm{C}\right)$. Various latent heat release patterns $(\wedge)$ in the mushy zone have been used as summarized in [142]. A simple but quite frequently used linear release pattern of latent heat with regard to temperature is given as follows:

$$
\Lambda(\theta)=\left(\theta-\theta_{u b}\right) /\left(\theta_{l b}-\theta_{u b}\right), \theta_{l b} \leq \theta \leq \theta_{u b}
$$

It has been reported that the magnitude of latent heat (L) has a much more significant impact on thermal modeling than its release pattern [323]. Biological samples also contain lipids, proteins, and other organic and inorganic substances with essentially negligible latent heat release comparing with water during freezing. Moreover, some amount of water may bind with solutes and never become frozen (i.e., the so-called bound water) during cooling. Therefore, the latent heat of a biological sample should be less than that of pure water that is confirmed by recent studies on measuring the latent heat of some biological solutions using DSC [324,325]. In the absence of experimental data, however, the latent heat of a biological sample may be estimated as a first cut by using the total tissue water content and the latent heat of pure water as follows [142]:

$$
L=\phi L_{w}
$$

where $\varphi$ is total water content in a biological sample in weight and the latent heat of solidification for pure water $\left(\mathrm{L}_{\mathrm{w}}\right)$ is $335 \mathrm{~J} / \mathrm{g}$. Some studies approximates the latent heat of biological tissue as the product of the total water content $(\varphi)$ and the latent heat of a physiological solution $(1 \times \mathrm{PBS}, \sim$ $300 \mathrm{~J} / \mathrm{g}[324,325]$ ), which is much closer to tissue than pure water in terms of chemical composition. The total water content of a number of tissues can be found in the literature [146,326] and/or determined quantitatively by drying (i.e., dry weight vs. wet weight) or magnetic resonance spectrometry.

Very few studies have been reported on the absorption pattern of latent heat during boiling in heating biological materials, probably because boiling is typically avoided in many thermal therapy protocols. The rationale is that boiling off tissue water at a temperature higher than $100{ }^{\circ} \mathrm{C}$ leads to tissue carbonization, a type of wound or lesion that is sometimes very difficult to heal in the host. In the event that evaporation does occur, the amount of latent heat release may be calculated similarly to Equation 34 based on the weight fraction of water in the sample. The latent heat of evaporation for pure water is $2,250 \mathrm{~J} / \mathrm{g}$. Similarly, the pattern of latent heat absorption may be modeled as being linearly dependent on temperature over a small temperature range (e.g., 99-100 $\left.{ }^{\circ} \mathrm{C}\right)$ [316].

\subsection{Thermophysical Properties}

The knowledge of thermophysical properties (mainly thermal conductivity and specific heat) of biological tissues is crucial for accurate modeling of the thermal response in a bioheat transfer process. Many studies have been performed to measure the properties of various biological tissues, and the results from these studies have been reviewed and tabulated in the literature [146,285,326,327]. Nonetheless, data on thermophysical properties of tissue below $-30{ }^{\circ} \mathrm{C}$ or above $40{ }^{\circ} \mathrm{C}$ are still scant. Such data are undoubtedly in demand because these temperatures are typically encountered in thermal destruction and stabilization applications.
The main factors that affect tissue thermophysical properties are temperature and sample composition (mainly water content). Because thermophysical properties of water $(>0$ ${ }^{\circ} \mathrm{C}$ ) and ice $\left(<0{ }^{\circ} \mathrm{C}\right)$ over a wide temperature range (from liquid nitrogen to boiling water) are well-known and the total water content of many tissues are available $[38,228,321,326,328]$, the properties of biological samples may be estimated using those of water/ice based on their total water content. By lumping together the effects of all non-aqueous contents, the specific heat (c) of unfrozen biomaterials may be estimated as follows [142]:

$$
c_{u f}=[\phi+0.4(1-\phi)] c_{w}
$$

where the subscript uf represents unfrozen and the first and second terms in the brackets represent the effect on specific heat of aqueous and non-aqueous contents in tissue, respectively. A similar relationship between water content and thermal conductivity $\left(\mathrm{k}_{\mathrm{T}}\right)$ of unfrozen biomaterials is as follows [142]:

$$
k_{T, u f}=[\phi+0.28(1-\phi)] k_{T, w}
$$

where the first and second terms in the brackets represent the effect on thermal conductivity of the aqueous and nonaqueous contents in tissue, respectively. One can suggest a similar approach based on water content to estimate the thermophysical properties of frozen tissue. In this case, Equations 35 and 36 can be modified to predict the specific heat and thermal conductivity of frozen tissue as follows [142]:

$$
\begin{aligned}
& c_{f}=\phi c_{i c e}+0.4(1-\phi) c_{w} \\
& k_{T, f}=\phi k_{T, i c e}+0.28(1-\phi) k_{T, w}
\end{aligned}
$$

where the subscript $f$ represents frozen and the first and second terms in Equations 37 and 38 represent the effect of tissue water and non-aqueous contents on the thermophysical properties, respectively. Because the non-aqueous contents do not undergo phase change during freezing, their contributions to the specific heat and thermal conductivity represented by the second term of Equations 37 and 38 are calculated based on that of water rather than ice. In addition, one might use the thermal conductivity and specific heat of water at $0{ }^{\circ} \mathrm{C}$ to approximate that of sub-cooled water below $0{ }^{\circ} \mathrm{C}$ as the first cut considering that the latter are still not wellestablished. Finally, determining the thermophysical properties of subcooled and vitrified water or solutions below their freezing point is crucial for accurate thermal modeling of the bioheat transfer processes in thermal stabilization by vitrification (without ice formation).

\section{SUMMARY AND OUTLOOK}

Temperatures over a wide range (from cryogenic to hyperthermic regimens) have been utilized to either selectively destroy unwanted or stabilize important biologicals for the treatment of diseases. Thermal destruction can be realized by freezing biologicals to below $-20{ }^{\circ} \mathrm{C}$ using cryoprobes or heating them to more than $50{ }^{\circ} \mathrm{C}$ using $\mathrm{RF} / \mathrm{microwave}$, laser, and HIFU as the energy source in a minimally invasive manner. Cryopreservation of biologicals by slow-freezing is associated with injury due to ice formation and freeze concen- 
tration induced cell dehydration. Conventional vitrification is associated with cytotoxicity of high concentration of cryoprotectants. Research focus in cryopreservation is shifting to achieve vitrification using a low concentration of cryoprotectants (low-CPA vitrification), which combines the benefits of both slow-freezing and conventional vitrification while avoiding their shortcomings. Eventually, thermal stabilization at ambient temperature (dry or lyopreservation) is the solution to the increasing demand of wide and convenient distribution of biopreserved products for modern cell-based medicine. However, lyopreservation of eukaryotic mammalian cells at ambient temperature is still challenging today. Integrating modern micro and nanotechnology into the field of cell preservation might be the solution to the challenges. Studies have been performed to understand both hyperthermic and cryothermic injury at the molecular, cell, and tissue levels. The mechanism of injury to biologicals of hyperthermic temperatures is better understood than that of cryogenic temperatures. Interestingly, using therapeutic agents such as TNF- $\alpha$ and anticancer drugs to augment thermal injury and the targeted/controlled delivery of the agents to tumor site using nanotechnology are attracting more and more attention. Mechanistic models for hyperthermic injury have been developed with success whereas developing such models for cryothermic injury is more challenging and very much in need. Much more work is still in need for thermal modeling of bioheat transfer. For hyperthermic applications, it is particularly challenging to model the change of blood perfusion with regard to both temperature and time (or the extent of vascular stasis) for various types of tissues. For cryogenic applications, the heat transfer process is affected by additional thermophysical events such as ice formation and glass transition. Therefore, measurement of latent heat (as a result of ice formation and glass transition) and thermophysical properties of various biological materials at cryogenic (either frozen or vitrified) temperatures is of great importance for accurate thermal modeling of the bioheat transfer process. With the development of advanced models strengthened by further experimental investigations, the thermostability of biologicals over a wide temperature range (from that of liquid nitrogen to that of boiling water) can be engineered for either effective destruction of unwanted biomaterials (e.g., tumor) or banking of desired biologicals (e.g., stem cells) for the emerging cell-based medicine.

\section{ACKNOWLEDGEMENTS}

This work was partially supported by grants from the Wendy Will Case Cancer Fund, National Science Foundation (CBET-1033426), and National Institute of Biomedical Imaging and Bioengineering of the National Institutes of Health (R01EB012108). Special gratitude is due to Dr. John C. Bischof at the University of Minnesota and Dr. Mehmet Toner at Harvard University (Medical School) for their mentorship and guidance during the author's doctoral and postdoctoral training in their labs where much of the work reviewed in this article was done. The author would like to thank Dr. Alex Fowler at the University of Massachusetts, Dartmouth, for many useful discussions on thermal stabilization of biologicals. Many thanks are due to Dr. Dieter Haemmerich at the Medical University of South Carolina for a critical review of the manuscript.

\section{REFERENCES}

[1] G. d. Lu and J. Needham, Celestial Lancets: A History and Rationale of Acupuncture and Moxa, New York, NY: Routledge/Curzon, 1980.

[2] N. Sivin, "Science and Medicine in Imperial China-The State of the Field", J. Asian Stud., vol. 47, pp. 41-90, 1988.

[3] P. U. Unschuld, Huang Di nei jing su wen: Nature, Knowledge, Imagery in an Ancient Chinese Medical Text, Berkeley and Los Angeles: University of California Press, 2003.

[4] J. A. Waddle, "Radiofrequency ablation of liver and lung tumors", Radiologic Technology, Sept-Oct, 2006.

[5] E. Duffell, "Curative power of fever", Lancet, vol. 358, p. 1276, 2001.

[6] A. C. Aufderheide, The Scientific Study of Mummies, Cambridge, UK: Cambridge University Press, 2003.

[7] D. Biello, "Cold Comfort: Cool Receptors May Ease Chronic Pain", Sci. Am., August 22, 2006.

[8] F. Adams, "Aphorisms by Hippocrates (Section VII)", http://classics.mit.edu/Hippocrates/aphorisms.html, accessed: April 13, 2010.

[9] C. Phillips, "Radiofrequency Ablation Making Inroads as Cancer Treatment", NCI Cancer Bulletin, July 19, 2005.

[10] M. Bommadevara and L. Zhu, "Temperature difference between the body core and arterial blood supplied to the brain during hyperthermia or hypothermia in humans", Biomech. Model Mechanobiol., vol. 1, pp. 137-149, 2002.

[11] M. Cabanac, "Selective brain cooling in humans: "fancy" or fact?", FASEB J., vol. 7, pp. 1143-6; discussion 1146-1147, 1993.

[12] F. K. Storm, Hyperthermia in Cancer Therapy, Boston: GK Hall Medical Publisher, 1989.

[13] M. Gautherie, Biological Basis of Oncologic Thermotherapy, Berlin-Heidelberg: Springer-Verlag, 1990.

[14] E. J. Hall, "Hyperthermia", in Radiobiology for the Radiobiologist (4th Edition) Philadelphia, PA: Lippincott Company, 1994.

[15] B. R. Paliwal, F. W. Hetzel, and M. W. Dewhirst, Biol, Phys and Clini Aspe Hyperthermia, New York: American Institute of Physics, 1987.

[16] B. Field and J. W. Hand, Introduction to the Clinical Aspects of Clinical Hyperthermia, Philadelphia, PA: Taylor and Francis, 1990.

[17] M. M. Desai and I. S. Gill, "Current status of cryoablation and radiofrequency ablation in the management of renal tumors", Curr. Opin. Urol., vol. 12, pp. 387-93, 2002.

[18] M. Jahangiri, G. Weir, K. Mandal, I. Savelieva, and J. Camm, "Current strategies in the management of atrial fibrillation", Ann. Thorac. Surg., vol. 82, pp. 357-64, 2006.

[19] M. Marberger, "Energy-based ablative therapy of prostate cancer: high-intensity focused ultrasound and cryoablation", Curr. Opin. Urol., vol. 17, pp. 194-199, 2007.

[20] S. J. Savage and I. S. Gill, "Renal tumor ablation: energy-based technologies", World J. Urol., vol. 18, pp. 283-8, 2000.

[21] K. R. Diller and T. P. Ryan, "Heat transfer in living systems: Current opportunities", J. Heat Transfer., vol. 120, pp. 810-29, 1998.

[22] C. Schumann, C. Rieder, J. Bieberstein, A. Weihusen, S. Zidowitz, J. H. Moltz, and T. Preusser "State of the Art in Computer-Assisted Planning, Intervention, and Assessment of Liver-Tumor Ablation", Crit. Rev. Biomed. Eng., vol. 38, pp. 31-52, 2010.

[23] N. O. Bernardo and I. S. Gill, "Laparoscopic partial nephrectomy: current status", Arch. Esp. Urol., vol. 55, pp. 868-80, 2002.

[24] M. A. Hall-Craggs and J. S. Vaidya, "Minimally invasive therapy for the treatment of breast tumours", Eur. J. Radiol., vol. 42, pp. 52-7, 2002.

[25] M. Spaliviero, A. Moinzadeh, and I. S. Gill, "Laparoscopic cryotherapy for renal tumors", Technol. Cancer Res. Treat., vol. 3, pp. 177-80, 2004.

[26] A. A. Gage and J. G. Baust, "Cryosurgery for tumors", J. Am. Coll. Surg., vol. 205, pp. 342-356, 2007.

[27] D. Haemmerich and P. F. Laeseke, "Thermal tumour ablation: devices, clinical applications and future directions", Int. J. Hyperthermia, vol. 21, pp. 755-60, 2005.

[28] C. J. Diederich, "Thermal ablation and high-temperature thermal therapy: overview of technology and clinical implementation", Int. J. Hyperthermia, vol. 21, pp. 745-53, 2005.

[29] A. Shitzer, "Cryosurgery: Analysis and Experimentation of Cryoprobes in Phase Changing Media", J. Heat. Transfer, vol. 133, pp. 011005(011001-011012), 2011. 
[30] J. C. Rewcastle, G. A. Sandison, J. C. Saliken, B. J. Donnelly, and J. G. McKinnon, "Considerations during clinical operation of two commercially available cryomachines", J. Surg. Oncol., vol. 71, pp. 106-11, 1999.

[31] F. Reif, "Chapter 5 - Simple applications of macroscopic thermodynamics", in Fundamentals of Statistical and Thermal Physics New York: McGraw-Hill, 1965.

[32] R. J. Stafford, D. Fuentes, A. A. Elliott, J. S. Weinberg, and K. Ahrar, "Laser-Induced Thermal Therapy for Tumor Ablation ", Crit. Rev. Biomed. Eng., vol. 38, pp. 79-100, 2010.

[33] C. R. Simpson, M. Kohl, M. Essenpreis, and M. Cope, "Nearinfrared optical properties of ex vivo human skin and subcutaneous tissues measured using the Monte Carlo inversion technique", Phys. Med. Biol., vol. 43, pp. 2465-2478, 1998.

[34] S. R. Sershen, S. L. Westcott, N. J. Halas, and J. L. West, "Temperature-sensitive polymer-nanoshell composites for photothermally modulated drug delivery", J. Biomed. Mater Res., vol. 51, pp. 293-298, 2000.

[35] G. Ter Haar and C. Coussios, "High intensity focused ultrasound: Physical principles and devices", Int. J. Hyperther., vol. 23, pp. 89104, 2007.

[36] C. H. Farny, R. G. Holt, and R. A. Roy, "The Correlation Between Bubble-Enhanced HIFU Heating and Cavitation Power", IEEE Trans. Biomed. Eng., vol. 57, pp. 175-184, 2010.

[37] C. C. Coussios, C. H. Farny, G. Ter Haar, and R. A. Roy, "Role of acoustic cavitation in the delivery and monitoring of cancer treatment by high-intensity focused ultrasound (HIFU)", Int. J. Hyperther., vol. 23, pp. 105-20, 2007.

[38] X. He, S. Mcgee, J. E. Coad, F. Schmidlin, P. A. Iaizzo, D. J. Swanlund, S. Kluge, E. Rudie, and J. C. Bischof "Investigation of the thermal and tissue injury behaviour in microwave thermal therapy using a porcine kidney model", Int. J. Hyperther., vol. 20, pp. 567-93, 2004.

[39] L. Zhu, L. X. Xu, and N. Chencinski, "Quantification of the 3-D electromagnetic power absorption rate in tissue during transurethral prostatic microwave thermotherapy using heat transfer model", IEEE Trans. Biomed. Eng., vol. 45, pp. 1163-1172, 1998.

[40] C. Polk and E. Postow, Handbook of Biological Effects of Electromagnetic Fields (2rd edition), Boca Raton, FL: CRC Press LLC, 1995.

[41] D. Haemmerich, "Biophysics of Radiofrequency Ablation", Crit. Rev. Biomed. Eng., vol. 38, pp. 53-63, 2010.

[42] C. L. Brace, "Microwave Tissue Ablation: Biophysics, Technology, and Applications", Crit. Rev. Biomed. Eng., vol. 38, pp. 65-78, 2010.

[43] E. S. Day, J. G. Morton, and J. L. West, "Nanoparticles for thermal cancer therapy", J. Biomech. Eng., vol. 131, p. 074001, 2009.

[44] X. Huang, I. H. El-Sayed, and M. A. El-Sayed, "Applications of gold nanorods for cancer imaging and photothermal therapy", Methods Mol. Biol., vol. 624, pp. 343-57, 2010.

[45] F. O. Belzer and J. H. Southard, "Organ preservation and transplantation", Prog. Clin. Biol. Res., vol. 224, pp. 291-303,

[46] M.8IA. Maathuis, H. G. Leuvenink, and R. J. Ploeg, "Perspectives in organ preservation", Transplantation, vol. 83, pp. 1289-98, 2007.

[47] B. J. Fuller and C. Y. Lee, "Hypothermic perfusion preservation: the future of organ preservation revisited?", Cryobiology, vol. 54, pp. 129-45, 2007.

[48] G. M. Fahy, D. R. MacFarlane, C. A. Angell, and H. T. Meryman, "Vitrification as an approach to cryopreservation", Cryobiology, vol. 21, pp. 407-26, 1984.

[49] J. O. M. Karlsson and M. Toner, "Long-term storage of tissues by cryopreservation: Critical issues", Biomaterials, vol. 17, pp. 24356, 1996.

[50] P. Mazur, "Freezing of living cells: mechanisms and implications", Am. J. Physiol., vol. 247, pp. C125-42, 1984.

[51] W. F. Rall and G. M. Fahy, "Ice-Free Cryopreservation of Mouse Embryos at -196-Degrees-C by Vitrification", Nature, vol. 313, pp. 573-5, 1985 .

[52] R. Coger and M. Toner, "Preservation Techniques for Biomaterials", in The Biomedical Engineering Handbook: 2nd Edition, J. D. Bronzino, Ed. Boca Raton: CRC Press LLC, 2000.

[53] X. He, "Preservation of Embryonic Stem Cells", in Embryonic Stem Cells Vienna, Austria: Intech, 2010.

[54] G. M. Fahy, B. Wowk, J. Wu, J. Phan, C. Rasch, A. Chang, and E. Zendejas, "Cryopreservation of organs by vitrification: perspectives and recent advances", Cryobiology, vol. 48, pp. 157-78, 2004.
[55] G. M. Fahy, B. Wowk, J. Wu, and S. Paynter, "Improved vitrification solutions based on the predictability of vitrification solution toxicity", Cryobiology, vol. 48, pp. 22-35, 2004.

[56] A. Fowler, and M. Toner, "Cryo-injury and biopreservation", Ann NY Acad Sci., vol. 1066, pp. 119-35, 2005.

[57] B. C. Heng, L. L. Kuleshova, S. M. Bested, H. Liu, and T. Cao, "The cryopreservation of human embryonic stem cells", Biotechnol. Appl. Biochem., vol. 41, pp. 97-104, 2005.

[58] C. J. Hunt, D. E. Pegg, and S. E. Armitage, "Optimising cryopreservation protocols for haematopoietic progenitor cells: A methodological approach for umbilical cord blood", Cryoletters, vol. 27, pp. 73-83, 2006.

[59] S. U. Chen, Y. R. Lien, Y. Y. Cheng, H. F. Chen, H. N. Ho, and Y. S. Yang, "Vitrification of mouse oocytes using closed pulled straws (CPS) achieves a high survival and preserves good patterns of meiotic spindles, compared with conventional straws, open pulled straws (OPS) and grids", Hum. Reprod., vol. 16, pp. 2350-6, 2001.

[60] S. U. Chen, Y. R. Lien, H. F. Chen, K. H. Chao, H. N. Ho, and Y. S. Yang, "Open pulled straws for vitrification of mature mouse oocytes preserve patterns of meiotic spindles and chromosomes better than conventional straws", Hum. Reprod., vol. 15, pp. 2598-603, 2000.

[61] B. J. Fuller, "Cryoprotectants: The essential antifreezes to protect life in the frozen state", Cryoletters, vol. 25, pp. 375-88, 2004.

[62] G. M. Beattie, J. H. Crowe, A. D. Lopez, V. Cirulli, C. Ricordi, and A. Hayek, "Trehalose: A cryoprotectant that enhances recovery and preserves function of human pancreatic islets after long-term storage", Diabetes, vol. 46, pp. 519-23, 1997.

[63] B. Wowk, E. Leitl, C. M. Rasch, N. Mesbah-Karimi, S. B. Harris, and G. M. Fahy, "Vitrification enhancement by synthetic ice blocking agents", Cryobiology, vol. 40, pp. 228-36, 2000.

[64] X. He, E. Y. Park, A. Fowler, M. L. Yarmush, and M. Toner, "Vitrification by ultra-fast cooling at a low concentration of cryoprotectants in a quartz micro-capillary: a study using murine embryonic stem cells", Cryobiology, vol. 56, pp. 223-32, 2008.

[65] P. Boutron, "Comparison with the theory of the kinetics and extent of ice crystallization and of the glass-forming tendency in aqueous cryoprotective solutions", Cryobiology, vol. 23, pp. 88-102, 1986.

[66] V. Berejnov, N. S. Husseini, O. A. Alsaied, and R. E. Thorne "Effects of cryoprotectant concentration and cooling rate on vitrification of aqueous solutions", J. Appl. Crystallogr., vol. 39, pp. 244$51,2006$.

[67] J. O. M. Karlsson, E. G. Cravalho, and M. Toner, "A Model of Diffusion-Limited Ice Growth inside Biological Cells during Freezing", J. Appl. Phys., vol. 75, pp. 4442-5, 1994.

[68] M. Toner, E. G. Cravalho, and M. Karel, "Thermodynamics and Kinetics of Intracellular Ice Formation during Freezing of Biological Cells", J. Appl. Phys., vol. 67, pp. 1582-93, 1990.

[69] G. Yang, A. Zhang, L. X. Xu, and X. He, "Modeling the cell-type dependence of diffusion-limited intracellular ice nucleation and growth during both vitrification and slow freezing", J. Appl. Phys., vol. 105, pp. 114701-11, 2009.

[70] P. Bruggeller, and E. Mayer, "Complete Vitrification in Pure Liquid Water and Dilute Aqueous-Solutions", Nature, vol. 288, pp. 569-71, 1980.

[71] S. N. Bhat, A. Sharma, and S. V. Bhat, "Vitrification and glass transition of water: Insights from spin probe ESR", Phys. Rev. Lett., vol. 95, pp. 2357021-2357024, 2005.

[72] S. Yavin, and A. Arav, "Measurement of essential physical properties of vitrification solutions", Theriogenology, vol. 67, pp. 81-9, 2007.

[73] D. K. Gardner, C. B. Sheehan, L. Rienzi, M. Katz-Jaffe, and M. G. Larman, "Analysis of oocyte physiology to improve cryopreservation procedures", Theriogenology, vol. 67, pp. 64-72, 2007.

[74] G. Vajta, and Z. P. Nagy, "Are programmable freezers still needed in the embryo laboratory? Review on vitrification", Reprod. Biomed. Online., vol. 12, pp. 779-96, 2006.

[75] X. Han, H. Ma, A. Jiao, and J. K. Critser, "Investigations on the heat transport capability of a cryogenic oscillating heat pipe and its application in achieving ultra-fast cooling rates for cell vitrification cryopreservation", Cryobiology, vol. 56, pp. 195-203, 2008.

[76] A. Jiao, X. Han, J. K. Critser, and H. Ma, "Numerical investigations of transient heat transfer characteristics and vitrification tendencies in ultra-fast cell cooling processes", Cryobiology, vol. 52, pp. 386-92, 2006. 
[77] H. J. Lee, H. Elmoazzen, D. Wright, J. Biggers, B. R. Rueda, Y. S. Heo, M. Toner, and T. L. Toth, "Ultra-rapid vitrification of mouse oocytes in low cryoprotectant concentrations", Reprod. Biomed. Online, vol. 20, pp. 201-8, 2010.

[78] W. Zhang, G. Yang, A. Zhang, L. X. Xu, and X. He, "Preferential vitrification of water in small alginate microcapsules significantly augments cell cryopreservation by vitrification", Biomed. Microdevices., vol. 12, pp. 89-96, 2010.

[79] J. H. Crowe, F. A. Hoekstra, and L. M. Crowe, "Anhydrobiosis", Ann. Rev. Phys., vol. 54, pp. 579-99, 1992.

[80] J. Browne, A. Tunnacliffe, and A. Burnell, "Anhydrobiosis: plant desiccation gene found in a nematode", Nature, vol. 416, p. 38, 2002.

[81] R. N. Perry, "Desiccation survival of parasitic nematodes", Parasitology, vol. 119 Suppl, pp. S19-30, 1999

[82] J. S. Clegg, "Cryptobiosis--a peculiar state of biological organization", Comp. Biochem. Physiol. B. Biochem. Mol. Biol., vol. 128, pp. 613-24, 2001

[83] J. H. Crowe, L. M. Crowe, and F. Tablin, "Stabilization of dry mammalian cells: Lessons from nature", Integr. Comp. Biol., vol. 44, pp. 542-2, 2004.

[84] J. H. Crowe and L. M. Crowe, "Preservation of mammalian cellslearning nature's tricks", Nat. Biotechnol., vol. 18, pp. 145-146, 2000 .

[85] J. H. Crowe and A. F. Cooper, "Cryptobiosis", Sci. Am., vol. 225, pp. 30-6, 1971.

[86] W. P. Armstrong, "The Power Of Plants-July, 1996", www.waynesword.net, accessed: April 21, 2010.

[87] J. H. Crowe, L. M. Crowe, A. E. Oliver, N. Tsvetkova, W. Wolkers, and F. Tablin, "The trehalose myth revisited: introduction to a symposium on stabilization of cells in the dry state", Cryobiology, vol. 43, pp. 89-105, 2001.

[88] J. H. Crowe, L. M. Crowe, W. F. Wolkers, A. E. Oliver, X. C. Ma, J. H. Auh, M. K. Tang, S. J. Zhu, J. Norris, and F. Tablin, "Stabilization of dry mammalian cells: Lessons from nature", Integr. Comp. Biol., vol. 45, pp. 810-820, 2005.

[89] J. H. Crowe and L. M. Crowe, "Preservation of mammalian cellslearning nature's tricks", Nat. Biotechnol., vol. 18, pp. 145-146, 2000.

[90] W. F. Wolkers, F. Tablin, and J. H. Crowe, "From anhydrobiosis to freeze-drying of eukaryotic cells", Comp. Biochem. Physiol. A. Mol. Integr. Physiol., vol. 131, pp. 535-43, 2002.

[91] A. Eroglu, M. J. Russo, R. Bieganski, A. Fowler, S. Cheley, H. Bayley, and M. Toner, "Intracellular trehalose improves the survival of cryopreserved mammalian cells", Nat. Biotechnol., vol. 18, pp. 163-67, 2000.

[92] L. Rey and J. C. May, Freeze-drying/lyophilization of pharmaceutical and biological products, Marcel Dekker, Inc., New York, 1999.

[93] F. Felix, Freeze-drying of pharmaceuticals and biopharmaceuticals, Cambridge, UK: RSC Publishing, 2007.

[94] A. M. Abdul-Fattah, D. S. Kalonia, and M. J. Pikal, "The challenge of drying method selection for protein pharmaceuticals: product quality implications", J. Pharm. Sci., vol. 96, pp. 1886-916, 2007.

[95] S. L. Nail, S. Jiang, S. Chongprasert, and S. A. Knopp, "Fundamentals of freeze-drying", Pharm. Biotechnol., vol. 14, pp. 281-360, 2002.

[96] R. J. Bellows and C. J. King, "Freeze-drying of aqueous solutions: Maximum allowable operating temperature", Cryobiology, vol. 9, pp. 559-561, 1972.

[97] M. J. Pikal and S. Shah, "The collapse temperature in freeze drying: Dependence on measurement methodology and rate of water removal from the glassy phase", Int. J. Pharm., vol. 62, pp. 165-86, 1990.

[98] H. Gieseler, H. Lee, B. Mulherkar, and M. J. Pikal, "Applicability of Manomentric Temperature Measurement (MTM) and SMART Freeze-Dryer Technology to Development of an Optimized FreezeDrying Cycle: Prelim-inary Investigation of Two Amorphous Systems", Proc. 1st European Congress on Life Science Process TechnologyNuremberg, Germany, 2005.

[99] E. Meister, E. Marek, and H. Gieseler, "Collapse Temperature Measurement by Freeze-Dry Microscopy and Transferability to Freeze Drying Processes: Influence of Solute Concentration on Collapse Behavior and Effect on Cycle Design", Proc. AAPS Annual Meeting and ExpositionSan Antonio (TX), USA, 2006.
[100] M. J. Pikal, "Use of laboratory data in freeze drying process design: heat and mass transfer coefficients and the computer simulation of freeze drying", J. Parenter. Sci. Technol., vol. 39, pp. 115-38, 1985.

[101] A. P. MacKenzie, "Basic principles of freeze-drying for pharmaceutics", Bull. Parenteral. Drug Assoc., vol. 20, pp. 101-29, 1966.

[102] M. J. Pikal, S. Shah, D. Senior, and J. E. Lang, "Physical chemistry of freeze-drying: measurement of sublimation rates for frozen aqueous solutions by a microbalance technique", J. Pharm. Sci., vol. 72, pp. 635-50, 1983.

[103] E. Meister and H. Gieseler, "Evaluation of Collapse Temperatures by Freeze-Dry Microscopy: Impact of Excipient Concentration on Measured Transition and the Overall Dependance on Measurement Methodology", Proc. 5th World Meeting on Pharmaceutics and Pharmaceutical TechnologyGeneva Switzerland, 2006.

[104] T. Kramer, D. M. Kremer, M. J. Pikal, W. J. Petre, E. Y. Shalaev, and L. A. Gatlin, "A procedure to optimize scale-up for the primary drying phase of lyophilization", J. Pharm. Sci., vol. 98, pp. 307-18, 2009.

[105] F. Fonseca, S. Passot, P. Lieben, and M. Marin, "Collapse temperature of bacterial suspensions: the effect of cell type and concentration", Cryo. Lett., vol. 25, pp. 425-434, 2004.

[106] F. Fonseca, S. Passot, O. Cunin, and M. Marin, "Collapse temperature of freeze-dried Lactobacillus bulgaricus suspensions and protective media", Biotechnol. Prog., vol. 20, pp. 229-38, 2004.

[107] X. M. He, A. Fowler, and M. Toner, "Water activity and mobility in solutions of glycerol and small molecular weight sugars: Implication for cryo- and lyopreservation", J. Appl. Phys., vol. 100, p. 074702 (074711pp), 2006.

[108] X. He, A. Fowler, M. Menze, S. Hand, and M. Toner, "Desiccation kinetics and biothermodynamics of glass forming trehalose solutions in thin films", Ann. Biomed. Eng., vol. 36, pp. 1428-39, 2008.

[109] B. C. Hancock, S. L. Shamblin, and G. Zografi, "Molecular mobility of amorphous pharmaceutical solids below their glass transition temperatures", Pharm. Res., vol. 12, pp. 799-806, 1995.

[110] G. Yang, K. Gilstrap, A. Zhang, L. X. Xu, and X. He, "Collapse temperature of solutions important for lyopreservation of living cells at ambient temperature", Biotechnol. Bioeng., vol. 106, pp. 247-59, 2010.

[111] J. P. Acker, T. Chen, A. Fowler, and M. Toner, "Engineering desiccation tolerance in mammalian cells: tools and techniques", in Life in the frozen state, B. J. Fuller, L. Lane, E. E. Benson, Eds. Boca Raton, FL: CRC Press LLC, pp. 563-81, 2004.

[112] T. Chen, J. P. Acker, A. Eroglu, S. Cheley, H. Bayley, A. Fowler, and M. Toner, "Beneficial effect of intracellular trehalose on the membrane integrity of dried mammalian cells", Cryobiology, vol. 43, pp. 168-81, 2001.

[113] A. Eroglu, M. Toner, and T. L. Toth, "Beneficial effect of microinjected trehalose on the cryosurvival of human oocytes", Fertil. Steril., vol. 77, pp. 152-8, 2002.

[114] P. Bhowmick, A. Eroglu, D. L. Wright, M. Toner, and T. L. Toth, "Osmometric behavior of mouse oocytes in the presence of different intracellular sugars", Cryobiology, vol. 45, pp. 183-7, 2002.

[115] A. Eroglu, J. A. Lawitts, M. Toner, and T. L. Toth, "Quantitative microinjection of trehalose into mouse oocytes and zygotes, and its effect on development", Cryobiology, vol. 46, pp. 121-34, 2003.

[116] A. Eroglu, G. Elliott, D. L. Wright, M. Toner, and T. L. Toth, "Progressive elimination of microinjected trehalose during mouse embryonic development", Reprod. Biomed. Online., vol. 10, pp. 503-10, 2005.

[117] S. L. Gordon, S. R. Oppenheimer, A. M. Mackay, J. Brunnabend, I. Puhlev, and F. Levine, "Recovery of human mesenchymal stem cells following dehydration and rehydration", Cryobiology, vol. 43 , pp. 182-7, 2001

[118] N. Guo, I. Puhlev, D. R. Brown, J. Mansbridge, and F. Levine, "Trehalose expression confers desiccation tolerance on human cells", Nat. Biotechnol., vol. 18, pp. 168-71, 2000.

[119] I. Puhlev, N. Guo, D. R. Brown, and F. Levine, "Desiccation tolerance in human cells", Cryobiology, vol. 42, pp. 207-17, 2001.

[120] J. P. Acker, X. M. Lu, V. Young, S. Cheley, H. Bayley, A. Fowler, and $\mathrm{M}$. Toner, "Measurement of trehalose loading of mammalian cells porated with a metal-actuated switchable pore", Biotechnol. Bioeng., vol. 82, pp. 525-32, 2003.

[121] G. D. Elliott, X. H. Liu, J. L. Cusick, M. Menze, J. Vincent, T. Witt, S. Hand, and M. Toner, "Trehalose uptake through P2X7 
purinergic channels provides dehydration protection", Cryobiology, vol. 52, pp. 114-27, 2006.

[122] X. H. Liu, A. Aksan, M. A. Menze, S. C. Hand, and M. Toner, "Trehalose loading through the mitochondrial permeability transition pore enhances desiccation tolerance in rat liver mitochondria", Biochim. Biophys. Acta, vol. 1717, pp. 21-6, 2005.

[123] R. Shirakashi, C. M. Kostner, K. J. Muller, M. Kurschner, U. Zimmermann, and V. L. Sukhorukov, "Intracellular delivery of trehalose into mammalian cells by electropermeabilization", J. Membr. Biol., vol. 189, pp. 45-54, 2002.

[124] R. Reuss, J. Ludwig, R. Shirakashi, F. Ehrhart, H. Zimmermann, S. Schneider, M. M. Weber, U. Zimmermann, H. Schneider, and V. L. Sukhorukov, "Intracellular delivery of carbohydrates into mammalian cells through swelling-activated pathways", J. Membr. Biol., vol. 200, pp. 67-81, 2004.

[125] A. E. Oliver, K. Jamil, J.H. Crowe, F. Tablin, "Loading MSCs with trehalose by endocytosis", Cell Preserv. Technol., vol. 2, pp. 35-49, 2004.

[126] W. F. Wolkers, S. A. Looper, R. A. Fontanilla, N. M. Tsvetkova, F. Tablin, and J. H. Crowe, "Temperature dependence of fluid phase endocytosis coincides with membrane properties of pig platelets", Biochim. Biophys. Acta, vol. 1612, pp. 154-63, 2003.

[127] X. M. He, A. A. Amin, A. Fowler, and M. Toner, "Thermally induced introduction of trehalose into primary rat hepatocytes", Cell Preserv. Technol., vol. 4, pp. 178-187, 2006.

[128] G. M. Beattie, J. H. Crowe, A. D. Lopez, V. Cirulli, C. Ricordi, and A. Hayek, "Trehalose: a cryoprotectant that enhances recovery and preserves function of human pancreatic islets after long-term storage", Diabetes, vol. 46, pp. 519-23, 1997.

[129] J. H. Crowe, "Trehalose as a "chemical chaperone": fact and fantasy", Adv. Exp. Med. Biol., vol. 594, pp. 143-58, 2007.

[130] T. Kanias and J. P. Acker, "Mammalian cell desiccation: facing the challenges", Cell Preserv. Technol., vol. 4, pp. 253-76, 2006.

[131] W. Zhang, J. Rong, Q. Wang, and X. He, "The encapsulation and intracellular delivery of trehalose using a thermally responsive nanocapsule", Nanotechnol, vol. 20, p. 275101 (275114 pp), 2009.

[132] J. L. Holovati, M. I. Gyongyossy-Issa, and J. P. Acker, "Effects of trehalose-loaded liposomes on red blood cell response to freezing and post-thaw membrane quality", Cryobiology, vol. 58, pp. 75-83, 2009.

[133] J. L. Holovati and J. P. Acker, "Spectrophotometric measurement of intraliposomal trehalose", Cryobiology, vol. 55, pp. 98-107, 2007.

[134] K. L. Scott, Gyongyossy-Issa, M. I.C., Acker, J.P., "Response of hemotopoietic progenitor cells to trehalose-loaded liposomes (Abstract)", Cryibiology, vol. 53, p. 380, 2006.

[135] W. Zhang, K. Gilstrap, N. Wu, K. C. Remant, M. A. Moss, Q. Wang, X. Lu, and X. He, "Synthesis and characterization of thermally responsive pluronic F127-Chitosan nanocapsules for controlled release and intracellular delivery of small molecules", ACS Nano., vol. 4, pp. 6747-59, 2010.

[136] A. G. de Castro, J. Lapinski, and A. Tunnacliffe, "Anhydrobiotic engineering", Nat. Biotechnol., vol. 18, p. 473, 2000.

[137] G. Iturriaga, "The LEA proteins and trehalose loving couple: a step forward in anhydrobiotic engineering", Biochem. J., vol. 410, pp. e1-2, 2008.

[138] S. C. Hand, D. Jones, M. A. Menze, and T. L. Witt, "Life without water: Expression of plant LEA genes by an anhydrobiotic arthropod", J. Exp. Zool. A. Ecol. Genet. Physiol., vol. 307A, pp. 62-6, 2007.

[139] Z. Huang and A. Tunnacliffe, "Desiccation response of mammalian cells: anhydrosignaling", Methods Enzymol., vol. 428, pp. 269-77, 2007.

[140] A. Tunnacliffe, A. Garcia de Castro, and M. Manzanera, "Anhydrobiotic engineering of bacterial and mammalian cells: is intracellular trehalose sufficient?", Cryobiology, vol. 43, pp. 124-32, 2001.

[141] D. Li and X. He, "Desiccation induced structural alterations in a 66-amino acid fragment of an anhydrobiotic nematode late embryogenesis abundant (LEA) protein", Biomacromolecules, vol. 10, pp. 1469-77, 2009.

[142] X. He and J. C. Bischof, "Quantification of temperature and injury response in thermal therapy and cryosurgery", Crit. Rev. Biomed. Eng., vol. 31, pp. 355-422, 2003.

[143] J. C. Bischof and X. He, "Thermal stability of proteins", Ann. N. Y. Acad. Sci., vol. 1066, pp. 12-33, 2005.
[144] J. C. Bischof, "Micro and nanoscale phenomenon in bioheat transfer", Heat Mass Transf., vol. 42, pp. 955-66, 2006.

[145] N. T. Wright, "On a relationship between the Arrhenius parameters from thermal damage studies", J. Biomech. Eng., vol. 125, pp. 3004, 2003.

[146] K. R. Diller, J. W. Valvano, and J. A. Pearce, "Bioheat transfer", in CRC Thermal Engineering Handbook F. Kreith, Ed. Boca Raton, FL: CRC Press, 2000.

[147] N. E. Hoffmann and J. C. Bischof, "The cryobiology of cryosurgical injury", Urology, vol. 60, pp. 40-9, 2002.

[148] J. Pearce and S. Thomsen, "Rate process analysis of thermal damage", in Optical Thermal Response of Laser-Irradiated Tissue, A. J. Welch, and M. J. C. van Germert, eds. New York: Plenum Press, 1995.

[149] M. W. Dewhirst, B. L. Viglianti, M. Lora-Michiels, M. Hanson, and P. J. Hoopes, "Basic principles of thermal dosimetry and thermal thresholds for tissue damage from hyperthermia", Int. J. Hyperther., vol. 19, pp. 267-94, 2003.

[150] W. C. Dewey, "Failla memorial lecture. The search for critical cellular targets damaged by heat", Radiat. Res., vol. 120, pp. 191 204, 1989.

[151] B. Alberts, D. Bray, A. Johnson, J. Lewis, M. Raff, K. Roberts, and P. Walter, Essential Cell Biology: An introduction to the molecular biology of the cell, New York: Garland Publishing, Inc., 1998.

[152] J. R. Lepock, "Involvement of membranes in cellular responses to hyperthermia", Radiat Res, vol. 92, pp. 433-8, 1982.

[153] J. R. Lepock, "Cellular effects of hyperthermia: relevance to the minimum dose for thermal damage", Int. J. Hyperther., vol. 19, pp. 252-266, 2003.

[154] B. T. Wimberly, D. E. Brodersen, W. M. Clemons, Jr., R. J Morgan-Warren, A. P. Carter, C. Vonrhein, T. Hartsch, and V. Ramakrishnan, "Structure of the 30S ribosomal subunit", Nature, vol. 407, pp. 327-39, 2000.

[155] K. P. Ritchie, B. M. Keller, K. M. Syed, and J. R. Lepock, "Hyperthermia (heat shock)-induced protein denaturation in liver, muscle and lens tissue as determined by differential scanning calorimetry", Int. J. Hyperther., vol. 10, pp. 605-18, 1994.

[156] J. R. Lepock, H. E. Frey, and K. P. Ritchie, "Protein denaturation in intact hepatocytes and isolated cellular organelles during heat shock", J. Cell Biol., vol. 122, pp. 1267-76, 1993.

[157] M. L. Freeman, M. J. Borrelli, K. Syed, G. Senisterra, D. M. Stafford, and J. R. Lepock, "Characterization of a signal generated by oxidation of protein thiols that activates the heat shock transcription factor", J. Cell Physiol., vol. 164, pp. 356-66, 1995.

[158] X. He, W. F. Wolkers, J. H. Crowe, D. J. Swanlund, and J. C. Bischof, "In situ thermal denaturation of proteins in dunning AT-1 prostate cancer cells: implication for hyperthermic cell injury", Ann. Biomed. Eng., vol. 32, pp. 1384-98, 2004.

[159] J. R. Lepock, H. E. Frey, H. Bayne, and J. Markus, "Relationship of hyperthermia-induced hemolysis of human erythrocytes to the thermal denaturation of membrane proteins", Biochim. Biophys. Acta, vol. 980, pp. 191-201, 1989.

[160] A. E. Cress and E. W. Gerner, "Cholesterol levels inversely reflect the thermal sensitivity of mammalian cells in culture", Nature, vol. 283, pp. 677-9, 1980.

[161] D. Palecz, E. Grzelinska, G. Bartosz, W. Leyko, and J. V. Moller, "Ligand and lipid domain stabilization of a membraneous $\mathrm{Ca} 2+$ ATPase during hyperthermia", Biochim. Biophys. Acta, vol. 937, pp. 23-30, 1988.

[162] L. J. Anghileri and J. Robert, "Effects of hyperthermia and lanthanum on tumor cell leakage", Int. J. Clin. Pharmacol. Ther. Toxicol., vol. 25, pp. 374-8, 1987.

[163] P. J. Quinn, "Principles of membrane stability and phase behavior under extreme conditions", J. Bioenerg. Biomembr., vol. 21, pp. 319, 1989.

[164] M. B. Yatvin, J. W. Vorpahl, M. N. Gould, and M. Lyte, "The effects of membrane modification and hyperthermia on the survival of P-388 and V-79 cells", Eur. J. Cancer Clin. Oncol., vol. 19, pp. $1247-53,1983$

[165] M. B. Yatvin and W. A. Cramp, "Role of cellular membranes in hyperthermia: some observations and theories reviewed", Int. J. Hyperther., vol. 9, pp. 165-85, 1993.

[166] W. Rao, Z.-S. Deng, and J. Liu, "A Review of Hyperthermia Combined With Radiotherapy/Chemotherapy on Malignant Tumors", Crit. Rev. Biomed. Eng., vol. 38, pp. 101-16, 2010. 
[167] R. K. Visaria, R. J. Griffin, B. W. Williams, E. S. Ebbini, G. F. Paciotti, C. W. Song, and J. C. Bischof, "Enhancement of tumor thermal therapy using gold nanoparticle-assisted tumor necrosis factor-alpha delivery", Mol. Cancer Ther., vol. 5, pp. 1014-20, 2006.

[168] S. Unezaki, K. Maruyama, N. Takahashi, M. Koyama, T. Yuda, A. Suginaka, and M. Iwatsuru, "Enhanced delivery and antitumor activity of doxorubicin using long-circulating thermosensitive liposomes containing amphipathic polyethylene glycol in combination with local hyperthermia", Pharm. Res., vol. 11, pp. 1180-5, 1994.

[169] H. D. Han, M. S. Choi, T. Hwang, C. K. Song, H. Seong, T. W. Kim, H. S. Choi, and B. C. Shin, "Hyperthermia-induced antitumor activity of thermosensitive polymer modified temperature-sensitive liposomes", J. Pharm. Sci., vol. 95, pp. 1909-17, 2006.

[170] G. Kong and M. W. Dewhirst, "Hyperthermia and liposomes", Int. J. Hyperther., vol. 15, pp. 345-70, 1999.

[171] R. Visaria, J. C. Bischof, M. Loren, B. Williams, E. Ebbini, G. Paciotti, and R. Griffin, "Nanotherapeutics for enhancing thermal therapy of cancer", Int. J. Hyperther., vol. 23, pp. 501-11, 2007.

[172] A. M. Ponce, Z. Vujaskovic, F. Yuan, D. Needham, and M. W. Dewhirst, "Hyperthermia mediated liposomal drug delivery", Int. J. Hyperther., vol. 22, pp. 205-13, 2006.

[173] M. W. Dewhirst, "Hyperthermia and nanotechnology - a note from the Editor-in-chief", Int. J. Hyperther., vol. 24, pp. 449-50, 2008.

[174] C. L. Dennis, A. J. Jackson, J. A. Borchers, P. J. Hoopes, R. Strawbridge, A. R. Foreman, J. van Lierop, C. Gruttner, and R. Ivkov, "Nearly complete regression of tumors via collective behavior of magnetic nanoparticles in hyperthermia", Nanotechnol, vol. 20, p. 395103, 2009.

[175] A. Burke, X. Ding, R. Singh, R. A. Kraft, N. Levi-Polyachenko, M. N. Rylander, C. Szot, C. Buchanan, J. Whitney, J. Fisher, H. C. Hatcher, R. D'Agostino, Jr., N. D. Kock, P. M. Ajayan, D. L. Carroll, S. Akman, F. M. Torti, and S. V. Torti, "Long-term survival following a single treatment of kidney tumors with multiwalled carbon nanotubes and near-infrared radiation", Proc. Natl. Acad. Sci. USA, vol. 106, pp. 12897-902, 2009.

[176] H. Park, J. Yang, J. Lee, S. Haam, I. H. Choi, and K. H. Yoo, "Multifunctional nanoparticles for combined doxorubicin and photothermal treatments", ACS Nano., vol. 3, pp. 2919-26, 2009.

[177] M. Urano, "Tumor response to hyperthermia", Hyperther. in Oncol., vol. 1, pp. 161-200, 1988.

[178] K. R. Diller, "Stress protein expression kinetics", Annu. Rev. Biomed. Eng., vol. 8, pp. 403-424, 2006.

[179] M. N. Rylander, Y. Feng, J. Bass, and K. R. Diller, "Thermally induced injury and heat-shock protein expression in cells and tissues", Ann. N. Y. Acad. Sci., vol. 1066, pp. 222-42, 2005.

[180] M. N. Rylander, K. R. Diller, S. Wang, and S. J. Aggarwal, "Correlation of HSP70 expression and cell viability following thermal stimulation of bovine aortic endothelial cells", J. Biomech. Eng., vol. 127, pp. 751-757, 2005.

[181] M. N. Rylander, Y. Feng, J. Bass, and K. R. Diller, "Heat shock protein expression and injury optimization for laser therapy design", Lasers Surg. Med., vol. 39, pp. 731-46, 2007.

[182] A. S. Song and K. R. Diller, "Modeling heat shock protein expression produced by a heat wrap", J. Biomech. Eng., vol. 131, p. 074510,2009

[183] S. Wang, K. R. Diller, and S. J. Aggarwal, "Kinetics study of endogenous heat shock protein 70 expression", J. Biomech. Eng., vol. 125, pp. 794-797, 2003.

[184] S. Wang, W. Xie, M. N. Rylander, P. W. Tucker, S. Aggarwal, and K. R. Diller, "HSP70 kinetics study by continuous observation of HSP-GFP fusion protein expression on a perfusion heating stage", Biotechnol. Bioeng., vol. 99, pp. 146-54, 2008.

[185] X. M. He and J. C. Bischof, "The kinetics of thermal injury in human renal carcinoma cells", Ann. Biomed. Eng.. vol. 33, pp. 502$10,2005$.

[186] S. Bhowmick, J. E. Coad, D. J. Swanlund, and J. C. Bischof, "In vitro thermal therapy of AT-1 Dunning prostate tumours", Int. J. Hyperther., vol. 20, pp. 73-92, 2004.

[187] X. He, S. Bhowmick, and J. C. Bischof, "Thermal therapy in urologic systems: a comparison of arrhenius and thermal isoeffective dose models in predicting hyperthermic injury", J. Biomech. Eng., vol. 131, p. 074507, 2009.

[188] B. Shah and S. Bhowmick, "Evaluation of important treatment parameters in supraphysiological thermal therapy of human liver cancer HepG2 cells", Ann. Biomed. Eng., vol. 34, pp. 1745-57, 2006.

[189] S. Bhowmick, N. E. Hoffmann, and J. C. Bischof, "Thermal therapy of prostate tumor tissue in the dorsal skin flap chamber", $\mathrm{Mi}$ crovasc. Res., vol. 64, pp. 170-3, 2002.

[190] Y. Shen, P. Liu, A. Zhang, and L. X. Xu, "Study on tumor microvasculature damage induced by alternate cooling and heating", Ann. Biomed. Eng., vol. 36, pp. 1409-19, 2008.

[191] J. E. Coad and J. C. Bischof, "Histologic differences between cryothermic and hyperthermic therapies", Proc. SPIE, vol. 4954, pp. 27-36, 2003.

[192] R. S. Cotran, V. Kumar, and S. L. Robbins, Robbins pathologic basis of disease (5th edition), Philadelphia, PA: W.B. Sanders Company, 1994.

[193] L. Hennings, Y. Kaufmann, R. Griffin, E. Siegel, P. Novak, P. Corry, E. G. Moros, and G. Shafirstein, "Dead or alive? Autofluorescence distinguishes heat-fixed from viable cells", Int. J. Hyperther., vol. 25, pp. 355-63, 2009.

[194] M. Toner, "Nucleation of ice crystals inside biological cells", In: P. Steponkus, Ed. Advances in Low-Temperature Biology, JAI Press, London, vol. 2, pp. 1-51, 1993.

[195] J. C. Bischof, W. F. Wolkers, N. M. Tsvetkova, A. E. Oliver, and J. $\mathrm{H}$. Crowe, "Lipid and protein changes due to freezing in Dunning AT-1 cells", Cryobiology, vol. 45, pp. 22-32, 2002.

[196] W. F. Wolkers, S. K. Balasubramanian, E. L. Ongstad, H. C. Zec and J. C. Bischof, "Effects of freezing on membranes and proteins in LNCaP prostate tumor cells", Biochim. Biophys. Acta., vol. 1768, pp. 728-736, 2007.

[197] S. K. Balasubramanian, W. F. Wolkers, and J. C. Bischof, "Membrane hydration correlates to cellular biophysics during freezing in mammalian cells", Biochim. Biophys. Acta., vol. 1788, pp. 945-53, 2009.

[198] P. L. Steponkus and D. V. Lynch, "Freeze/thaw-induced destabilization of the plasma membrane and the effects of cold acclimation", J. Bioenerg. Biomembr., vol. 21, pp. 21-41, 1989.

[199] T. Yamada, K. Kuroda, Y. Jitsuyama, D. Takezawa, K. Arakawa, and S. Fujikawa, "Roles of the plasma membrane and the cell wall in the responses of plant cells to freezing", Planta, vol. 215, pp. 770-8, 2002.

[200] B. H. Chao, X. He, and J. C. Bischof, "Pre-treatment inflammation induced by TNF-alpha augments cryosurgical injury on human prostate cancer", Cryobiology, vol. 49, pp. 10-27, 2004.

[201] R. Goel, K. Anderson, J. Slaton, F. Schmidlin, G. Vercellotti, J. Belcher, and J. C. Bischof, "Adjuvant approaches to enhance cryosurgery", J. Biomech. Eng., vol. 131, p. 074003, 2009.

[202] R. Goel, D. Swanlund, J. Coad, G. F. Paciotti, and J. C. Bischof, "TNF-alpha-based accentuation in cryoinjury--dose, delivery, and response", Mol. Cancer Ther., vol. 6, pp. 2039-47, 2007.

[203] B. Han, A. Iftekhar, and J. C. Bischof, "Improved cryosurgery by use of thermophysical and inflammatory adjuvants", Technol. Cancer Res. Treat., vol. 3, pp. 103-11, 2004.

[204] B. Han, D. J. Swanlund, and J. C. Bischof, "Cryoinjury of MCF-7 human breast cancer cells and inhibition of post-thaw recovery using TNF-alpha", Technol. Cancer Res. Treat., vol. 6, pp. 625-34, 2007.

[205] J. Jiang, R. Goel, M. A. Iftekhar, R. Visaria, J. D. Belcher, G. M. Vercellotti, and J. C. Bischof, "Tumor necrosis factor-alphainduced accentuation in cryoinjury: mechanisms in vitro and in vivo", Mol. Cancer Ther., vol. 7, pp. 2547-55, 2008.

[206] H. Koushafar and B. Rubinsky, "Effect of antifreeze proteins on frozen primary prostatic adenocarcinoma cells", Urology, vol. 49, pp. 421-5, 1997.

[207] L. Pham, R. Dahiya, and B. Rubinsky, "An in vivo study of antifreeze protein adjuvant cryosurgery", Cryobiology, vol. 38, pp. 169-75, 1999.

[208] B. Han and J. C. Bischof, "Direct cell injury associated with eutectic crystallization during freezing", Cryobiology, vol. 48, pp. 8-21, 2004.

[209] C. L. Wang, K. Y. Teo, and B. Han, "An amino acidic adjuvant to augment cryoinjury of MCF-7 breast cancer cells", Cryobiology, vol. 57, pp. 52-59, 2008.

[210] Y. Sugiyama, S. Saji, K. Miya, K. Kunieda, H. Takao, Y. Kawaguchi, A. Kimura, S. Honda, and K. Matsui, "[Therapeutic effect of multimodal therapy, such as cryosurgery, locoregional immunotherapy and systemic chemotherapy against far advanced breast cancer]", Gan. To. Kagaku Ryoho., vol. 28, pp. 1616-9, 2001. 
[211] Y. Kawaguchi, Y. Sugiyama, and S. Saji, "Cryoimmunological therapy with local injection of OK-432 against advance or recurrent breast cancer", Gan. To. Kagaku Ryoho., vol. 30, pp. 1583-86, 2003.

[212] V. Forest, M. Peoc'h, L. Campos, D. Guyotat, and J. M. Vergnon, "Effects of cryotherapy or chemotherapy on apoptosis in a nonsmall-cell lung cancer xenografted into SCID mice", Cryobiology, vol. 50, pp. 29-37, 2005.

[213] V. Forest, M. Peoc'h, L. Campos, D. Guyotat, and J. M. Vergnon, "Benefit of a combined treatment of cryotherapy and chemotherapy on tumour growth and late cryo-induced angiogenesis in a nonsmall-cell lung cancer model", Lung Cancer, vol. 54, pp. 79-86, 2006.

[214] S. Ikekawa, K. Ishihara, S. Tanaka, and S. Ikeda, "Basic studies of cryochemotherapy in a murine tumor system", Cryobiology, vol. 22, pp. 477-83, 1985.

[215] D. M. Clarke, J. M. Baust, R. G. Van Buskirk, and J. G. Baust, "Chemo-cryo combination therapy: an adjunctive model for the treatment of prostate cancer", Cryobiology, vol. 42, pp. 274-285, 2001.

[216] L. M. Mir and B. Rubinsky, "Treatment of cancer with cryochemotherapy", Br. J. Cancer, vol. 86, pp. 1658-60, 2002.

[217] F. Yuan, W. Zhou, J. Zhang, Z. Zhang, C. Zou, L. Huang, Y. Zhang, and Z. Dai, "Anticancer drugs are synergistic with freezing in induction of apoptosis in HCC cells", Cryobiology, vol. 57, pp. 60-5, 2008.

[218] D. M. Clarke, J. M. Baust, R. G. Van Buskirk, and J. G. Baust, "Addition of anticancer agents enhances freezing-induced prostate cancer cell death: implications of mitochondrial involvement", Cryobiology, vol. 49, pp. 45-61, 2004.

[219] J. F. Yan and J. Liu, "Nanocryosurgery and its mechanisms for enhancing freezing efficiency of tumor tissues", Nanomed., vol. 4, pp. 79-87, 2008.

[220] J. Liu and Z. S. Deng, "Nano-cryosurgery: advances and challenges", J. Nanosci. Nanotechnol., vol. 9, pp. 4521-42, 2009.

[221] F. S. Trad, M. Toner, and J. D. Biggers, "Effects of cryoprotectants and ice-seeding temperature on intracellular freezing and survival of human oocytes", Hum. Reprod., vol. 14, pp. 1569-77, 1999.

[222] M. L. Yarmush, M. Toner, J. C. Dunn, A. Rotem, A. Hubel, and R. G. Tompkins, "Hepatic tissue engineering. Development of critical technologies", Ann. N. Y. Acad. Sci., vol. 665, pp. 238-52, 1992.

[223] S. K. Balasubramanian, J. C. Bischof, and A. Hubel, "Water transport and IIF parameters for a connective tissue equivalent", Cryobiology, vol. 52, pp. 62-73, 2006.

[224] S. K. Balasubramanian, R. T. Venkatasubramanian, A. Menon, and J. C. Bischof, "Thermal injury prediction during cryoplasty through in vitro characterization of smooth muscle cell biophysics and viability", Ann. Biomed. Eng., vol. 36, pp. 86-101, 2008.

[225] D. Irimia and J. O. Karlsson, "Kinetics and mechanism of intercellular ice propagation in a micropatterned tissue construct", Biophys. J., vol. 82, pp. 1858-68, 2002.

[226] S. L. Stott, D. Irimia, and J. O. Karlsson, "Parametric analysis of intercellular ice propagation during cryosurgery, simulated using monte carlo techniques", Technol. Cancer Res. Treat, vol. 3, pp. 113-23, 2004.

[227] W. J. Armitage and B. K. Juss, "Freezing monolayers of cells without gap junctions", Cryobiology, vol. 46, pp. 194-6, 2003.

[228] X. He and J. C. Bischof, "Analysis of thermal stress in cryosurgery of kidneys", J. Biomech. Eng., vol. 127, pp. 656-61, 2005.

[229] Y. Rabin, P. Olson, M. J. Taylor, P. S. Steif, T. B. Julian, and N. Wolmark, "Gross damage accumulation on frozen rabbit liver due to mechanical stress at cryogenic temperatures", Cryobiology, vol. 34, pp. 394-405, 1997.

[230] Y. Rabin and P. S. Steif, "Analysis of thermal stresses around a cryosurgical probe", Cryobiology, vol. 33, pp. 276-90, 1996.

[231] Y. Rabin, P. S. Steif, M. J. Taylor, T. B. Julian, and N. Wolmark, "An experimental study of the mechanical response of frozen biological tissues at cryogenic temperatures", Cryobiology, vol. 33, pp. 472-82, 1996.

[232] P. S. Steif, M. C. Palastro, and Y. Rabin, "Analysis of the effect of partial vitrification on stress development in cryopreserved blood vessels", Med. Eng. Phys., vol. 29, pp. 661-70, 2007.

[233] P. S. Steif, M. C. Palastro, and Y. Rabin, "The effect of temperature gradients on stress development during cryopreservation via vitrification", Cell Preserv. Technol., vol. 5, pp. 104-15, 2007.
[234] P. S. Steif, D. A. Noday, and Y. Rabin, "Can thermal expansion differences between cryopreserved tissue and cryoprotective agents alone cause cracking?", Cryo. Lett., vol. 30, pp. 414-21, 2009.

[235] S. Najimi and B. Rubinsky, "Non-invasive detection of thermal stress fractures in frozen biological materials", Cryo. Lett., vol. 18, pp. 209-16, 1997.

[236] R. T. Venkatasubramanian, E. D. Grassl, V. H. Barocas, D. Lafontaine, and J. C. Bischof, "Effects of freezing and cryopreservation on the mechanical properties of arteries", Ann. Biomed. Eng., vol. 34, pp. 823-32, 2006.

[237] A. Zhang, S. Cheng, D. Gao, and L. X. Xu, "Thermal stress study of two different artery cryopreservation methods", Cryo. Lett., vol. 26, pp. 113-20, 2005.

[238] F. R. Schmidlin, C. C. Rupp, N. E. Hoffmann, J. E. Coad, D. J. Swanlund, J. C. Hulbert, and J. C. Bischof, "Measurement and prediction of thermal behavior and acute assessment of injury in a pig model of renal cryosurgery", J. Endourol., vol. 15, pp. 193-7, 2001.

[239] C. C. Rupp, N. E. Hoffmann, F. R. Schmidlin, D. J. Swanlund, J. C. Bischof, and J. E. Coad, "Cryosurgical changes in the porcine kidney: histologic analysis with thermal history correlation", Cryobiology, vol. 45, pp. 167-82, 2002.

[240] G. Hruby, A. Edelstein, J. Karpf, E. Durak, C. Phillips, D. Lehman, and J. Landman, "Risk factors associated with renal parenchymal fracture during laparoscopic cryoablation", BJU Int., vol. 102, pp. 723-26, 2008.

[241] N. K. Janzen, K. T. Perry, K. R. Han, B. Kristo, S. Raman, J. W. Said, A. S. Belldegrun, and P. G. Schulam, "The effects of intentional cryoablation and radio frequency ablation of renal tissue involving the collecting system in a porcine model", J. Urol., vol. 173, pp. 1368-74, 2005.

[242] D. B. Rukstalis, M. Khorsandi, F. U. Garcia, D. M. Hoenig, and J. K. Cohen, "Clinical experience with open renal cryoablation", Urology, vol. 57, pp. 34-9, 2001.

[243] S. Y. Nakada, F. T. Lee, Jr., T. Warner, S. G. Chosy, and T. D. Moon, "Laparoscopic cryosurgery of the kidney in the porcine model: an acute histological study", Urology, vol. 51, pp. 161-6, 1998.

[244] B. Han, J. D. Miller, and J. K. Jung, "Freezing-induced fluid-matrix interaction in poroelastic material", J. Biomech. Eng., vol. 131, p. $021002,2009$.

[245] S. Baicu, M. J. Taylor, Z. Chen, and Y. Rabin, "Vitrification of carotid artery segments: An integrated study of thermophysical events and functional recovery toward scale-up for clinical applications", Cell Pre. Tech., vol. 4, pp. 236-44, 2006.

[246] M. Wusteman, M. Robinson, and D. Pegg, "Vitrification of large tissues with dielectric warming: biological problems and some approaches to their solution", Cryobiology, vol. 48, pp. 179-89, 2004.

[247] N. E. Hoffmann and J. C. Bischof, "Cryosurgery of normal and tumor tissue in the dorsal skin flap chamber: Part II--injury response", J. Biomech. Eng., vol. 123, pp. 310-6, 2001.

[248] D. E. Pegg, "Viability assays for preserved cells, tissues, and organs", Cryobiology, vol. 26, pp. 212-231, 1989.

[249] S. K. Sahu and C. W. Song, "Thermal sensitivity and kinetics of thermotolerance in bovine aortic endothelial cells in culture", Int. J. Hyperther., vol. 7, pp. 103-11, 1991.

[250] J. Gearhart, "New potential for human embryonic stem cells", Science, vol. 282, pp. 1061-1062, 1998.

[251] P. Bhowmick, J. E. Coad, S. Bhowmick, J. L. Pryor, T. Larson, J. De La Rosette, and J. C. Bischof, "In vitro assessment of the efficacy of thermal therapy in human benign prostatic hyperplasia", Int. J. Hyperther., vol. 20, pp. 421-39, 2004.

[252] E. G. Cravalho, M. Toner, D. C. Gaylor, and R. C. Lee, "Response of cells to supraphysiological temperatures: experimental measurements and kinetic models", in Electrical Trauma: The Pathophysiology, Manifestations and Clinical Management, R. C. Lee, E. G. Cravalho, and J. F. Burke, Eds. Cambridge, UK: Cambridge Univ. Press, 1992.

[253] J. M. Lee, S. H. Choi, H. S. Park, M. W. Lee, C. J. Han, J. I. Choi, J. Y. Choi, S. H. Hong, J. K. Han, and B. I. Choi, "Radiofrequency thermal ablation in canine femur: evaluation of coagulation necrosis reproducibility and MRI-histopathologic correlation", AJR Am. J. Roentgenol., vol. 185, pp. 661-7, 2005.

[254] S. E. Donnelly, B. J. Donnelly, J. C. Saliken, E. L. Raber, and A. D. Vellet, "Prostate cancer: gadolinium-enhanced MR imaging at 3 weeks compared with needle biopsy at 6 months after cryoablation", Radiology, vol. 232, pp. 830-33, 2004. 
[255] C. A. t. Porter, D. A. Woodrum, M. R. Callstrom, G. D. Schmit, S. Misra, J. W. Charboneau, and T. D. Atwell, "MRI after technically successful renal cryoablation: early contrast enhancement as a common finding", AJR Am. J. Roentgenol., vol. 194, pp. 790-3, 2010.

[256] T. Mala, L. Frich, L. Aurdal, O. P. Clausen, B. Edwin, O. Soreide, and I. Gladhaug, "Intraoperative contrast-enhanced MR-imaging as predictor of tissue damage during cryoablation of porcine liver", Magn. Reson Imaging, vol. 21, pp. 733-40, 2003.

[257] H. L. Cheng, C. M. Purcell, J. M. Bilbao, and D. B. Plewes, "Prediction of subtle thermal histopathological change using a novel analysis of Gd-DTPA kinetics", J. Magn. Reson Imaging, vol. 18, pp. 585-98, 2003.

[258] Y. Feng, J. Tinsley Oden, and M. N. Rylander, "A two-state cell damage model under hyperthermic conditions: theory and in vitro experiments", J. Biomech. Eng., vol. 130, p. 041016, 2008.

[259] G. J. Dienes, "A kinetic model of biological radiation response", Radiat. Res., vol. 28, pp. 183-202, 1966.

[260] J. Landry and N. Marceau, "Rate-limiting events in hyperthermic cell killing", Radiat. Res., vol. 75, pp. 573-85, 1978.

[261] I. A. Chang, "Considerations for thermal injury analysis for RF ablation devices", Open Biomed. Eng. J., vol. 4, pp. 3-12,

[262] F. C. Henriques and A. R. Moritz, "Studies of Thermal Injury: I. The Conduction of Heat to and through Skin and the Temperatures Attained Therein. A Theoretical and an Experimental Investigation", Am. J. Pathol., vol. 23, pp. 530-49, 1947.

[263] A. R. Moritz and F. C. Henriques, "Studies of thermal injury: II. The relative importance of time and surface temperature in the causation of cutaneous burns", Am. J. Pathol., vol. 23, pp. 695-720, 1947.

[264] A. R. Moritz and F. C. Henriques, Jr., "The reciprocal relationship of surface temperature and time in the production of hyperthermic cutaneous injury", Am. J. Pathol., vol. 23, p. 897, 1947.

[265] H. Eyring and A. E. Stearn, "The application of the theory of absolute reaction rates to proteins", Chemical Reviews, vol. 24, pp. 253$70,1939$.

[266] F. H. Johnson, H. Eyring, and B. J. Stoner, "Temperature", in The Theory of Rate Process in Biology and Medicine New York: John Wiley \& Sons, Inc., pp. 549-98, 1974.

[267] S. A. Sapareto and W. C. Dewey, "Thermal dose determination in cancer therapy", Int. J. Radiat. Oncol. Biol. Phys., vol. 10, pp. 787800, 1984.

[268] J. A. Pearce, "Models for Thermal Damage in Tissues: Processes and Applications ", Crit. Rev. Biomed. Eng., vol. 38, pp. 1-20, 2010.

[269] S. J. Payne, T. Peng, and D. P. O'Neill, "Mathematical modeling of thermal ablation", Crit. Rev. Biomed. Eng., vol. 38, pp. 21-30, 2010.

[270] R. E. Pitt, "Cryobiological implications of diff erent methods of calculating the chemical potential of water in partially frozen suspending media", Cryo. Lett., vol. 11, pp. 227-240, 1990.

[271] F. Hobbs, Ice physics, London: Oxford University Press, 1974.

[272] M. Toner, R. G. Tompkins, E. G. Cravalho, and M. L. Yarmush, "Transport phenomena during freezing of isolated hepatocytes", Aiche. J., vol. 38, pp. 1512-22, 1992.

[273] G. Yang, M. Veres, G. Szalai, A. Zhang, L. X. Xu, and X. He, "Biotransport phenomena in freezing mammalian oocytes", Ann. Biomed. Eng., vol. 39, pp. 580-91, 2011.

[274] M. Toner, E. G. Cravalho, M. Karel, and D. R. Armant, "Cryomicroscopic analysis of intracellular ice formation during freezing of mouse oocytes without cryoadditives", Cryobiology, vol. 28, pp. $55-71,1991$

[275] K. R. Diller, "Bioheat and mass transfer as viewed through a microscope", J. Biomech. Eng., vol. 127, pp. 67-84, 2005.

[276] C. Chen and W. Z. Li, "Diffusion controlled ice growth with soft impingement inside biological cells during freezing", Cryo. letters, vol. 29 , pp. 371-81, 2008.

[277] G. Zhao, D. Luo, and D. Gao, "Universal model for intracellular ice formation and its growth", AIChE J., vol. 52, pp. 2596 - 606, 2006.

[278] J. O. Karlsson, E. G. Cravalho, I. H. Borel Rinkes, R. G. Tompkins, M. L. Yarmush, and M. Toner, "Nucleation and growth of ice crystals inside cultured hepatocytes during freezing in the presence of dimethyl sulfoxide", Biophys. J., vol. 65, pp. 2524-36, 1993.

[279] P. Mazur, "Kinetics of water loss from cells at subzero temperatures and the likelihood of intracellular freezing", J. Gen. Physiol., vol. 47, pp. 347-69, 1963.
[280] R. L. Levin, E. G. Cravalho, and C. E. Huggins, "A membrane model describing the effect of temperature on the water conductivity of erythrocyte membranes at subzero temperatures", Cryobiology, vol. 13, pp. 415-29, 1976.

[281] R. V. Devireddy, D. Raha, and J. C. Bischof, "Measurement of water transport during freezing in cell suspensions using a differential scanning calorimeter", Cryobiology, vol. 36, pp. 124-155, 1998.

[282] R. V. Devireddy, J. E. Coad, and J. C. Bischof, "Microscopic and calorimetric assessment of freezing processes in uterine fibroid tumor tissue", Cryobiology, vol. 42, pp. 225-43, 2001.

[283] D. Luo, X. Han, L. He, X. Cui, S. Cheng, C. Lu, J. Liu, and D. Gao, "A modified differential scanning calorimetry for determination of cell volumetric change during the freezing process", Cryo. Lett., vol. 23, pp. 229-36, 2002.

[284] J. C. Bischof, "Quantitative measurement and prediction of biophysical response during freezing in tissues", Ann. Rev. Biomed. Eng., vol. 2, pp. 257-88, 2000.

[285] B. Han and J. C. Bischof, "Engineering challenges in tissue preservation", Cell Preserv. Technol., vol. 2, pp. 91-112, 2004.

[286] J. P. Acker and L. E. McGann, "Innocuous intracellular ice improves survival of frozen cells", Cell Transplant, vol. 11, pp. 563 71, 2002.

[287] J. P. Acker and L. E. McGann, "Protective effect of intracellular ice during freezing?" Cryobiology, vol. 46, pp. 197-202, 2003.

[288] A. A. Konstas, M. A. Neimark, A. F. Laine, and J. Pile-Spellman, "A theoretical model of selective cooling using intracarotid cold saline infusion in the human brain", J. Appl. Physiol., vol. 102, pp. 1329-40, 2007

[289] X. Xu, P. Tikuisis, and G. Giesbrecht, "A mathematical model for human brain cooling during cold-water near-drowning", J. Appl. Physiol., vol. 86, pp. 265-72, 1999.

[290] R. W. P. King, B. S. Trembly, and J. W. Strohbehn, "The electromagnetic-field of an insulated antenna in a conducting or dielectric medium", IEEE Trans. Microw. Theory Tech., vol. 31, pp. 574-83, 1983.

[291] G. B. Gentili, F. Gori, and M. Leoncini, "Electromagnetic and thermal models of a water-cooled dipole radiating in a biological tissue", IEEE Trans. Biomed. Eng., vol. 38, pp. 98-103, 1991.

[292] J. Enderle, S. M. Blanchard, and J. Bronzino, Intro Biomedl Eng, Burlington, MA: Elsvier Academic Press, 2005

[293] H. H. Pennes, "Analysis of tissue and arterial blood temperatures in the resting human forearm", J. Appl. Physiol., vol. 1, pp. 93-122, 1948.

[294] J. C. Chato, "Heat-Transfer to blood-vessels", J. Biomech. Eng., vol. 102, pp. 110-8, 1980 .

[295] M. M. Chen and K. R. Holmes, "Microvascular contributions in tissue heat transfer", Ann. N. Y. Acad. Sci., vol. 335, pp. 137-50, 1980.

[296] S. Weinbaum, L. M. Jiji, and D. E. Lemons, "Theory and experiment for the effect of vascular microstructure on surface tissue heat transfer--Part I: Anatomical foundation and model conceptualization", J. Biomech. Eng., vol. 106, pp. 321-30, 1984.

[297] K. H. Keller and L. Seiler, "Analysis of peripheral heat transfer in man", J. Appl. Physiol., vol. 30, pp. 779, 1971.

[298] J. W. Mitchell and G. E. Myers, "An analytical model of the counter-current heat exchange phenomena", Biophys. J., vol. 8, pp. 897-911, 1968.

[299] J. Mooibroek and J. J. Lagendijk, "A fast and simple algorithm for the calculation of convective heat transfer by large vessels in threedimensional inhomogeneous tissues", IEEE Trans. Biomed. Eng., vol. 38, pp. 490-501, 1991.

[300] H. W. Huang, Z. P. Chen, and R. B. Roemer, "A counter current vascular network model of heat transfer in tissues", J. Biomech. Eng., vol. 118, pp. 120-129, 1996.

[301] S. Weinbaum and L. M. Jiji, "A new simplified bioheat equation for the effect of blood flow on local average tissue temperature", $J$. Biomech. Eng., vol. 107, pp. 131-9, 1985.

[302] E. H. Wissler, "Comments on the new bioheat equation proposed by Weinbaum and Jiji", J. Biomech. Eng., vol. 109, pp. 226-33, 1987.

[303] D. Shrivastava, B. McKay, and R. B. Roemer, "An analytical study of heat transfer in finite tissue with two blood vessels and uniform dirichlet boundary conditions", J. Heat Transfer, vol. 127, pp. 179$88,2005$.

[304] D. Shrivastava and R. Roemer, "An analytical study of heat transfer in a finite tissue region with two blood vessels and general 
Dirichlet boundary conditions", Int. J. Heat. Mass Transf., vol. 48, pp. 4090-102, 2005.

[305] D. Shrivastava and R. B. Roemer, "Readdressing the issue of thermally significant blood vessels using a countercurrent vessel network", J. Biomech. Eng., vol. 128, pp. 210-6, 2006.

[306] H. Arkin, L. X. Xu, and K. R. Holmes, "Recent developments in modeling heat transfer in blood perfused tissues", IEEE Trans. Biomed. Eng., vol. 41, pp. 97-107, 1994.

[307] C. K. Charney, "Mathematical models of bioheat transfer", Advances in Heat Tansfer vol. 22, pp. 19-155, 1992.

[308] E. H. Wissler, "Pennes' 1948 paper revisited", J. Appl. Physiol., vol. 85, pp. 35-41, 1998.

[309] D. A. Nelson, "Invited editorial on "Pennes' 1948 paper revisited", J. Appl. Physiol., vol. 85, pp. 2-3, 1998.

[310] R. B. Roemer, "Engineering aspects of hyperthermia therapy", Ann. Rev. Biomed. Eng., vol. 1, pp. 347-76, 1999.

[311] M. C. Kolios, A. E. Worthington, M. D. Sherar, and J. W. Hunt, "Experimental evaluation of two simple thermal models using transient temperature analysis", Phys. Med. Biol., vol. 43, pp. 3325-40, 1998.

[312] C. W. Song, "Effect of local hyperthermia on blood flow and microenvironment: a review", Cancer Res., vol. 44, pp. 4721s-30s, 1984.

[313] P. Vaupel, "Pathophysiological mechanisms of hyperthermia in cancer therapy", in Biological basis of oncologic thermotherapy, M. Gautherie, Ed. Berlin: Springer-Verlag, 1990.

[314] M. Dewhirst, D. Sim, J. Gross, and K. MA, "Effect of heating rate on tumour and normal tissue microcirculatory function", in Hyperthermic Oncology, J. Overgaard, Ed. London, UK: Taylor \& Francis, 1984.

[315] D. J. Schutt and D. Haemmerich, "Effects of variation in perfusion rates and of perfusion models in computational models of radio frequency tumor ablation", Med. Phys., vol. 35, pp. 3462-70, 2008.

[316] J. P. Abraham and E. M. Sparrow, "A thermal-ablation bioheat model including liquid-to-vapor phase change, pressure- and necrosis-dependent perfusion, and moisture-dependent properties", Int. J. Heat and Mass Transf., vol. 50, pp. 2537-44, 2007.

[317] M. G. Skinner, M. N. Iizuka, M. C. Kolios, and M. D. Sherar, "A theoretical comparison of energy sources--microwave, ultrasound and laser--for interstitial thermal therapy", Phys. Med. Biol., vol. 43, pp. 3535-47, 1998.

[318] S. L. Brown, J. W. Hunt, and R. P. Hill, "Differential thermal sensitivity of tumour and normal tissue microvascular response during hyperthermia", Int. J. Hyperther., vol. 8, pp. 501-514, 1992.

[319] T. E. Dudar and R. K. Jain, "Differential response of normal and tumor microcirculation to hyperthermia", Cancer Res., vol. 44, pp. 605-12, 1984.

[320] J. C. Acker, M. W. Dewhirst, G. M. Honore, T. V. Samulski, J. A Tucker, and J. R. Oleson, "Blood perfusion measurements in human tumours: evaluation of laser Doppler methods", Int. J. Hyperther., vol. 6, pp. 287-304, 1990.

[321] V. Alexiades and A. D. Solomon, Mathematical modeling of melting and freezing processes, Washington: Hemisphere Publishing Corp., 1993.

[322] R. J. Silbey, R. A. Alberty, and M. G. Bawendi, Physical Chemistry (4th edition), Hoboken, NJ: John Wiley \& Sons, Inc., 2004.

[323] R. V. Devireddy, D. J. Smith, and J. C. Bischof, "Effect of microscale mass transport and phase change on numerical prediction of freezing in biological tissues", J. Heat Transfer, vol. 124, pp. 365-374, 2002

[324] B. Han and J. C. Bischof, "Thermodynamic nonequilibrium phase change behavior and thermal properties of biological solutions for cryobiology applications", J. Biomech. Eng., vol. 126, pp. 196-203, 2004.

[325] B. Han, J. H. Choi, J. A. Dantzig, and J. C. Bischof, "A quantitative analysis on latent heat of an aqueous binary mixture", Cryobiology, vol. 52, pp. 146-51, 2006.

[326] F. A. Duck, Physical properties of tissue: a comprehensive reference book, San Diego, CA: Academic Press, 1990.

[327] J. Choi and J. C. Bischof, "Review of biomaterial thermal property measurements in the cryogenic regime and their use for prediction of equilibrium and non-equilibrium freezing applications in cryobiology", Cryobiology, vol. 60, pp. 52-70, 2010.

[328] N. E. Hoffmann and J. C. Bischof, "Cryosurgery of normal and tumor tissue in the dorsal skin flap chamber: Part I--thermal response", J. Biomech. Eng., vol. 123, pp. 301-09, 2001.

(C) Xiaoming He; Licensee Bentham Open.

This is an open access article licensed under the terms of the Creative Commons Attribution Non-Commercial License (http://creativecommons.org/licenses/by-nc/3.0/) which permits unrestricted, non-commercial use, distribution and reproduction in any medium, provided the work is properly cited. 